Article

\title{
On the Microstructure and Properties of Nb-18Si-6Mo-5Al-5Cr-2.5W-1Hf Nb-Silicide Based Alloys with Ge, Sn and Ti Additions (at.\%)
}

\author{
Jiang Zhao ${ }^{1,2}$, Claire Utton ${ }^{1}$ and Panos Tsakiropoulos ${ }^{1, * \mathbb{D}}$ \\ 1 Department of Materials Science and Engineering, Sir Robert Hadfield Building, The University of Sheffield, \\ Mappin Street, Sheffield S1 3JD, UK; zhaojiang6325@hotmail.com (J.Z.); c.utton@sheffield.ac.uk (C.U.) \\ 2 College of Materials and Chemical Engineering, Key Laboratory of Inorganic Nonmetallic Crystalline and \\ Energy Conversion Materials, Three Gorges University, Yichang 443002, China \\ * Correspondence: p.tsakiropoulos@sheffield.ac.uk
}

Received: 23 September 2020; Accepted: 6 October 2020; Published: 13 October 2020

check for updates

\begin{abstract}
We studied the microstructures and isothermal oxidation of the $\mathrm{Nb}$-silicide-based alloys Nb-11.5Ti-18Si-5Mo-2W-4.9Sn-4.6Ge-4.5Cr-4.7Al-1Hf (JZ4) and Nb-21Ti-18Si-6.7Mo-1.2W-4.4Sn-4.2Ge $-4 \mathrm{Cr}-3.7 \mathrm{Al}-0.8 \mathrm{Hf}$ (JZ5), calculated their average creep rate for the creep goal conditions of $\mathrm{T}=1200{ }^{\circ} \mathrm{C}$ and $\sigma=170 \mathrm{MPa}$, and compared properties of the two alloys with those of other refractory metal (RM) complex concentrated alloys (RCCAs). Both alloys had a density less than $7.3 \mathrm{~g} / \mathrm{cm}^{3}$ and lower than the density of multiphase bcc solid solution $+\mathrm{M}_{5} \mathrm{Si}_{3}$ silicide RCCAs. There was macrosegregation of $\mathrm{Si}$ in both alloys, which had the same phases in their as-cast microstructures, namely $\beta \mathrm{Nb}_{5} \mathrm{Si}_{3}$, $\alpha \mathrm{Nb}_{5} \mathrm{Si}_{3}, \mathrm{~A} 15-\mathrm{Nb}_{3} \mathrm{X}(\mathrm{X}=\mathrm{Al}, \mathrm{Ge}, \mathrm{Si}, \mathrm{Sn}), \mathrm{TM}_{5} \mathrm{Sn}_{2} \mathrm{X}(\mathrm{X}=\mathrm{Al}, \mathrm{Ge}, \mathrm{Si}), \mathrm{C} 14-\mathrm{Cr}_{2} \mathrm{Nb}$, but no solid solution. After heat treatment at $1500{ }^{\circ} \mathrm{C}$ for $100 \mathrm{~h}$, a low volume fraction of a $\mathrm{W}$-rich $(\mathrm{Nb}, \mathrm{W})_{\mathrm{ss}}$ solid solution was observed in both alloys together with $\beta \mathrm{Nb}_{5} \mathrm{Si}_{3}, \alpha \mathrm{Nb}_{5} \mathrm{Si}_{3}$ and $\mathrm{A} 15-\mathrm{Nb}_{3} \mathrm{X}$ but not the $\mathrm{TM}_{5} \mathrm{Sn}_{2} \mathrm{X}$, whereas the Laves phase was observed only in JZ4. At $800^{\circ} \mathrm{C}$, both alloys did not pest, and there was no spallation of their scales at $1200{ }^{\circ} \mathrm{C}$. At both temperatures, both alloys followed parabolic oxidation kinetics and their weight changes were lower than those of Ti-rich $\mathrm{Nb}$-silicide-based alloys. The oxidation of both alloys was superior to that of other RCCAs studied to date. For each alloy the Si macrosegregation, volume fraction of solid solution, chemical composition of solid solution and $\mathrm{Nb}_{5} \mathrm{Si}_{3}$, and weight changes in isothermal oxidation at 800 and $1200{ }^{\circ} \mathrm{C}$ that were calculated using the alloy design methodology NICE agreed well with the experimental results.
\end{abstract}

Keywords: Nb-silicide-based alloys; complex concentrated alloys; high entropy alloys; alloy design; microstructures; oxidation; intermetallics; silicides

\section{Introduction}

Ultra-high temperature materials (UHTMs) are currently being developed as potential replacements of Ni-based superalloys to meet performance and environmental targets in future aero engines. Metallic UHTMs are refractory metal (RM) intermetallic composites (RMICs), RM high entropy alloys (RHEAs) and RM complex concentrated alloys (RCCAs) [1,2]. RMICs include Nb- or Mo-silicide-based alloys [3-5]. Nb-silicide-based alloys are attracting much attention for blade applications [1,3]. Some $\mathrm{Nb}$ silicide-based alloys are also RCCAs [1].

Metallic UHTMs must meet property goals for creep, toughness and oxidation resistance $[3,4,6]$. The creep strength should be greater than $170 \mathrm{MPa}$ at a creep rate of $2 \times 10^{-8} \mathrm{~s}^{-1}$ at $1200{ }^{\circ} \mathrm{C}$ (for $\mathrm{Nb}$ silicide-based alloys, this goal assumes density $\rho=7 \mathrm{~g} / \mathrm{cm}^{3}$ ). The fracture toughness of critical components should be $\geq 20 \mathrm{MPa} \sqrt{ } \mathrm{m}$. The recession rate due to oxidation should be less than $0.25 \mu \mathrm{m} / \mathrm{h}$ at $1315{ }^{\circ} \mathrm{C}$. The oxidation goal is derived from the requirement of achieving the oxidation life at $1315^{\circ} \mathrm{C}$ 
of the second generation single crystal Ni-based superalloys at $1150^{\circ} \mathrm{C}$. The toughness goal requires metallic behaviour of the metallic UHTMs to distinguish them from engineering ceramics or ceramic UHTMs. Thus, owing to the toughness goal, the new metallic materials should have at least a small volume fraction of a ductile, metallic phase. The latter is the bcc $\mathrm{Nb}$ solid solution in the case of $\mathrm{Nb}$-silicide-based alloys $[1,4,7]$.

Research has ascertained the key role of specific alloying additions for meeting property goals in $\mathrm{Nb}$-silicide-based alloys [3,7-20]. RM additions are indispensable for strength and creep, simple metal and metalloid element (SMME) and transition metal (TM) additions are needed for oxidation resistance and TMs and SMMEs are crucial for toughness $(\mathrm{RM}=\mathrm{Mo}, \mathrm{Ta}, \mathrm{W}, \mathrm{SMME}=\mathrm{Al}, \mathrm{B}, \mathrm{Ge}, \mathrm{Si}, \mathrm{Sn}, \mathrm{TM}=\mathrm{Cr}$, Hf, Ti) [1,20-25]. Processing can have a significant effect on toughness [1]. Nb-silicide-based alloys can meet the creep and toughness goals and have closed substantially the gap with the oxidation goal. It is not likely that a metallic UHTM could meet all three property goals $[1,4,20,26]$.

Contamination of RMs and RM alloys by interstitials is well known [1,2,27-33] as is the pest oxidation phenomenon for RM alloys and compounds [27-31,34,35]. Nb-silicide-based alloys and RCCAs can suffer from pest oxidation and interstitial contamination $[1,20]$. Nb-silicide-based alloys that meet some property target(s) and/or are close to other(s) targets, i.e., alloys that offer an acceptable balance of properties to be considered candidate materials for use in aero engines, will require environmental coatings (EC) [3]. Most likely an EC will be made of metallic bond coat (BC)/thermally grown oxide (TGO)/ceramic top coat (TC) [36]. Two key prerequisites for the substrate alloy, allied with the oxidation goal, are the prevention of pest oxidation and scale spallation. It is desirable for the $\mathrm{BC}$ to form a well-adhering $\alpha \mathrm{Al}_{2} \mathrm{O}_{3}$ scale as the TGO. The $\mathrm{BC}$ could consist of layers of different materials because it must also shield the substrate from interstitial contamination [36]. Nb-silicide-based alloys, including those that are also RCCAs, cannot form $\alpha \mathrm{Al}_{2} \mathrm{O}_{3}$ scales $[1,20]$. The same seems to be the case for the other RCCAs studied to date [1,2].

In Nb-silicide-based alloys, the suppression of pest oxidation that is achieved with the addition of Ge or Sn depends on type and concentration of other alloying elements [37-44]. Individual additions of Ge or Sn in Nb-silicide-based alloys cannot suppress the spallation of their scales at high temperatures [41-43], in the case of $\mathrm{Sn}$ irrespective of its concertation in an alloy [37-39,41,42,44]. However, the oxidation behaviour changed when Ge and $\mathrm{Sn}$ were added simultaneously in Nb-silicide-based alloys.

In actual fact, Ge and $\mathrm{Sn}$ in synergy had the following effects:

(a) With $\mathrm{Al}, \mathrm{Cr}$ and $\mathrm{Ti}$, it suppressed pest oxidation at $800^{\circ} \mathrm{C}$ and scale spallation at $1200{ }^{\circ} \mathrm{C}$ in the alloy Nb-24Ti-18Si-5Al-5Cr-5Ge-5Sn (OHS1) [45]);

(b) With Hf, Ta, Ti and $\mathrm{W}$ the synergy (i) did not suppress pest oxidation at $800{ }^{\circ} \mathrm{C}$ in the alloys Nb-12Ti-18Si-6Ta-2.5W-1Hf-2Sn-2Ge (JZ1) and Nb-12Ti-18Si-6Ta-2.5W-1Hf-5Sn-5Ge (JZ2) [46], and (ii) improved the adhesion of the scale when the Sn concentration was increased in the alloy JZ2 [46];

(c) With $\mathrm{Al}, \mathrm{Cr}, \mathrm{Hf}, \mathrm{Ta}$, Ti and $\mathrm{W}$ it (iii) suppressed pest oxidation at $800{ }^{\circ} \mathrm{C}$ and improved scale adhesion at $1200^{\circ} \mathrm{C}$ in the alloy Nb-12Ti-18Si-6Ta-2.5W-1Hf-5Sn-5Ge-5Al-5Cr (JZ3) [47], the scale of which did not separate but was cracked along edges, (iv) did not suppress pest oxidation at $800{ }^{\circ} \mathrm{C}$ owing to micro-cracking of the alloy that was attributed to the high hardness of alloyed $\mathrm{Nb}_{5} \mathrm{Si}_{3}$ and the very low vol.\% $\mathrm{Nb}_{\mathrm{ss}}$, and (v) suppressed scale spallation at $1200{ }^{\circ} \mathrm{C}$ when the $\mathrm{Sn}$ concentration was increased in the alloy Nb-12Ti-18Si-6Ta-2.5W-1Hf-7.5Sn-5Ge-5Al-5Cr (JZ3+) [47]; $\mathrm{Nb}_{5} \mathrm{Si}_{3}$ alloyed with $\mathrm{Ge}$ is desirable for creep and oxidation resistance [6] (the nominal compositions of alloys are also given in the Abbreviations).

Remarkably, (1) the oxidation of the alloy JZ3+ at $1200{ }^{\circ} \mathrm{C}$ was better compared with the alloy OHS1 (parabolic oxidation of JZ3 + with rate constant only one order of magnitude higher than that of the single crystal superalloy CMSX-4) even though its Ti concentration was half that of OHS1 $[45,47]$ and $(2)$ calculated contribution of intrinsic resistances $[1,20]$ to the creep of JZ3+ for the creep goal conditions was close to the creep target [47]. 
The research presented in this paper was inspired by our eagerness to find out if there are low density $\mathrm{Nb}$-silicide-based alloys with satisfactory creep and oxidation compared with the single crystal Ni superalloy CMSX-4. Key research findings that informed this research were (i) the better creep of $\mathrm{Nb}$-silicide-based alloys with RM additions compared with Ni-based superalloys $[1,20,48,49]$, (ii) the superior solid solution strengthening of $\mathrm{Nb}$ by Mo compared with $\mathrm{Ta}[1,28,31]$, (iii) the elimination of scale spallation and/or pest oxidation when $\mathrm{Sn}$ and $\mathrm{Ge}$ were in synergy with $\mathrm{Al}, \mathrm{Cr}$ and TM, or $\mathrm{Al}, \mathrm{Cr}, \mathrm{TM}$ and $\mathrm{Ta}, \mathrm{W}$ additions [45-47] and (iv) the attainment of oxidation rates in the Ti-poor $\mathrm{Nb}$-silicide-based alloys JZ3 and JZ3 + that are comparable with those of Ti-rich alloys [1,47].

The structure of the paper is as follows. In the next section, the alloy design/selection and its constraints is discussed and the nominal compositions of the selected alloys are given. The experimental details are then followed by the experimental results for the microstructures of the alloys and their isothermal oxidation at 800 and $1200{ }^{\circ} \mathrm{C}$ for $100 \mathrm{~h}$. The discussion considers the densities of the alloys, the macrosegregation of $\mathrm{Si}$, the as-cast and heat-treated microstructures and their oxidation. Alike [46,47], the experimental results are compared with the calculations (predictions) of NICE [20] throughout the discussion and similarly to [1] properties of the two alloys of this research, which are also RCCAs [2], are compared with those of other RCCAs studied to date. Furthermore, in the discussion of the results the two alloys of this study are compared with the Ta-containing alloys JZ1, JZ2 [46], JZ3 and JZ3+ [47]. A recommendation for future research is proposed at the end of the paper.

\section{Alloy Design}

The design/selection of the alloys used property targets for creep and oxidation and the alloy design methodology NICE [20]. The creep targets were creep rates ( $\left.\hat{\varepsilon}_{\text {alloy }}\right)$ at $1200{ }^{\circ} \mathrm{C}$ and $170 \mathrm{MPa}$ of (a) $4 \times 10^{-7} \mathrm{~s}^{-1}$ and (b) $1.96 \times 10^{-6} \mathrm{~s}^{-1}$ that are the experimental creep rates of the single crystal Ni-based superalloy CMSX-4, respectively, at $1200{ }^{\circ} \mathrm{C}$ and $50 \mathrm{MPa}$, and at $1200{ }^{\circ} \mathrm{C}$ and $100 \mathrm{MPa}$. Note that the creep property target in this research was different from that used in the design of the Ta-containing alloys JZ1, JZ2 [46], JZ3 and JZ3+ [47]. The oxidation targets were weight gains $\triangle W / A$ in isothermal oxidation at 800 and $1200{ }^{\circ} \mathrm{C}$, respectively, of (c) $10 \mathrm{mg} / \mathrm{cm}^{2}$ and (d) $50 \mathrm{mg} / \mathrm{cm}^{2}$, the same as in [46,47].

The constraints of the alloy design were as follows. The alloy(s) should (i) lie in the domain defined by the areas $\mathrm{A}$ and $\mathrm{B}$ in the $\Delta x$ versus $\delta$ map of $\mathrm{Nb}$-silicide-based alloys and RCCAs, Figures 1 and 19, respectively, in [50] and [1], (ii) contain $\mathrm{Al}, \mathrm{Cr}, \mathrm{Ge}, \mathrm{Hf}, \mathrm{Mo}, \mathrm{Sn}$, Ti and $\mathrm{W}$, (iii) have density lower than state-of-the-art Ni-based superalloys ( $\rho \approx 9 \mathrm{~g} / \mathrm{cm}^{3}$ for third generation, $\rho \approx 8.64$ to $8.95 \mathrm{~g} / \mathrm{cm}^{3}$ for second generation [51]), and lower than the density of multiphase bcc solid solution $+\mathrm{M}_{5} \mathrm{Si}_{3}$ silicide(s) RCCAs $\left(7.78 \leq \rho \leq 8.46 \mathrm{~g} / \mathrm{cm}^{3}\right.$ [2]), (iv) contain Mo and W with Mo/W higher than the RM/W (RM = Mo,Ta) in the RCCAs studied to date (RM/W $\leq 1$ [2]), (v) have Ti/Hf higher than that in the RCCAs studied to date (Ti/Hf $\leq 3$ [2]) and (vi) have Si macrosegregation (MACSi) less than 5 at.\%.

With reference to the above constraints, (i), (iv) and (v) were related to creep, (ii), (iv) and (v) were linked with (iii), and (ii) was linked with oxidation resistance. The constraint (vi) was prompted by data about MACSi (a) in the Ta-containing alloys JZ1, JZ2 [46], JZ3 and JZ3+ [47] and (b) in Nb-silicide-based alloys with/without addition of Ge or Sn or Ge + Sn that shows average MACSi of about 4.2 and 2.9 at.\% for Ti-rich and Ti-poor Nb-silicide-based alloys, respectively (see Figure A1 in the Appendix A).

For each creep target $\left(\varepsilon_{\text {alloy }}\right)$ the value of the alloy parameter $\Delta x_{\text {alloy }}$ was calculated from

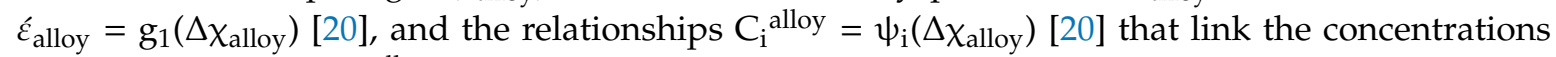
of alloying addition $C_{i}{ }^{\text {alloy }}$ with $\Delta$ xalloy were used to calculate the concentration of each element $i$. The values of $\Delta \chi_{\text {alloy }}$ were 0.1815 or 0.1725 , respectively, for creep targets (a) and (b). Similarly, for each oxidation target $(\triangle \mathrm{W} / \mathrm{A})$ the parameters $\mathrm{VEC}, \delta$ and $\Delta \mathrm{x}$, and the ratio $\mathrm{Nb} /(\mathrm{Ti}+\mathrm{Hf})$ were calculated from $(\Delta \mathrm{W} / \mathrm{A})_{\mathrm{Ti}}=\mathrm{f}_{\mathrm{j}, \mathrm{Ti}}\left(\mathrm{j}^{\mathrm{cal}}{ }_{\text {alloy }}\right)[20]$, where $\left.\mathrm{j}=\mathrm{VEC}, \delta, \Delta \mathrm{x}, \mathrm{Nb} /(\mathrm{Ti}+\mathrm{Hf})\right)$, the subscript $\mathrm{T}$ is the temperature and $i$ is 800 or $1200^{\circ} \mathrm{C}$.

For the creep target (a), and the oxidation targets (c) and (d) the alloy design methodology NICE gave the alloy composition (at.\%) Nb-11.5Ti-18Si-5Mo-2W-4.9Sn-4.6Ge-4.5Cr-4.7Al-1Hf, with ratios $\mathrm{Mo} / \mathrm{W}=2.5, \mathrm{Sn} / \mathrm{Ge}=1.07, \mathrm{Al} / \mathrm{Cr}=1.04$ and $\mathrm{Ti} / \mathrm{Hf}=11.5$ that are not significantly different from those 
in the alloy JZ3+ [47]. We shall call this alloy JZ4. For the property targets (b), (c) and (d), the alloy design methodology NICE gave the alloy Nb-21Ti-18Si-6.7Mo-1.2W-4.4Sn-4.2Ge-4Cr-3.7Al-0.8Hf with ratios $\mathrm{Al} / \mathrm{Cr}=0.93, \mathrm{Sn} / \mathrm{Ge}=1.05, \mathrm{Mo} / \mathrm{W}=5.6, \mathrm{Ti} / \mathrm{Hf}=26.2$, with the former two essentially the same and the latter two more than double the corresponding ratios in the alloys JZ3+ [47] and JZ4. We shall call the second alloy JZ5. This alloy was expected to have lower $\mathrm{T}_{\text {Liquidus }}$ compared with JZ4, owing to its higher Ti concentration. Note that the $\mathrm{Nb} /(\mathrm{Ti}+\mathrm{Hf})$ ratios of the alloys JZ4 and JZ5, respectively, of 3.5 and 1.65, are consistent with the empirical creep rule according to which the secondary creep rate of $\mathrm{Nb}$-silicide-based alloys increases as this ratio decreases $[6,20,49]$.

\section{Experiment}

The alloys were made with high purity $\mathrm{Al}, \mathrm{Cr}, \mathrm{Ge}, \mathrm{Hf}, \mathrm{Mo}, \mathrm{Nb}, \mathrm{Si}, \mathrm{Sn}$, Ti and $\mathrm{W}$ elements (better than 99.99 wt.\%) supplied by Goodfellow using arc melting in an argon atmosphere with a non-consumable tungsten electrode and a water-cooled copper crucible. Each alloy was melted five times to achieve chemical homogeneity. Similarly to the alloys JZ1, JZ2 [46], JZ3 and JZ3+ [47], it was very difficult to make the alloys with their compositions close to the nominal ones (given in the previous section), owing to the loss of elements by evaporation during arc melting (note that loss of Ge during melting also has been reported in [6]). The alloy JZ4 was prepared with a composition as close as possible to the nominal one after three attempts, where losses were compensated with an increase in the weight of elemental additions. The alloy JZ5 was prepared with a composition close to the nominal one using elemental TM and RM additions and ingots of the alloys Nb-24Ti-18Si-5Al-5Cr-5Mo (JG2 [52]), Nb-24Ti-18Si-5Al-5Cr-5Sn (ZX8 [42]), Nb-18Si-5Ge (ZF1 [24]), Nb-20Si-5Mo-3W (YG6 [53]) as master alloys.

Specimens from the top, bulk and bottom areas of each alloy button were mounted in Bakelite, ground using 120, 400, 800 and 1200 grit papers, and polished to a 1- $\mu \mathrm{m}$ surface finish using diamond pastes. These specimens were used for the SEM studies and EDS analyses (see below). According to DSC experiments (data not shown) the alloys did not exhibit melting up to $1600{ }^{\circ} \mathrm{C}$. Specimens from the bulk of the buttons were wrapped in Ta foil, placed in an alumina crucible, and heat treated at $1500{ }^{\circ} \mathrm{C}$ for $100 \mathrm{~h}$ in an alumina tube furnace under a flow of Ti-gettered argon. The specimens were cooled in the furnace.

We used a Siemens D5000 X-ray diffractometer with monochromatic $\mathrm{CuK} \alpha$ radiation and Powder Diffraction File data with the ICDD PDF-4+ and Sieve + software to identify the phases in as-cast and heat-treated alloys. The microstructures were studied using back-scattered electron (BSE) imaging in an Inspect F SEM. The chemical composition of large areas from the top, bulk and bottom of each alloy button and of the phases in these areas were analysed using JEOL 6400 SEM and Philips XL $30 S$ FEG SEMs equipped with energy dispersive X-ray spectrometry (EDS) and a voltage of $20 \mathrm{kV}$. At least five EDS analyses of phases with sizes larger than $5 \mu \mathrm{m}$ and of large areas were performed. The EDS data are given with the average, minimum and maximum values and standard deviation. EDS standards were specimens of high purity $\mathrm{Nb}, \mathrm{Ti}, \mathrm{Si}, \mathrm{Hf}, \mathrm{Mo}, \mathrm{W}, \mathrm{Ge}, \mathrm{Sn}, \mathrm{Al}, \mathrm{Cr}$ and $\mathrm{Al}_{2} \mathrm{O}_{3}$ that were polished to a 1- $\mu \mathrm{m}$ finish. A specimen of pure Co was used to calibrate the EDS detector. Calibration was repeated every hour during analysis. Area fractions of the $\mathrm{Nb}_{\mathrm{ss}}$ and $\mathrm{A} 15$ phases were calculated using the software Image-Pro with BSE images taken in the Inspect F SEM.

The isothermal oxidation of each alloy at $800^{\circ} \mathrm{C}$ and $1200^{\circ} \mathrm{C}$ was studied for $100 \mathrm{~h}$ using thermal gravimetric (TG) analysis (NETZSCH STA $449 \mathrm{~F} 3$ thermal analyser with the rate of $3^{\circ} \mathrm{C}$ per minute in both heating and cooling) and $3 \times 3 \times 3 \mathrm{~mm}^{3}$ specimens from the as-cast alloys that were ground to 1200 grit. There was no evidence of micro-cracking in the as-cast buttons and in the as-prepared oxidation specimens of both alloys. An AccuPyc II 1340 gas pycnometer was used to measure the density of the alloys. 


\section{Results}

\subsection{Microstructures}

The densities of the as-cast alloys and the area $\%$ of the $\mathrm{Nb}_{\mathrm{SS}}$ and $\mathrm{A} 15-\mathrm{Nb}_{3} \mathrm{X}(\mathrm{X}=\mathrm{Al}, \mathrm{Ge}, \mathrm{Si}$, $\mathrm{Sn}$ ) in the as-cast and heat-treated alloys are given in the Table 1 . The density and the vol.\% of the aforementioned phases of the alloy JZ4 were higher than those of the alloy JZ5.

Table 1. Density of the as-cast (AC) alloys and area \% of selected phases in the bulk of the as-cast and heat-treated (HT) alloys JZ4 and JZ5.

\begin{tabular}{cccc}
\hline Alloy & Density $\left(\mathrm{g} / \mathbf{c m}^{3}\right)$ & Solid Solution $\mathbf{( \% )}$ & A15 (\%) \\
\hline \multirow{2}{*}{ JZ4-AC } & $7.28 \pm 0.01$ & - & $19.8 \pm 3.2$ \\
& $7.27-7.29$ & $3.3 \pm 0.5$ & $17.3-23.4$ \\
\hline \multirow{2}{*}{ JZ4-HT $^{\mathrm{a}}$} & - & $2.7-3.6$ & $12.2 \pm 2.0$ \\
& & - & $10.9-14.5$ \\
\hline \multirow{2}{*}{ JZ5-AC } & $6.91 \pm 0.06$ & $2.3 \pm 0.3$ & $12.7 \pm 1.1$ \\
& $6.87-7.01$ & $2.1-2.6$ & $11.4-13.4$ \\
\hline \multirow{2}{*}{ JZ5-HT $^{\mathrm{a}}$} & - & & $10.6 \pm 0.3$ \\
& & & 10.9
\end{tabular}

a Some hafnia may be included in the measurement because the oxide exhibited the same contrast as the solid solution.

The average chemical compositions of the alloys and of the phases in their microstructures are given in the Table 2 (compare with the microstructures of the alloys JZ3 and JZ3+ in Table 2 in [47]). The chemical analysis data of the as-cast (AC) and heat-treated (HT) alloys is given in the Tables S1 and S2 in the Supplementary Materials. Compared with the nominal alloy compositions, in the cast alloy JZ4 (JZ4-AC) the concentrations of $\mathrm{Cr}, \mathrm{Ge}, \mathrm{Mo}$, Sn and W were slightly higher, and the ratios $\mathrm{Mo} / \mathrm{W}, \mathrm{Sn} / \mathrm{Ge}, \mathrm{Al} / \mathrm{Cr}$ and Ti/Hf (respectively, 2.6, 1.07, 1.04 and 11.5) essentially the same, whereas in the cast alloy JZ5 (JZ5-AC) the concentrations of $\mathrm{Al}, \mathrm{Cr}, \mathrm{Ge}, \mathrm{Si}$ and $\mathrm{Sn}$ were slightly higher, and the ratios $\mathrm{Mo} / \mathrm{W}, \mathrm{Sn} / \mathrm{Ge}, \mathrm{Al} / \mathrm{Cr}$ and Ti/Hf (respectively, 5.7, 1.1, 0.96, 25.5) were actually the same. There was macrosegregation of Si (MACSi) in both alloys, 3 and 4.5 at.\%, respectively, in JZ4-AC and JZ5-AC.

Table 2. Average chemical compositions (at.\%) and summary of phases in the as-cast and heat-treated alloys JZ4 and JZ5.

\begin{tabular}{|c|c|}
\hline \multicolumn{2}{|c|}{ Alloy } \\
\hline $\mathrm{JZ4}$ & JZ5 \\
\hline \multicolumn{2}{|c|}{ As Cast } \\
\hline $\mathrm{Nb}-12.5 \mathrm{Ti}-17.8 \mathrm{Si}-6.2 \mathrm{Mo}-2.3 \mathrm{~W}-5.8 \mathrm{Sn}-5.2 \mathrm{Ge}-1.1 \mathrm{Hf}-5 \mathrm{Al}-5.2 \mathrm{Cr}$ & $\mathrm{Nb}-20.4 \mathrm{Ti}-19.2 \mathrm{Si}-6.3 \mathrm{Mo}-1.1 \mathrm{~W}-5.7 \mathrm{Sn}-5.2 \mathrm{Ge}-0.9 \mathrm{Hf}-4.5 \mathrm{Al}-4.7 \mathrm{Ge}$ \\
\hline $\mathrm{Nb}_{5} \mathrm{Si}_{3}$, Ti-rich $\mathrm{Nb}_{5} \mathrm{Si}_{3}$ & $\mathrm{Nb}_{5} \mathrm{Si}_{3}$, Ti-rich $\mathrm{Nb}_{5} \mathrm{Si}_{3}$ \\
\hline $\mathrm{A} 15-\mathrm{Nb}_{3} \mathrm{X}$, Ti-rich A15 & $\mathrm{A} 15-\mathrm{Nb}_{3} \mathrm{X}$, Ti-rich A15 \\
\hline $\mathrm{TM}_{5} \mathrm{Sn}_{2} \mathrm{X}$ & $\mathrm{TM}_{5} \mathrm{Sn}_{2} \mathrm{X}$ \\
\hline $\mathrm{C} 14-\mathrm{NbCr}_{2}$ Laves & $\mathrm{C} 14-\mathrm{NbCr}_{2}$ Laves \\
\hline $\mathrm{HfO}_{2}$ & $\mathrm{HfO}_{2}$ \\
\hline \multicolumn{2}{|c|}{ Heat Treated } \\
\hline $\mathrm{Nb}-12.3 \mathrm{Ti}-18.2 \mathrm{Si}-5.8 \mathrm{Mo}-2.2 \mathrm{~W}-5.4 \mathrm{Sn}-5.4 \mathrm{Ge}-1.2 \mathrm{Hf}-4.8 \mathrm{Al}-4.8 \mathrm{Cr}$ & Nb-20.5Ti-18.8Si-6.2Mo-1.2W-5.7Sn-5.6Ge-1Hf-4.7Al-4.9Cr \\
\hline$(\mathrm{Nb}, \mathrm{W})_{\mathrm{ss}}$ & $(\mathrm{Nb}, \mathrm{W})_{\mathrm{ss}}$ \\
\hline $\mathrm{Nb}_{5} \mathrm{Si}_{3}$, Ti-rich $\mathrm{Nb}_{5} \mathrm{Si}_{3}$ & $\mathrm{Nb}_{5} \mathrm{Si}_{3}$, Ti-rich $\mathrm{Nb}_{5} \mathrm{Si}_{3}$ \\
\hline $\mathrm{A} 15-\mathrm{Nb}_{3} \mathrm{X}$ & $\mathrm{A} 15-\mathrm{Nb}_{3} \mathrm{X}$ \\
\hline \multicolumn{2}{|l|}{$\mathrm{C} 14-\mathrm{NbCr}_{2}$ Laves } \\
\hline $\mathrm{HfO}_{2}$ & $\mathrm{HfO}_{2}$ \\
\hline
\end{tabular}


The same phases were present in the cast microstructures of both alloys, namely $\mathrm{Nb}_{5} \mathrm{Si}_{3}, \mathrm{~A}_{15}-\mathrm{Nb}_{3} \mathrm{X}$, $\mathrm{TM}_{5} \mathrm{Sn}_{2} \mathrm{X}, \mathrm{C} 14-\mathrm{Cr}_{2} \mathrm{Nb}$ and $\mathrm{HfO}_{2}$; see Table 2 and Tables S1 and S2 and Figures S1 and S2 in the Supplementary Materials. The $\mathrm{Nb}_{5} \mathrm{Si}_{3}$ silicide existed in both the $\beta$ and $\alpha$ forms. In both alloys, Ti-rich $\mathrm{Nb}_{5} \mathrm{Si}_{3}$ and Ti-rich $\mathrm{A} 15-\mathrm{Nb}_{3} \mathrm{X}$ were also observed. The XRD did not confirm the presence of $\mathrm{Nb}$ solid solution. The absence of the latter was also confirmed by EDS in both alloys. In the bottom of the button of JZ4-AC the $\mathrm{TM}_{5} \mathrm{Sn}_{2} \mathrm{X}$ and Ti-rich $\mathrm{Nb}_{5} \mathrm{Si}_{3}$ and Ti-rich $\mathrm{A} 15-\mathrm{Nb}_{3} \mathrm{X}$ were not observed.

The typical microstructure of JZ4-AC is shown in Figure 1a,c and the EDS data are given in Table S1. The microstructures in the top and bulk of JZ4-AC were similar. The Mo solubility in the silicide was 4.5 at.\%. The areas exhibiting lighter contrast at the edges of $\mathrm{Nb}_{5} \mathrm{Si}_{3}$ grains were rich in $\mathrm{Ti}$ and had relatively lower concentration of Si (about 20.8 at.\%) and higher concentration of Sn (about 5 at.\%) than the bulk of the grains. The $<\mathrm{Si}>(=\mathrm{Si}+\mathrm{Sn}+\mathrm{Ge}+\mathrm{Al})$ content in the "normal" and Ti-rich $\mathrm{Nb}_{5} \mathrm{Si}_{3}$ was 37 at. $\%$ and 36.2 at.\%, respectively. The A15 was formed between the $\mathrm{Nb}_{5} \mathrm{Si}_{3}$ grains. The Mo solubility was the same (14.2 at.\% and 14.4 at.\%) in the "normal" and the Ti-rich A15 and the <Si> content was 19.8 at $\%$ and 23.8 at.\%, respectively.
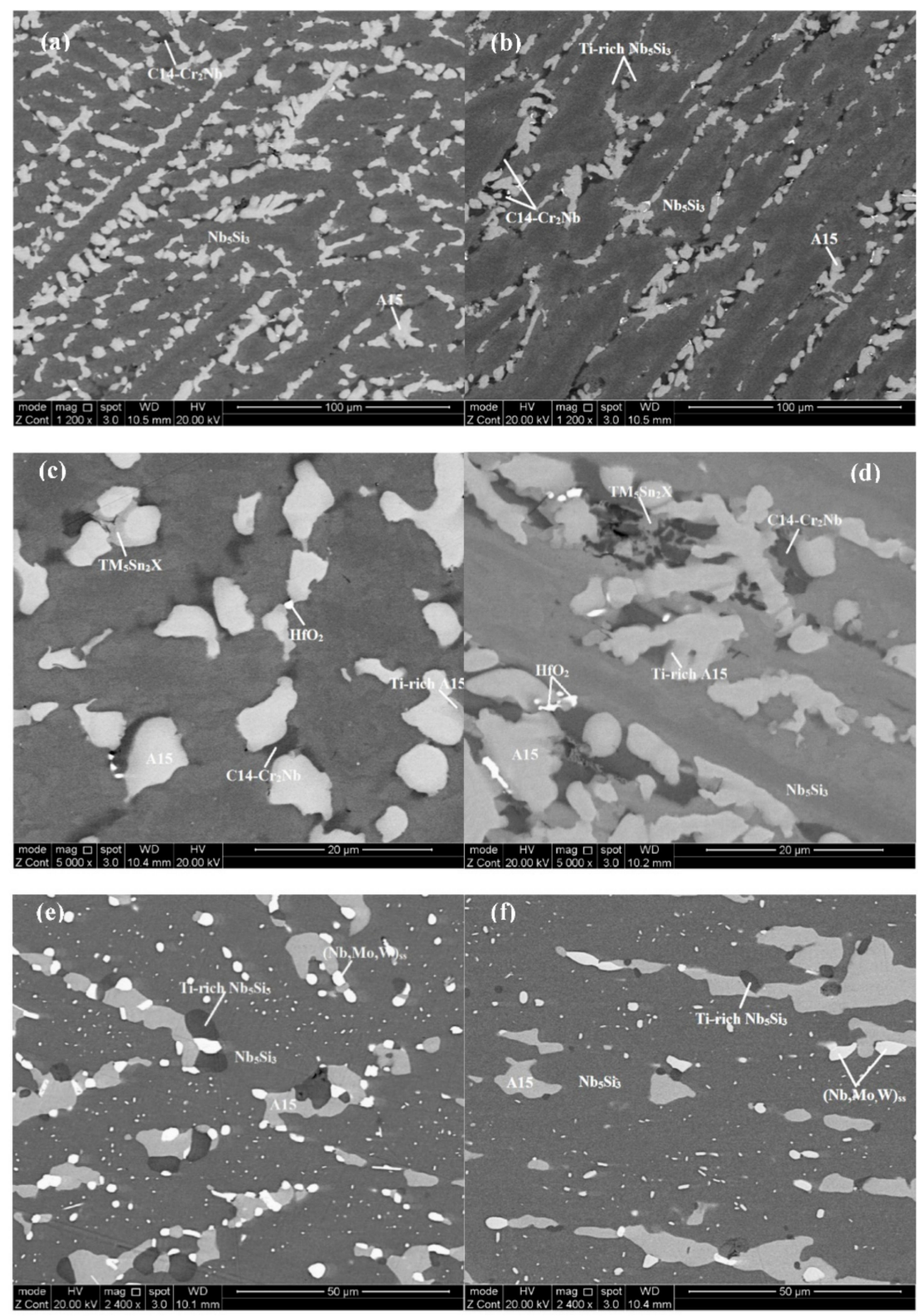

Figure 1. The as-cast (a-d) and heat-treated $(\mathbf{e}, \mathbf{f})$ microstructures of the alloys JZ4 $(\mathbf{a}, \mathbf{c}, \mathbf{e})$ and JZ5 $(\mathbf{b}, \mathbf{d}, \mathbf{f})$. 
In between the primary silicide grains, a phase was observed that exhibited a similar contrast to that of the Ti-rich A15. The composition of this phase corresponded to the $\mathrm{Nb}_{5} \mathrm{Sn}_{2} \mathrm{Si}$ intermetallic, in agreement with the XRD data (Figure S1). Only two analyses of this phase were possible owing to the size. In this compound the $\mathrm{Nb}$ was substituted by $\mathrm{Ti}$ and the $\mathrm{Si}$ by $\mathrm{Al}$ and $\mathrm{Ge}$. Considering its relatively high concentrations of $\mathrm{Ti}$, Ge and $\mathrm{Al}$ and the fact that $\mathrm{Nb}_{5} \mathrm{Sn}_{2} \mathrm{Si}_{1} \mathrm{Nb}_{5} \mathrm{Sn}_{2} \mathrm{Ge}, \mathrm{Nb}_{5} \mathrm{Sn}_{2} \mathrm{Al}$ and $\mathrm{Ti}_{5} \mathrm{Sn}_{2} \mathrm{Si}$ all have the $\mathrm{W}_{5} \mathrm{Si}_{3}$ as prototype [54], this phase is given as $\mathrm{TM}_{5} \mathrm{Sn}_{2} \mathrm{X}$ in Table $\mathrm{S1}$, where $\mathrm{TM}=\mathrm{Nb}$, Ti and $\mathrm{X}=\mathrm{Si}, \mathrm{Ge}, \mathrm{Al}$. The composition of the Laves phase was in agreement with [21].

The microstructure of JZ5-AC is shown in Figure 1b,d. There were no differences in the microstructure in the top, bulk and bottom of the button. The partitioning of elements between the $\mathrm{Nb}_{5} \mathrm{Si}_{3}$ and $\mathrm{A} 15$ was the same as in JZ4-AC, with increased concentrations of Mo, $\mathrm{W}$ and $\mathrm{Cr}$ in the A15. The $<\mathrm{Si}>$ content in the "normal" and Ti-rich $\mathrm{Nb}_{5} \mathrm{Si}_{3}$ was essentially the same as in JZ4-AC and the content in the "normal" and Ti-rich A15 was slightly higher than that in JZ4-AC. The C14- $\mathrm{Cr}_{2} \mathrm{Nb}$ Laves phase was slightly richer in Ti and leaner in $\mathrm{Nb}, \mathrm{Cr}$ and $\mathrm{W}$ compared with JZ4-AC. The $\mathrm{TM}_{5} \mathrm{Sn}_{2} \mathrm{X}$ compound was richer in Ti. Two analyses of this phase were possible (Table S2). The microhardness of $\mathrm{Nb}_{5} \mathrm{Si}_{3}$ was $1445 \pm 50 \mathrm{HV}$ compared with $1508 \pm 41 \mathrm{HV}$ in JZ4-AC. The hardness of the cast alloys JZ4 and JZ5 was $862 \mathrm{HV}$ and $838 \mathrm{HV}$, respectively.

After the heat treatment there was no chemical inhomogeneity of $\mathrm{Si}$ in both alloys. In the alloy $\mathrm{JZ4}-\mathrm{HT}$ the ratios $\mathrm{Mo} / \mathrm{W}, \mathrm{Sn} / \mathrm{Ge}, \mathrm{Al} / \mathrm{Cr}$ and Ti/Hf, respectively, were 2.6, 1, 1 and 10.3, and in the alloy JZ5-HT they were 5.2, 1, 0.96 and 20.5, respectively, and were not different compared with the cast alloys with the exception of the Ti/Hf ratio which was slightly reduced. The same phases were observed in the heat-treated microstructures, namely $\mathrm{Nb}_{5} \mathrm{Si}_{3}, \mathrm{~A} 15-\mathrm{Nb}_{3} \mathrm{X},(\mathrm{Nb}, \mathrm{W})_{\mathrm{ss}}$ and $\mathrm{HfO}_{2}(\mathrm{Table} 2$ and Tables S1 and S2 and Figures S1 and S2 in the Supplementary Materials). A very small volume fraction of the C14- $\mathrm{Cr}_{2} \mathrm{Nb}$ Laves phase was observed only in JZ4-HT. The $\mathrm{Nb}_{5} \mathrm{Si}_{3}$ silicide existed in both the $\beta$ and $\alpha$ forms and Ti-rich $\mathrm{Nb}_{5} \mathrm{Si}_{3}$ was also observed. The vol.\% of the $\mathrm{A} 15$ compound was reduced notably in JZ4-HT, and solid solution rich in $\mathrm{W}$ and Mo formed at a small volume fraction (Table 1).

The microstructure of JZ4-HT is shown in Figure 1e. In the $\mathrm{Nb}_{5} \mathrm{Si}_{3}$, the Si concentration was reduced and the solubility of $\mathrm{Ti}, \mathrm{Sn}, \mathrm{Al}$ and $\mathrm{Cr}$ was increased. In the Ti-rich $\mathrm{Nb}_{5} \mathrm{Si}_{3}$ the solubility of $\mathrm{Sn}$ was lower and the solubilities of $\mathrm{Si}$ and Hf were higher compared with the "normal" silicide. The $<\mathrm{Si}>$ content of the "normal" and Ti-rich $\mathrm{Nb}_{5} \mathrm{Si}_{3}$ was 36.6 at.\% and 38.1 at.\%, respectively. The solid solution was Si-free and very rich in $\mathrm{W}\left(29.4\right.$ at.\%). It was formed around the $\mathrm{Nb}_{5} \mathrm{Si}_{3}$ silicide grains and as dispersed tiny particles in them. The Laves phase exhibited the same contrast as the Ti-rich $\mathrm{Nb}_{5} \mathrm{Si}_{3}$, its $\mathrm{Si}$ and $\mathrm{Al}$ contents, respectively, were increased and decreased by 2.5 at. $\%$ and 5 at.\%, compared with JZ4-AC (Table S1). Remarkably, the alloy was not contaminated by oxygen. Only a very small volume fraction of alumina had formed just below the surface of the heat-treated specimen.

The microstructure of JZ5-HT is shown in Figure 1f. The solid solution exhibited white contrast, was $\mathrm{Si}$ free and very rich in Mo and $\mathrm{W}$. Tiny particles of the solid solution were dispersed in the $\mathrm{Nb}_{5} \mathrm{Si}_{3}$ grains. The Si solubility in the $\mathrm{Nb}_{5} \mathrm{Si}_{3}$ was reduced to 20.3 at.\% and the $\mathrm{Sn}, \mathrm{Al}$ and $\mathrm{Cr}$ concentrations were increased, whereas in the Ti-rich $\mathrm{Nb}_{5} \mathrm{Si}_{3}$ there were higher concentrations of $\mathrm{Si}$ and $\mathrm{Hf}$ and lower concentration of $\mathrm{Sn}$, compared with JZ5-AC. The $<\mathrm{Si}>$ content of the "normal" and Ti-rich $\mathrm{Nb}_{5} \mathrm{Si}_{3}$ was 36.8 at. $\%$ and 37.9 at. $\%$, respectively (Table S2). There was a slight increase in the Cr content in the A15. There was no contamination of the JZ5-HT by oxygen.

Only one measurement of the hardness of $(\mathrm{Nb}, \mathrm{W})_{\mathrm{ss}}$ was possible in JZ4-HT and JZ5-HT using nano-indentation. The hardness of the solid solution was similar (about $850 \mathrm{HV}$ ) in both alloys. The hardness of JZ4-HT and JZ5-HT was 834 HV and 806 HV, respectively.

\subsection{Oxidation}

The TG data are shown in Figure 2, the oxidised specimens in Figure 3 and the rate constants and weight changes of the alloys JZ4 and JZ5 are given in the Table 3. In Figure 2, the data for the Ta-containing alloys JZ1 to JZ3+ $[46,47]$ are included for comparison purposes. The weight gains of the 
alloys JZ4 and JZ5 after $100 \mathrm{~h}$ at $800{ }^{\circ} \mathrm{C}$ were $0.82 \mathrm{mg} / \mathrm{cm}^{2}$ and $0.57 \mathrm{mg} / \mathrm{cm}^{2}$, respectively. Pest oxidation and spallation of oxide scales did not occur. Both alloys followed parabolic oxidation kinetics at $800{ }^{\circ} \mathrm{C}$. The oxidation of the alloy JZ4 at $1200{ }^{\circ} \mathrm{C}$ was similar to that of the alloy JZ3+ [47], and the weight gain was $13.43 \mathrm{mg} / \mathrm{cm}^{2}$. In the case of the alloy JZ5, the weight gain of $8.43 \mathrm{mg} / \mathrm{cm}^{2}$ was the lowest of all the JZ series of alloys. No spallation of the oxide scales was observed in the alloys JZ4 and JZ5.
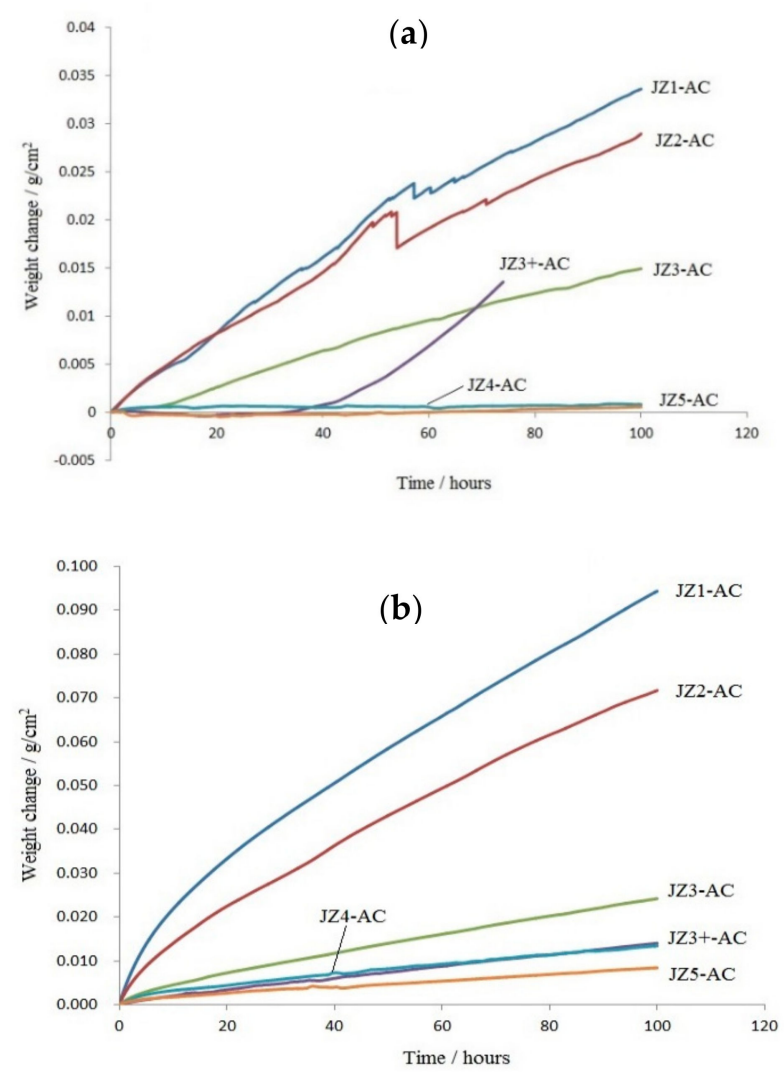

Figure 2. Thermal gravimetric (TG) data for the isothermal oxidation of the alloys JZ4 and JZ5 together with the data for the alloys JZ1, JZ2 [46], JZ3 and JZ3+ [47]. (a) $800{ }^{\circ} \mathrm{C}$, (b) $1200^{\circ} \mathrm{C}$.
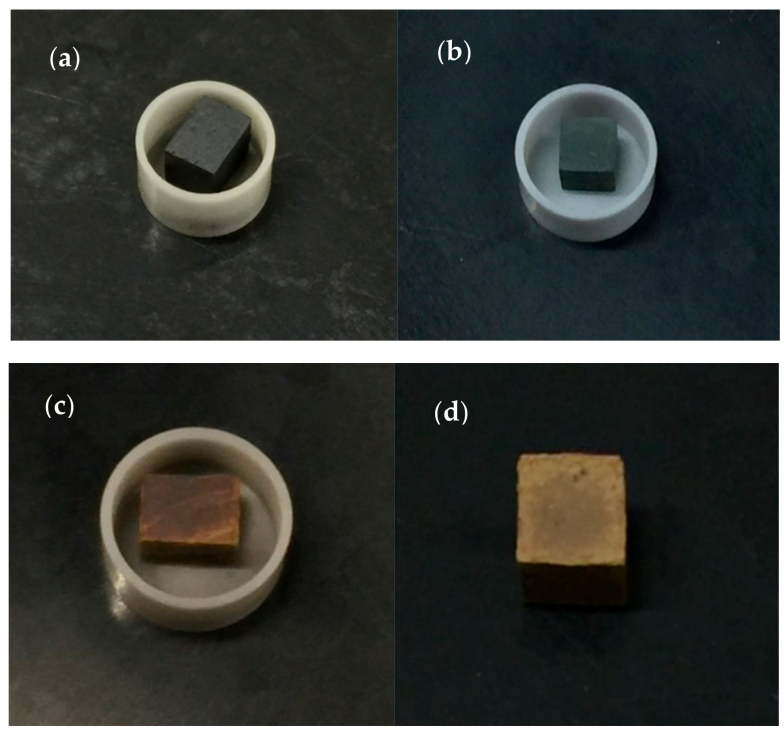

Figure 3. The specimens of the alloys JZ4 and JZ5 after isothermal oxidation at 800 and $1200{ }^{\circ} \mathrm{C}$; (a) and (c) alloy JZ4, (b,d) alloy JZ5; (a,b) $800{ }^{\circ} \mathrm{C},(\mathbf{c}, \mathbf{d}) 1200{ }^{\circ} \mathrm{C}$. 
Table 3. Weight gains and parabolic oxidation rate constants of the alloys JZ4 and JZ5 after isothermal oxidation at 800 and $1200{ }^{\circ} \mathrm{C}$ for $100 \mathrm{~h}$.

\begin{tabular}{|c|c|c|c|c|}
\hline \multirow[t]{2}{*}{ Alloy } & $\begin{array}{l}\text { Weight Gain } \\
\left(\mathrm{mg} / \mathrm{cm}^{2}\right)\end{array}$ & $\begin{array}{c}\text { Rate Constant } \\
k_{\mathrm{p}}\left(\mathrm{g}^{2} \mathrm{~cm}^{-4} \mathrm{~s}^{-1}\right)\end{array}$ & $\begin{array}{l}\text { Weight Gain } \\
\left(\mathrm{mg} / \mathrm{cm}^{2}\right)\end{array}$ & $\begin{array}{c}\text { Rate Constant } \\
k_{\mathrm{p}}\left(\mathrm{g}^{2} \mathrm{~cm}^{-4} \mathrm{~s}^{-1}\right)\end{array}$ \\
\hline & \multicolumn{2}{|c|}{$800^{\circ} \mathrm{C}$} & \multicolumn{2}{|c|}{$1200^{\circ} \mathrm{C}$} \\
\hline $\mathrm{JZ4}$ & $0.82(100 \mathrm{~h})$ & $\begin{array}{c}1.02 \times 10^{-12}(0-100 \mathrm{~h}) \\
9.9 \times 10^{-12}(0-9 \mathrm{~h}) \\
9.4 \times 10^{-13}(9-100 \mathrm{~h})\end{array}$ & $13.43(100 \mathrm{~h})$ & $\begin{array}{c}5.04 \times 10^{-10}(0-100 \mathrm{~h}) \\
2.92 \times 10^{-10}(0-14 \mathrm{~h}) \\
5.44 \times 10^{-10}(14-100 \mathrm{~h})\end{array}$ \\
\hline JZ5 & $0.57(100 \mathrm{~h})$ & $\begin{array}{l}7.33 \times 10^{-12}(0-100 \mathrm{~h}) \\
1.2 \times 10^{-11}(45-100 \mathrm{~h})\end{array}$ & $8.43(100 \mathrm{~h})$ & $\begin{array}{c}1.92 \times 10^{-10}(0-100 \mathrm{~h}) \\
9.46 \times 10^{-11}(0-9 \mathrm{~h}) \\
2.04 \times 10^{-10}(9-100 \mathrm{~h})\end{array}$ \\
\hline
\end{tabular}

\subsubsection{Oxidation at $800^{\circ} \mathrm{C}$}

Figure $4 \mathrm{a}, \mathrm{b}$ show the oxide scale and bulk of a cross section of the alloy JZ4 after the TG experiment. The thickness of the scale was about $3 \mu \mathrm{m}$. In the scale there were some short cracks parallel to its surface. Table S3 in the Supplementary Materials gives the chemical composition of the scale and of the phases in the bulk. The latter phases were the same as those in JZ4-AC, with the exception of the Ti-rich A15 that was not observed. There was no apparent change of the compositions of the phases compared with the JZ4-AC. The mixed oxide that formed the oxide scale was rich in $\mathrm{Nb}$ and $\mathrm{Si}$ and very lean in other elements. There was some internal oxidation in a very thin area below the scale where the oxidised A15 phase exhibited a darker contrast, see Figure 4a. Below this area the microstructure was not contaminated by oxygen.

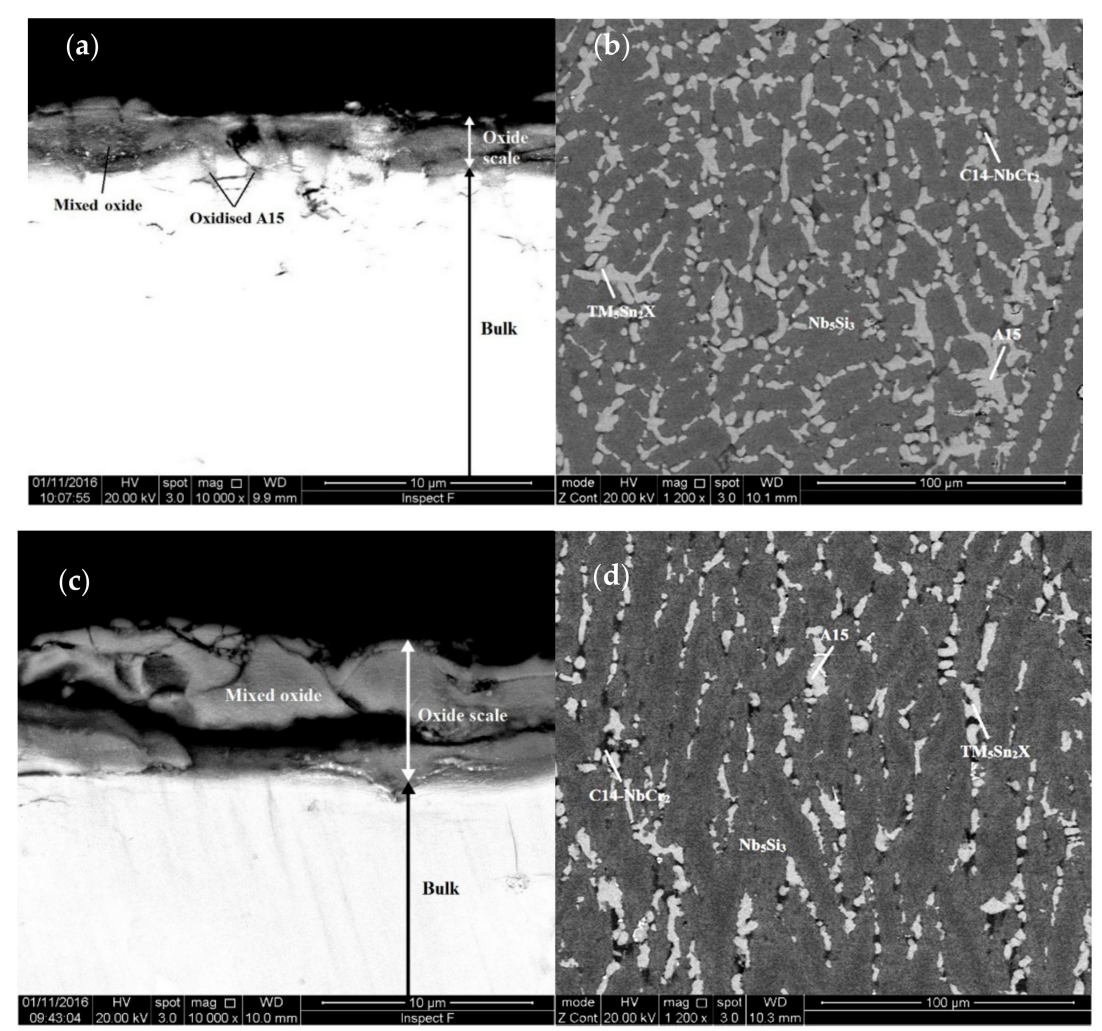

Figure 4. Back-scattered electron (BSE) images of the microstructure of cross sections of the oxidised alloys JZ4 $(\mathbf{a}, \mathbf{b})$ and JZ5 $(\mathbf{c}, \mathbf{d})$ at $800{ }^{\circ} \mathrm{C}(\mathbf{a}, \mathbf{c})$ scale, $(\mathbf{b}, \mathbf{d})$ bulk microstructure. Enhanced contrast in $(\mathbf{a}, \mathbf{c})$ to show oxide scale. 
The microstructure of a cross section of the alloy JZ5 is shown in the Figure $4 \mathrm{c}, \mathrm{d}$. The thickness of the oxide scale was at about $3 \mu \mathrm{m}$, similar to that of the alloy JZ4. The EDS data of the scale and the phases in bulk is given in the Table S4 in the Supplementary Materials. The phases in the bulk were $\mathrm{Nb}_{5} \mathrm{Si}_{3}, \mathrm{~A} 15, \mathrm{TM}_{5} \mathrm{Sn}_{2} \mathrm{X}$ and $\mathrm{Cr}_{2} \mathrm{Nb}$ Laves. The mixed oxide that formed the oxide scale was rich in $\mathrm{Nb}$, $\mathrm{Ti}$ and Si. There was no significant change of the compositions of the phases in the bulk compared with JZ5-AC. There was no evidence of internal oxidation and no contamination of the phases by oxygen.

\subsubsection{Oxidation at $1200{ }^{\circ} \mathrm{C}$}

Figures 5 and 6 show the microstructures of cross sections of the oxidised specimens of the alloys JZ4 and JZ5. For each alloy, three regions can be seen, namely the oxide scale, diffusion zone and bulk. The oxide scale that formed on the alloy JZ5 was significantly thinner compared with the alloy JZ4, about 50 and $200 \mu \mathrm{m}$, respectively. Cracks and holes were observed in the scales of both alloys.
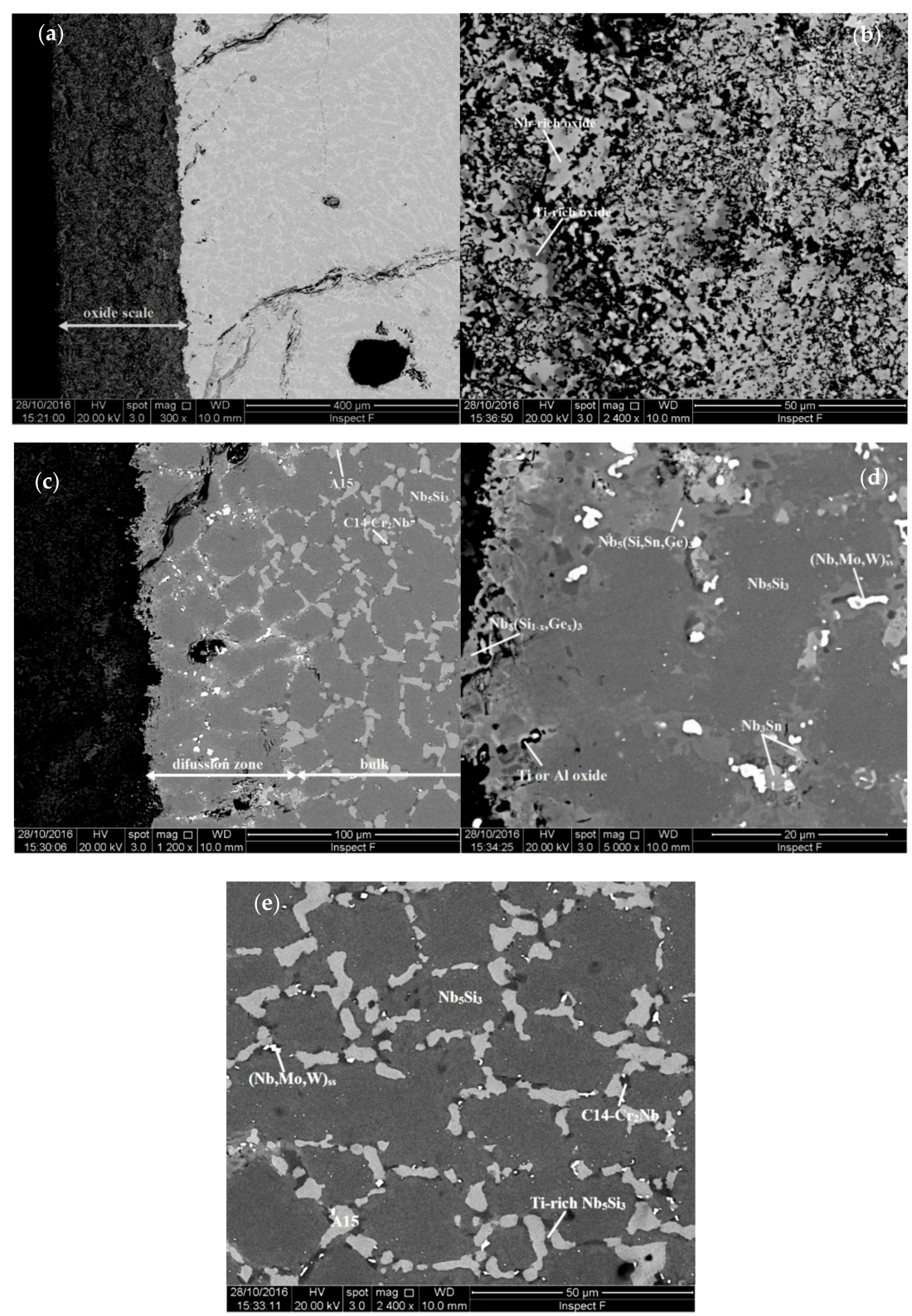

Figure 5. BSE images of the microstructure of a cross section of the oxidised alloy JZ4 at $1200^{\circ} \mathrm{C}$, (a) oxide scale and microstructure below it, (b) oxide scale, (c) diffusion zone and bulk, (d) microstructure of the diffusion zone and (e) bulk microstructure. 

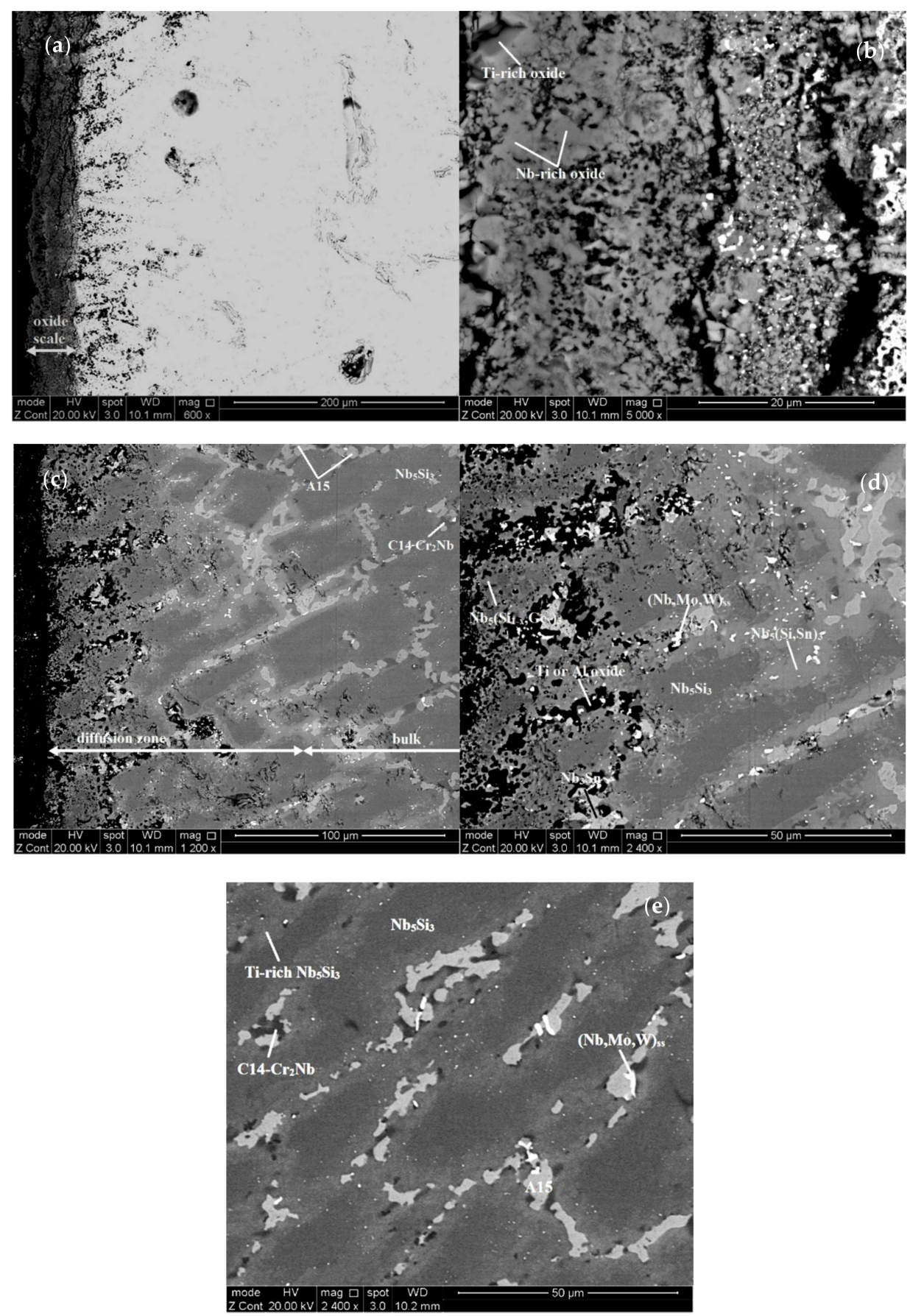

Figure 6. BSE images of the microstructure of a cross section of the oxidised alloy JZ5 at $1200{ }^{\circ} \mathrm{C}$, (a) oxide scale, diffusion zone and bulk, (b) oxide scale, (c) diffusion zone and bulk, (d) microstructure of the diffusion zone and (e) bulk microstructure.

The oxide scale of the alloy JZ4 consisted of three types of oxides, namely Nb-rich, Ti-rich (Table S5 in the Supplementary Materials) and Si-rich oxide. The latter exhibited black contrast, the same as the pores and cracks in the scale. Its concentration is not given in the Table S5. The concentrations of Sn and $\mathrm{Ge}$ in the scale were effectively zero. The $\mathrm{Nb}$-rich oxide contained no Mo and the Ti-rich oxide contained no $\mathrm{W}$. The latter oxide was richer in $\mathrm{Al}$ and $\mathrm{Cr}$ compared with the $\mathrm{Nb}$-rich oxide.

The phases in the diffusion zone of JZ4 were the $\mathrm{Nb}_{5} \mathrm{Si}_{3}, \mathrm{Nb}_{5}(\mathrm{Si}, \mathrm{Ge})_{3}$, Ge-rich $\mathrm{Nb}_{5}(\mathrm{Si}, \mathrm{Ge})_{3}, \mathrm{Nb}_{3} \mathrm{Sn}$, $(\mathrm{Nb}, \mathrm{W})_{\mathrm{ss}}$ and $\mathrm{HfO}_{2}$ (Table S5). The Ti and $\mathrm{Al}$ contents in these phases remained relatively high owing to the absence of $\mathrm{Ti}$ and/or $\mathrm{Al}$ oxides in the diffusion zone. These oxides were only observed in a few 
areas just below the scale. Compared with $\mathrm{JZ} 4-\mathrm{HT}$, the $(\mathrm{Nb}, \mathrm{W})_{\mathrm{ss}}$ in the diffusion zone was richer in Ge, Mo, W and poorer in Al, Cr, Ti. Compared with the solid solution in the bulk of the oxidised specimen, the $(\mathrm{Nb}, \mathrm{W})_{\mathrm{ss}}$ in the diffusion zone was poorer in Ti and richer in $\mathrm{Cr}, \mathrm{Mo}, \mathrm{W}$. The bulk microstructure of the oxidised specimen was similar to that of the cast alloy and included the solid solution, which was richer in Mo, W, $\mathrm{Al}$ and poorer in $\mathrm{Cr}$, compared with the solid solution in JZ4-HT. The concentration of Mo in the A15 was high (21.9 at.\%). The $\mathrm{Nb}_{5} \mathrm{Si}_{3}$ and Ti-rich $\mathrm{Nb}_{5} \mathrm{Si}_{3}$ were poorer in $\mathrm{Si}$ and the latter was also poorer in $\mathrm{W}$ and richer in Ti and Sn compared with the cast alloy. The Laves phase was richer in $\mathrm{Si}$ and poorer in $\mathrm{Al}$ and Ti. The $\mathrm{TM}_{5} \mathrm{Sn}_{2} \mathrm{X}$ was not observed in the bulk after the oxidation. X-ray maps corresponding to the scale and the diffusion zone below it are shown in the Figure 7. Chromium and Ti-rich areas in the scale, corresponding to the Ti-rich oxide, can be seen in the $\mathrm{Cr}$ and Ti maps (Figure 7i,1). Immediately below the scale the substrate was rich in Ge (Figure 7c). Tin-rich areas can be observed below the Ge-rich area (Figure 7c,d). The Sn-rich areas, some of which were also Ge-rich, corresponded with the areas in-between $\mathrm{Nb}_{5} \mathrm{Si}_{3}$ grains where the A15 and the solid solution were formed (Figure $5 \mathrm{~d}$ ).
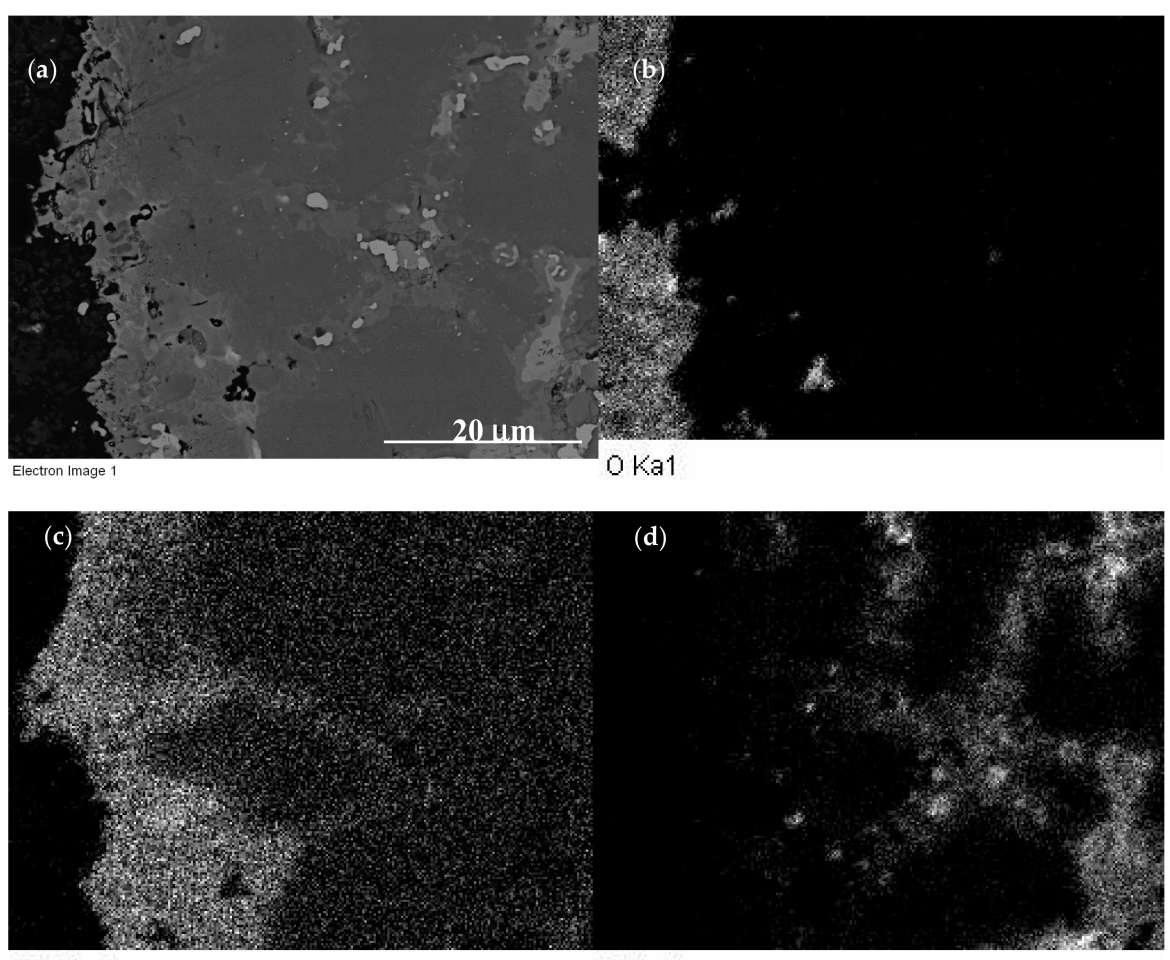

Ge Ka1

Sn La1

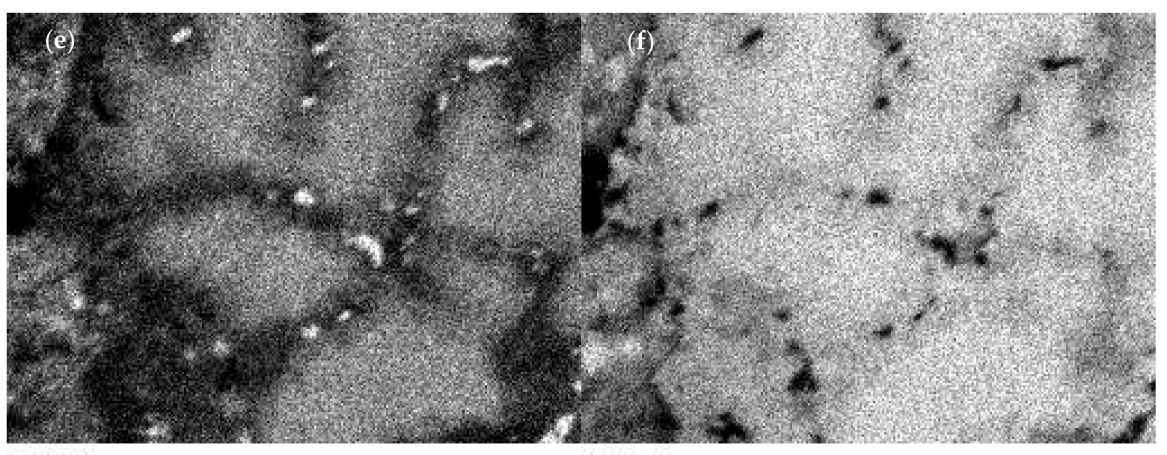

Si Ka1

Nb La1

Figure 7. Cont. 

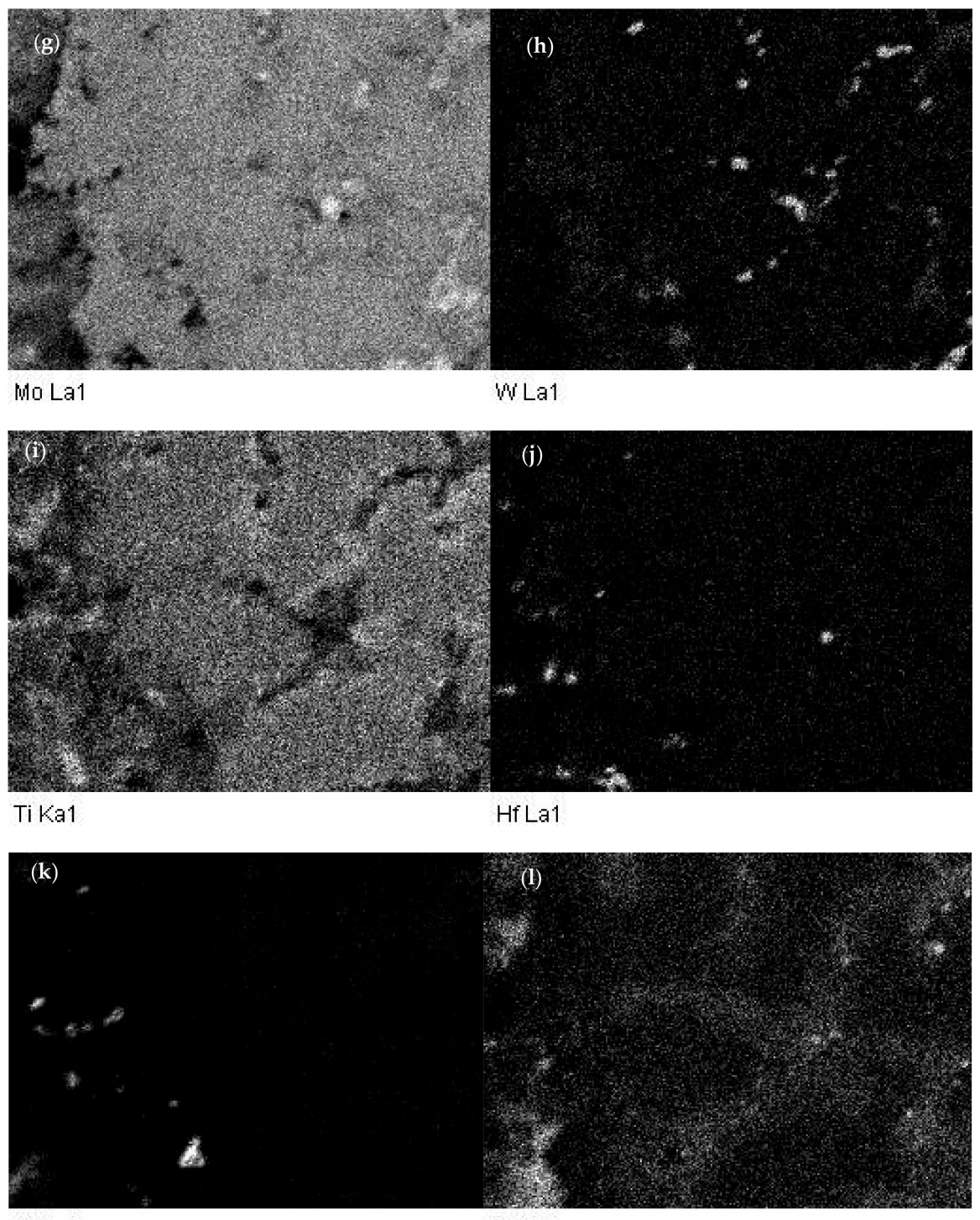

Figure 7. X-ray maps of a cross section of the oxidized specimen of JZ4 at $1200{ }^{\circ} \mathrm{C}$, where: (b) Oxygen; (c) Ge; (d) Sn; (e) Si; (f) Nb; (g) Mo; (h) W; (i) Ti; (j) Hf; (k) Al; (l) Cr.

The oxides in the scale that formed on the alloy JZ5 were similar to those of the alloy JZ4 (see Table S6 in the Supplementary Materials). A solid solution rich in Mo and W was present in the inner regions of the scale, where it exhibited white contrast, see Figure $6 \mathrm{~b}$. The phases in the diffusion zone that formed in JZ5 were the same as those in the alloy JZ4 and the vol.\% of the Ti and Al oxides was slightly increased compared with the alloy JZ4. Compared with JZ5-HT, the $(\mathrm{Nb}, \mathrm{W})_{\mathrm{ss}}$ in the diffusion zone was richer in Mo, $\mathrm{W}$ and poorer in Ti. The solid solution was also present in the bulk of the oxidised specimen but not the $\mathrm{TM}_{5} \mathrm{Sn}_{2} \mathrm{X}$ compound. The solid solution in the bulk of the oxidised specimen was richer in Mo, $\mathrm{W}$ and poorer in $\mathrm{Al}, \mathrm{Cr}$, Ti compared with JZ5-HT. The Ti-rich $\mathrm{Nb}_{5} \mathrm{Si}_{3}$ was richer in Ti and Sn and poorer in Si and W compared with the cast alloy. The A15 phase was richer in Mo and the Laves phase was poorer in Ti.

\section{Discussion}

\subsection{Density}

The densities of both alloys (Table 1) were (a) lower than those of the alloy JZ3+, which had the lowest density of the Ta-containing JZ series of alloys [46,47], (b) lower than the densities of Ti-free 
creep resistant $\mathrm{Nb}$-silicide-based alloys (see Figures 2 and 4 in [1]), and (c) significantly lower than the target density $\left(\rho=9 \mathrm{~g} / \mathrm{cm}^{3}\right)$ of $\mathrm{Nb}$-silicide-based alloys with RM additions and a strength of $450 \mathrm{MPa}$ at $1500{ }^{\circ} \mathrm{C}[55]$.

The higher Ti concentration in the alloy JZ5 resulted in its density falling below $7 \mathrm{~g} / \mathrm{cm}^{3}$ (Table 1). Furthermore, the density of JZ5 was lower than the density of some of the Ti-rich $\mathrm{Nb}$-silicide-based alloys studied to date (Figure 5 in [1], and Table 4). The densities of the alloys JZ4 and JZ5 also satisfied the constraint (iii) in alloy design (Section 2). The data in Table 4 shows that with the exception of the RCCA alloy JZ3, the densities of all the other $\mathrm{Nb}$-silicide-based alloys, which are also RCCAs, were lower than the lower density value $\left(7.78 \mathrm{~g} / \mathrm{cm}^{3}\right)$ of multiphase RCCAs with bcc solid solution + $\mathrm{M}_{5} \mathrm{Si}_{3}$ silicide(s) in their microstructure, as reported in Table 2 in [2].

Table 4. Density $\left(\rho, \mathrm{g} / \mathrm{cm}^{3}\right)$ and oxidation properties (weight change, $\Delta \mathrm{W} / \mathrm{A}\left(\mathrm{mg} / \mathrm{cm}^{2}\right)$, rate constants linear $\left(\mathrm{K}_{\mathrm{l}}, \mathrm{g} \cdot \mathrm{cm}^{-2} \mathrm{~s}^{-1}\right)$, parabolic $\left(\mathrm{K}_{\mathrm{p}}, \mathrm{g}^{2} \mathrm{~cm}^{-4} \mathrm{~s}^{-1}\right)$, pest oxidation, scale spallation- $\left.\mathrm{SP}\right)$ of $\mathrm{Nb}$-silicidebased alloys/refractory metal complex concentrated alloys (RCCAs) ${ }^{* *+++}$ with $\mathrm{Al}, \mathrm{Ge}, \mathrm{Si}, \mathrm{Sn}, \mathrm{TM}$, $\mathrm{RM}$ additions after isothermal oxidation at 800 or $1200^{\circ} \mathrm{C}$ for $100 \mathrm{~h}$. $\mathrm{TM}=\mathrm{Cr}, \mathrm{Hf}, \mathrm{Ti}, \mathrm{RM}=\mathrm{Mo}, \mathrm{Nb}$, $\mathrm{Ta}, \mathrm{W}$. Oxidation data from specimens were cut from cast alloy buttons which were prepared using arc melting.

\begin{tabular}{|c|c|c|c|c|c|c|c|c|}
\hline \multirow{2}{*}{ Alloy/RCCA } & \multirow{2}{*}{ Stable Phases $\#$} & \multirow{2}{*}{$\rho$} & \multicolumn{3}{|c|}{$800^{\circ} \mathrm{C}$} & \multicolumn{3}{|c|}{$1200^{\circ} \mathrm{C}$} \\
\hline & & & $\Delta \mathrm{W} / \mathrm{A}$ & Pest & Rate Constant & $\Delta \mathrm{W} / \mathrm{A}$ & $\mathrm{SP}^{+}$ & Rate Constant \\
\hline JG6 & 5-3, A15, C14 & 6.96 & 1.8 & No & $K_{p}=1 \times 10^{-11}$ & 90 & Yes* & $\mathrm{K}_{1}=2.8 \times 10^{-7}$ \\
\hline EZ8 & 5-3, A15, C14 & 6.89 & 1 & No & $\begin{aligned} \mathrm{K}_{\mathrm{l}} & =2 \times 10^{-9} \\
& (>20 \mathrm{~h}) \\
\mathrm{K}_{\mathrm{p}} & =5.3 \times 10^{-9} \\
& (\leq 20 \mathrm{~h})\end{aligned}$ & 14 & Yes & $K_{p}=6 \times 10^{-10}$ \\
\hline ZF9 & $\begin{array}{l}\text { ss, } \\
5-3\end{array}$ & 6.96 & 0.55 & No & $\mathrm{K}_{\mathrm{p}}=8.4 \times 10^{-13}$ & 42 & Yes & $\begin{array}{c}\mathrm{K}_{\mathrm{p}}=1.8 \times 10^{-9} \\
(\leq 20 \mathrm{~h}) \\
\mathrm{K}_{1}=1 \times 10^{-7} \\
(>20 \mathrm{~h})\end{array}$ \\
\hline OHS1 & 5-3, A15, C14 & 6.78 & 3.2 & No & $\mathrm{K}_{\mathrm{p}}=2.4 \times 10^{-11}$ & 31.3 & No & $\begin{aligned} \mathrm{K}_{\mathrm{l}}= & 1.1 \times 10^{-7} \\
& (>3.1 \mathrm{~h}) \\
\mathrm{K}_{\mathrm{p}}= & 4.9 \times 10^{-10} \\
& (\leq 3.1 \mathrm{~h})\end{aligned}$ \\
\hline JZ3 & ss, 5-3, A15, C14 & 7.94 & 14.9 & No & $\mathrm{K}_{\mathrm{l}}=4.4 \times 10^{-8}$ & 24.2 & Edge cracks & $K_{1}=6 \times 10^{-8}$ \\
\hline JZ3+ & ss, 5-3, A15, C14 & 7.54 & 13.9 & Yes & $K_{1}=6.5 \times 10^{-9}$ & 14 & No & $\mathrm{K}_{\mathrm{p}}=5.5 \times 10^{-10}$ \\
\hline $\mathrm{JZ4}$ & ss, 5-3, A15, C14 & 7.28 & 0.82 & No & $\mathrm{K}_{\mathrm{p}}=1 \times 10^{-12}$ & 13.4 & No & $K_{p}=5 \times 10^{-10}$ \\
\hline $\mathrm{JZ5}$ & ss, 5-3, A15, C14, & 6.91 & 0.57 & No & $\mathrm{K}_{\mathrm{p}}=7.3 \times 10^{-12}$ & 8.4 & No & $\mathrm{K}_{\mathrm{p}}=1.9 \times 10^{-10}$ \\
\hline
\end{tabular}

${ }^{*}$ Poor adhesion, scale spalled off easily on handling, ${ }^{+}$scale spallation; ${ }^{* *}$ nominal compositions (at.\%), JG6 $=$ 36Nb-24Ti-18Si-5Al-5Cr-5Hf-5Sn-2Mo [56], EZ8 = 38Nb-24Ti-18Si-5Al-5Cr-5Hf-5Sn [57,58], ZF9 = 38Nb-24Ti-18Si5Al-5Cr-5Hf-5Ge [43,59], OHS1 $=38 \mathrm{Nb}-24 \mathrm{Ti}-18 \mathrm{Si}-5 \mathrm{Al}-5 \mathrm{Cr}-5 \mathrm{Ge}-5 \mathrm{Sn}[45]{ }^{++}$as-cast alloys unless indicated otherwise, for alloy designations see the Abbreviations; ${ }^{\#}$ phases in heat-treated $\left(1400^{\circ} \mathrm{C} / 100 \mathrm{~h}\right.$, or $\left.1500^{\circ} \mathrm{C} / 100 \mathrm{~h}\right)$ microstructures, ss $=\mathrm{Nb}$ solid solution, $5-3=\mathrm{Nb}_{5} \mathrm{Si}_{3}, \mathrm{~A} 15=\mathrm{A} 15-\mathrm{Nb}_{3} \mathrm{X}, \mathrm{C} 14=\mathrm{C} 14-\mathrm{Cr}_{2} \mathrm{Nb}$ Laves phase.

\subsection{Macrosegregation}

Macrosegregation of Si (MACSi) existed in both alloys, and was more severe in the alloy JZ5. MACSi has been defined as the difference between the maximum and minimum concentrations of $\mathrm{Si}$ in the alloy, i.e., $\mathrm{MACSi}=\mathrm{C}_{\max } \mathrm{Si}-\mathrm{C}_{\min }{ }^{\mathrm{Si}}$ [60]. Tin and Ge have a stronger effect on the macrosegregation of Si compared with Mo and W (Figure A1 in Appendix A), in particular Sn. MACSi increases when the parameters $\Delta \mathrm{H}_{\mathrm{m}} / \mathrm{T}_{\mathrm{m}}$ ("alloy entropy of fusion"), $\mathrm{T}_{\mathrm{m}}{ }^{\mathrm{sp}}$ (melting temperature of sp electronic configuration elements) and $\left(\Delta \mathrm{H}_{\mathrm{m}} / \mathrm{T}_{\mathrm{m}}\right) /\left(\Delta \mathrm{H}_{\mathrm{m}}{ }^{\mathrm{sd}} / \Delta \mathrm{H}_{\mathrm{m}}{ }^{\mathrm{sp}}\right)$ increase and the ratios $\Delta \mathrm{H}_{\mathrm{m}}{ }^{\mathrm{sd}} / \Delta \mathrm{H}_{\mathrm{m}}{ }^{\mathrm{sp}}$ and $\mathrm{T}_{\mathrm{m}}{ }^{\text {sd }} / \mathrm{T}_{\mathrm{m}}$ sp and the parameters $\Delta \mathrm{H}_{\mathrm{m}}$ ("alloy enthalpy of melting"), $\mathrm{T}_{\mathrm{m}}$ (alloy melting temperature) and $\mathrm{T}_{\mathrm{m}}{ }^{\text {sd }}$ (melting temperature of the sd electronic configuration elements) decrease [60]. 
Data for MACSi in Ti-rich Nb-silicide-based alloys with/out Ge, Mo or Sn are compared with the alloy JZ5 in Table 5. The aforementioned trends are followed by $\mathrm{T}_{\mathrm{m}}$ (with the exception of the alloy KZ5), $\Delta \mathrm{H}_{\mathrm{m}} / \mathrm{T}_{\mathrm{m}}, \Delta \mathrm{H}_{\mathrm{m}}{ }^{\mathrm{sd}} / \Delta \mathrm{H}_{\mathrm{m}}{ }^{\mathrm{sp}}, \mathrm{T}_{\mathrm{m}}{ }^{\mathrm{sd}}, \mathrm{T}_{\mathrm{m}}{ }^{\mathrm{sp}}, \mathrm{T}_{\mathrm{m}}{ }^{\mathrm{sd}} / \mathrm{T}_{\mathrm{m}}{ }^{\mathrm{sp}}$ and $\left(\Delta \mathrm{H}_{\mathrm{m}} / \mathrm{T}_{\mathrm{m}}\right) /\left(\Delta \mathrm{H}_{\mathrm{m}}{ }^{\mathrm{sd}} / \Delta \mathrm{H}_{\mathrm{m}}{ }^{\mathrm{sp}}\right)$. The alloy JZ4 had MACSi $=3$ at. $\%$, slightly lower than that of JZ3+ [47]. The MACSi values calculated by NICE were 3.7 and 5 at.\%, respectively, for JZ4 and JZ5. The data for the alloys JZ1, JZ2 [46], JZ3, JZ3+ [47], JZ4 and JZ5 show that both experimental and calculated MACSi increased with decreasing Sn/Ge and $\mathrm{Al}+\mathrm{Cr}$ (figures not shown). Two noteworthy results of this research are (1) that the substitution of Ta by Mo in JZ4 not only improved oxidation resistance and reduced density but also reduced MACSi and (2) that MACSi can be controlled with solute additions that play a key role in the oxidation resistance of these alloys, namely $\mathrm{Al}, \mathrm{Cr}, \mathrm{Ge}$ and $\mathrm{Sn}$. The MACSi increased with the increase in the concentration of $\mathrm{Ti}$ in the alloy JZ5, but was lower than that of the oxidation-resistant alloy OHS1 [45].

Table 5. Alloy parameters for the macrosegregation of Si in the cast alloys JZ5, ZF9, JG6, JG4, JG3 and KZ5.

\begin{tabular}{|c|c|c|c|c|c|c|c|c|c|}
\hline Alloy & $\begin{array}{c}\Delta \mathrm{H}_{\mathrm{m}} \\
(\mathrm{kJ} / \mathrm{mol})\end{array}$ & $\begin{array}{l}\mathrm{T}_{\mathrm{m}} \\
(\mathrm{K})\end{array}$ & $\begin{array}{l}\Delta \mathrm{H}_{\mathrm{m}} / \mathrm{T}_{\mathrm{m}} \\
(\mathrm{J} / \mathrm{molK})\end{array}$ & $\Delta \mathbf{H}_{\mathrm{m}}^{\mathrm{sd}} / \Delta \mathbf{H}_{\mathrm{m}}^{\mathrm{sp}}$ & $\begin{array}{l}\mathrm{T}_{\mathrm{m}} \mathrm{sd} \\
(\mathrm{K})\end{array}$ & $\begin{array}{l}\mathrm{T}_{\mathrm{m}} \mathrm{sp} \\
(\mathrm{K})\end{array}$ & $\mathrm{T}_{\mathrm{m}}^{\mathrm{sd}} / \mathrm{T}_{\mathrm{m}}^{\mathrm{sp}}$ & $\begin{array}{c}{\left[\Delta \mathrm{H}_{\mathrm{m}} / \mathrm{T}_{\mathrm{m}}\right] \times} \\
{\left[\Delta \mathrm{H}_{\mathrm{m}} \mathrm{sd} / \Delta \mathrm{H}_{\mathrm{m}}{ }^{\mathrm{sp}}\right]^{-1}}\end{array}$ & $\begin{array}{l}\text { MACSi } \\
\text { (at.\%) }\end{array}$ \\
\hline JZ5 & 28.4 & 2082 & 13.65 & 1.33 & 1624 & 458 & 3.55 & 10.26 & 4.5 \\
\hline ZF9 & 27.71 & 2143 & 12.93 & 1.58 & 1755 & 388 & 4.52 & 8.18 & 3.1 \\
\hline JG6 & 27.06 & 2154 & 12.8 & 1.66 & 1771 & 383 & 4.62 & 7.71 & 3 \\
\hline JG4 & 28.33 & 2239 & 12.65 & 1.84 & 1877 & 362 & 5.19 & 6.88 & 2.7 \\
\hline JG3 & 27.92 & 2245 & 12.44 & 2 & 1905 & 340 & 5.6 & 6.22 & 2.6 \\
\hline KZ5 & 27.5 & 2239 & 12.28 & 2.05 & 1909 & 330 & 5.78 & 5.99 & 1.3 \\
\hline
\end{tabular}

KZ5 = Nb-24Ti-18Si-5Al-5Cr [61], ZF9 = Nb-24Ti-18Si-5Al-5Cr-5Ge-5Hf [59], JG3 = Nb-24Ti-18Si-5Al-5Cr-2Mo [52], JG4 = Nb-24Ti-18Si-5Al-5Cr-2Mo-5Hf [56], JG6 = Nb-24Ti-18Si-5Al-5Cr-2Mo-5Hf-5Sn [56].

There are no data in the literature about macrosegregation of solute elements in RCCAs that were cast using arc melting or other cold hearth processes [1,2], with the exception of the RCCAs studied in our group $[45,47,56,58,59]$. Figure 8 shows that in RCCAs, the MACSi decreases as the alloy parameters VEC or $\Delta \chi$ increase (the correlation between MACSi and the alloy parameter $\delta$ is poor, figure not shown). In the Figure 8 it should be noted (i) that the solid solution was not stable in the alloys OHS1 and EZ8, (ii) that in all the alloys the $\mathrm{Nb}_{5} \mathrm{Si}_{3}, \mathrm{~A} 15$ and $\mathrm{C} 14-\mathrm{Cr}_{2} \mathrm{Nb}$ were stable and (iii) that the solid solution was stable in the Ta or Mo containing alloys, respectively JZ3, JZ3+ [47] and JZ4, JZ5 (Table 4). It should also be noted that in the microstructures of the other RCCAs studied to date [2], stable phases were (iv) the solid solution with $\mathrm{M}_{5} \mathrm{Si}_{3}$ silicide, or (v) the solid solution with Laves phase, or (vi) the solid solution, with $\mathrm{M}_{5} \mathrm{Si}_{3}$ and Laves and (vii) that all the RCCAs did not contain A15 compound(s) [2]. On first sight it might seem strange that MACSi, which is linked with solidification conditions and solute partitioning $[1,41-43,60,62]$, on which depend the chemical compositions of the phases in the as-cast microstructures, correlates with the aforementioned parameters. However, the study of the alloying behaviour of $\mathrm{Nb}$-silicide-based alloys and their phases has shown (a) that the concentrations of solute elements in the $\mathrm{Nb}_{\mathrm{ss}}, \mathrm{Nb}_{5} \mathrm{Si}_{3}, \mathrm{~A} 15-\mathrm{Nb}_{3} \mathrm{X}$ and $\mathrm{C} 14-\mathrm{Cr}_{2} \mathrm{Nb}$ correlate well with the phase parameters VEC and $\Delta \chi[21,63,64]$ and (b) that the phase parameters correlate well with the alloy parameters, for example $\Delta \chi_{\text {alloy }}=\mathrm{h}\left(\Delta \mathrm{\chi}_{\mathrm{Nb5Si3}}\right)$ [20]. It is pointed out that the trends shown in the Figure 8 should be used with caution because the data about MACSi in RCCAs are limited. 

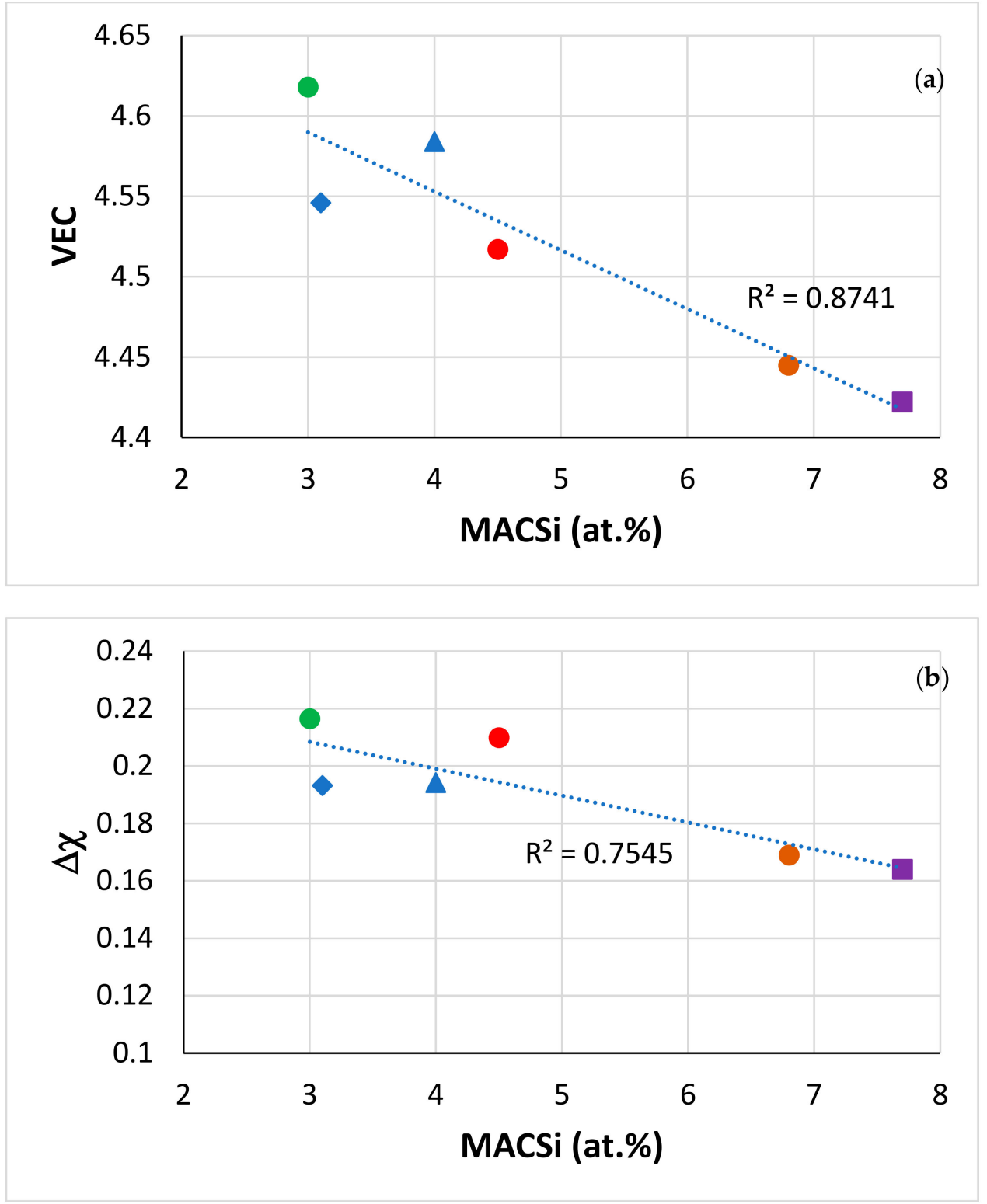

Figure 8. (a) VEC versus macrosegregation of Si (MACSi) and (b) $\triangle \chi$ versus MACSi of RCCAs studied in our research group. Data are as follows: green alloy JZ4, red JZ5, orange OHS1, square EZ8, triangle JZ3, diamond JZ3+, for nominal compositions of alloys see the Abbreviations. If the data for $\mathrm{JZ3}+$ were to be excluded (for the reasons discussed in [47]) in (a) $R^{2}=0.9537$ and in (b) $R^{2}=0.8901$.

\subsection{Microstructures}

The actual compositions of both alloys were close to the selected compositions. Remarkably, in both alloys the $\mathrm{Al} / \mathrm{Cr}$ and $\mathrm{Sn} / \mathrm{Ge}$ ratios were the same as in OHS1, JZ3 and JZ3+, and in the alloy JZ4 the Mo/W and Ti/Hf ratios were similar to those in JZ3 and JZ3+ [45-47].

In both alloys, the "architecture" of the cast microstructure was the same. Furthermore, the microstructure of the alloy JZ5 was slightly coarser. The solid solution was not observed in the as-cast buttons of both alloys but was stable after the heat treatment. In the interdendritic areas of the primary $\mathrm{Nb}_{5} \mathrm{Si}_{3}$, the $\mathrm{A} 15-\mathrm{Nb}_{3} \mathrm{X}, \mathrm{C} 14-\mathrm{Cr}_{2} \mathrm{Nb}$ and $\mathrm{TM}_{5} \mathrm{Sn}_{2} \mathrm{X}$ were formed. Note that the latter compound was not observed in the Ta-containing JZ series of alloys [46,47]. The primary $\mathrm{Nb}_{5} \mathrm{Si}_{3}$ was not facetted, in agreement with [6,59]. It is concluded that the substitution of Ta by Mo did not destabilise the A15 and Laves phases, decreased the vol.\% of the A15, particularly in the alloy JZ4 compared with JZ3, and unlike the Ta-containing alloys JZ3 and JZ3+ [47], suppressed the solid 
solution in the cast microstructure and promoted the formation of $\mathrm{TM}_{5} \mathrm{Sn}_{2} \mathrm{X}$ in both JZ4 and JZ5. Moreover, in JZ5-AC, the increase in the Ti concentration suppressed the sensitivity of the formation of $\mathrm{TM}_{5} \mathrm{Sn}_{2} \mathrm{X}$ on cooling rate and increased the volume fraction of this compound, which would suggest that $\mathrm{Ti}$ "boosted" its formation.

The $\mathrm{TM}_{5} \mathrm{Sn}_{2} \mathrm{X}$ compound in both alloys is based on the $\mathrm{Nb}_{5} \mathrm{Sn}_{2} \mathrm{Si}_{1} \mathrm{Ti}_{5} \mathrm{Sn}_{2} \mathrm{Si}, \mathrm{Nb}_{5} \mathrm{Sn}_{2} \mathrm{Ge}, \mathrm{Nb}_{5} \mathrm{Sn}_{2} \mathrm{Al}$ compounds that all have the tetragonal $\mathrm{W}_{5} \mathrm{Si}_{3}$ as prototype $[54,65]$. The $\mathrm{Nb}_{5} \mathrm{Sn}_{2} \mathrm{Si}$ compound is stable at $900{ }^{\circ} \mathrm{C}$ and $1200{ }^{\circ} \mathrm{C}$ according to Sun et al. [66]. Bulanova et al. [67] reported the $\mathrm{Ti}_{5} \mathrm{Si}_{1.2-1.6} \mathrm{Sn}_{1.8-1.4}$ compound in Ti-Si-Sn alloys. With the increase in the Ti concentration in JZ5 the Ti content of TM $\mathrm{TM}_{2} \mathrm{~S}$ also increased, as did the $\mathrm{Ti} / \mathrm{Nb}$ ratio and the $\mathrm{Al}+\mathrm{Ge}+\mathrm{Si}$ content (1.17 and 12.1 at.\%, and 2.96 and 14.4 at.\%, respectively, in JZ4 and JZ5). The Sn content was essentially the same in both alloys (about 24.8 at.\%). It should be noted (a) that the oxidation resistance of Ti-rich $\mathrm{Nb}$-silicide-based alloys was improved with Ti and Mo addition [68] and was enhanced further with the addition of Hf and Sn $[44,56]$, and (b) that this enhancement was associated with the formation of the $\mathrm{TM}_{5} \mathrm{Sn}_{2} \mathrm{X}$ compound at $1200{ }^{\circ} \mathrm{C}$ in the substrate just below the scale/substrate interface that has been observed in many Sn containing alloys $[41,42,45,56]$.

In both alloys, as the primary $\mathrm{Nb}_{5} \mathrm{Si}_{3}$ formed, the surrounding melt became rich in $\mathrm{Ti}, \mathrm{Mo}, \mathrm{W}, \mathrm{Sn}$, $\mathrm{Al}$ and $\mathrm{Cr}$. Considering the cast microstructures, in which the $\mathrm{TM}_{5} \mathrm{Sn}_{2} \mathrm{X}$ and $\mathrm{C} 14-\mathrm{Cr}_{2} \mathrm{Nb}$ Laves formed with small volume fractions, and that the phase with the highest melting temperature should form first, in the melt surrounding the $\mathrm{Nb}_{5} \mathrm{Si}_{3}$ the $\mathrm{A} 15-\mathrm{Nb}_{3} \mathrm{X}$ phase formed first followed by the $\mathrm{C} 14-\mathrm{Cr}_{2} \mathrm{Nb}$ and then the $\mathrm{TM}_{5} \mathrm{Sn}_{2} X$. It is suggested that in both alloys the solidification path was $\mathrm{L} \rightarrow \mathrm{L}+\beta \mathrm{Nb}_{5} \mathrm{Si}_{3}$ $\rightarrow \mathrm{L}+\beta \mathrm{Nb}_{5} \mathrm{Si}_{3}+\mathrm{A} 15-\mathrm{Nb}_{3} \mathrm{X} \rightarrow \mathrm{L}+\beta \mathrm{Nb}_{5} \mathrm{Si}_{3}+\mathrm{A} 15-\mathrm{Nb}_{3} \mathrm{X}+\mathrm{C} 14-\mathrm{Cr}_{2} \mathrm{Nb} \rightarrow \beta \mathrm{Nb}_{5} \mathrm{Si}_{3}+\mathrm{A} 15-\mathrm{Nb}_{3} \mathrm{X}+$ $\mathrm{C} 14-\mathrm{Cr}_{2} \mathrm{Nb}+\mathrm{TM}_{5} \mathrm{Sn}_{2} \mathrm{X}$. The presence of $\alpha \mathrm{Nb}_{5} \mathrm{Si}_{3}$ in the cast microstructures was attributed to the $\beta \mathrm{Nb}_{5} \mathrm{Si}_{3} \rightarrow \alpha \mathrm{Nb}_{5} \mathrm{Si}_{3}$ transformation during solid-state cooling.

The microstructures of both the heat-treated alloys consisted of the $\mathrm{Nb}_{5} \mathrm{Si}_{3}, \mathrm{~A} 15-\mathrm{Nb}_{3} \mathrm{X}$, and Mo and $\mathrm{W}$-rich solid solution $(\mathrm{Nb}, \mathrm{W})_{\mathrm{ss}}$, and a very small vol.\% of the $\mathrm{C} 14-\mathrm{Cr}_{2} \mathrm{Nb}$ Laves phase only in JZ4-HT. The $\mathrm{TM}_{5} \mathrm{Sn}_{2} \mathrm{X}$ was not stable at $1500{ }^{\circ} \mathrm{C}$ in both the alloys. The solid solutions were free of $\mathrm{Si}$ owing to the addition of Mo and $\mathrm{W}$, which promote the formation of the Si-free $\mathrm{Nb}_{\mathrm{ss}}$ [53]. It is suggested that the $\mathrm{Nb}_{5} \mathrm{Si}_{3}$ silicide, $\mathrm{A} 15-\mathrm{Nb}_{3} \mathrm{X}$ and the $(\mathrm{Nb}, \mathrm{W})_{\mathrm{ss}}$ were the stable phases in the microstructures of JZ4 and JZ5 at $1500{ }^{\circ} \mathrm{C}$, with the $\mathrm{C} 14-\mathrm{Cr}_{2} \mathrm{Nb}$ Laves phase maybe stable only in the alloy JZ4.

Both the $\beta$ and $\alpha \mathrm{Nb}_{5} \mathrm{Si}_{3}$ were present in the heat-treated alloys JZ4 and JZ5 (Figures S1 and S2). Molybdenum and $\mathrm{W}$ form, respectively, the $\mathrm{Mo}_{5} \mathrm{Si}_{3}$ and $\mathrm{W}_{5} \mathrm{Si}_{3}$, which have the $\mathrm{D} 8_{\mathrm{m}}$ structure and are isomorphous with the $\beta \mathrm{Nb}_{5} \mathrm{Si}_{3}$, but, unlike Ta, do not form silicides isomorphous with $\alpha \mathrm{Nb}_{5} \mathrm{Si}_{3}$. In the base alloy $\mathrm{Nb}-24 \mathrm{Ti}-18 \mathrm{Si}-5 \mathrm{Al}-5 \mathrm{Cr}$ (alloy $\mathrm{KZ} 5$ in [61]), the $\beta \mathrm{Nb}_{5} \mathrm{Si}_{3}$ formed in the cast microstructure and both $\beta \mathrm{Nb}_{5} \mathrm{Si}_{3}$ and $\alpha \mathrm{Nb}_{5} \mathrm{Si}_{3}$ were present after the heat treatment. The same was the case when Mo was added in the alloy Nb-18Si-5Al-5Cr-5Mo (alloy JG1 in [52]). The addition of Sn to the base alloy $\mathrm{KZ} 5$ promoted the $\beta \mathrm{Nb}_{5} \mathrm{Si}_{3} \rightarrow \alpha \mathrm{Nb}_{5} \mathrm{Si}_{3}$ transformation upon heat treatment (alloys $\mathrm{ZX7}$ and $\mathrm{ZX8}$ in $[41,42]$ ) (meaning the $\beta \mathrm{Nb}_{5} \mathrm{Si}_{3}$ that formed in the cast alloy transformed to $\alpha \mathrm{Nb}_{5} \mathrm{Si}_{3}$ after the heat treatment) but this transformation became sluggish when the base alloy KZ5 was alloyed with Ge with or without Hf (alloys ZF6 and ZF9 in [59]) (meaning that after the heat treatment both the $\beta \mathrm{Nb}_{5} \mathrm{Si}_{3}$ and $\alpha \mathrm{Nb}_{5} \mathrm{Si}_{3}$ were present in the microstructure, as was the case in KZ5), whereas the simultaneous addition of $\mathrm{Ge}$ and $\mathrm{Sn}$ in the base alloy $\mathrm{KZ} 5$ stabilised the $\beta \mathrm{Nb}_{5} \mathrm{Si}_{3}$ in the alloy OHS1 (meaning the $\beta \mathrm{Nb}_{5} \mathrm{Si}_{3} \rightarrow \alpha \mathrm{Nb}_{5} \mathrm{Si}_{3}$ transformation did not occur upon the heat treatment [45]). Furthermore, the $\beta_{\mathrm{Nb}_{5}} \mathrm{Si}_{3} \rightarrow \alpha \mathrm{Nb}_{5} \mathrm{Si}_{3}$ transformation occurred in the case of the $\mathrm{Al}, \mathrm{Cr}$, Ge and Sn free and Ti poor alloy $\mathrm{Nb}-8.3 \mathrm{Ti}-21.1 \mathrm{Si}-5.4 \mathrm{Mo}-4 \mathrm{~W}-0.7 \mathrm{Hf}$ buttons and suction cast bars (alloy CM1 in [62]) upon heat treatment. It is therefore likely that, owing to the simultaneous addition of Ge and Sn with Mo, $\mathrm{W}, \mathrm{Al}$ and $\mathrm{Cr}$, the stability of $\mathrm{NNb}_{5} \mathrm{Si}_{3}$ was increased in JZ4 and JZ5 compared with JZ3 and JZ3+. Could the solubility of $\mathrm{Mo}$ in $\mathrm{Nb}_{5} \mathrm{Si}_{3}$ affect the aforementioned transformation?

In as-cast and heat-treated $\mathrm{Ti}$ free $\mathrm{Nb}$-xMo-36Si and $\mathrm{Nb}-\mathrm{xMo}-37.5 \mathrm{Si}$ ( $\mathrm{x}=0$ to 10 at.\%) alloys that were prepared using arc melting, Sekido et al. [69] reported (a) Mo concentrations of 5.2 at.\% and 3.6 at. $\%$ in $\beta \mathrm{Nb}_{5} \mathrm{Si}_{3}$ and $\alpha \mathrm{Nb}_{5} \mathrm{Si}_{3}$, respectively, (b) that Mo stabilised the $\beta \mathrm{Nb}_{5} \mathrm{Si}_{3},(\mathrm{c})$ that the $\beta \mathrm{Nb}_{5} \mathrm{Si}_{3}$ 
$\rightarrow \alpha \mathrm{Nb}_{5} \mathrm{Si}_{3}$ transformation did not occur when the concentration of Mo in $\mathrm{Nb}_{5} \mathrm{Si}_{3}$ exceeded 6 at. $\%$ and (d) that after heat treatment at $1400{ }^{\circ} \mathrm{C}$ for $100 \mathrm{~h}$ a mixture of both $\beta \mathrm{Nb}_{5} \mathrm{Si}_{3}$ and $\alpha \mathrm{Nb}_{5} \mathrm{Si}_{3}$ were formed when the Mo concentration in the $\mathrm{Nb}_{5} \mathrm{Si}_{3}$ was 4 or 5 at.\%. Concentrations of 2.5 at.\% Mo and 0.6 at.\% Mo were reported, respectively, in $\beta \mathrm{Nb}_{5} \mathrm{Si}_{3}$ and $\alpha \mathrm{Nb}_{5} \mathrm{Si}_{3}$ for the cast and heat-treated conditions of the alloy $\mathrm{Nb}-18 \mathrm{Si}-5 \mathrm{Al}-5 \mathrm{Cr}-5 \mathrm{Mo}$ and slightly lower Mo concentration (1.9 at.\%) in the $\mathrm{\beta Nb}_{5} \mathrm{Si}_{3}$ in the cast alloy Nb-24Ti-18Si-5Al-5Cr-5Mo [52]. The above data suggest that the solubility of Mo (i) is different in $\beta \mathrm{Nb}_{5} \mathrm{Si}_{3}$ and $\alpha \mathrm{Nb}_{5} \mathrm{Si}_{3}$, (ii) depends on the presence or not of Ti in the alloy and (iii) depends on the concentration of Mo in the alloy. In the alloys JZ4 and JZ5, where both $\beta \mathrm{Nb}_{5} \mathrm{Si}_{3}$ and $\alpha \mathrm{Nb}_{5} \mathrm{Si}_{3}$ were present in the cast and heat-treated conditions, the average concentration of $\mathrm{Mo}$ in $\mathrm{Nb}_{5} \mathrm{Si}_{3}$ was similar to (d), namely 4.5 and 4.9 at. $\%$, and 4.3 and 5 at. $\%$, respectively, in the cast and heat-treated alloys JZ4 and JZ5 (Tables S1 and S2).

The solubility of $\mathrm{W}$ in $\mathrm{Nb}_{5} \mathrm{Si}_{3}$ was in the range 1 to 1.7 at.\% in both the as-cast alloys, and slightly lower in JZ5-AC, and was $\leq 0.6$ at.\% after the heat treatment in both alloys. The $\mathrm{W}$ solubility in $\alpha \mathrm{Nb}_{5} \mathrm{Si}_{3}$ was reported to be about 1 at.\% in Nb-W-Si alloys [70] and $\leq 0.6$ at.\% in the alloys Nb-20Si-5Hf-5W, $\mathrm{Nb}-20 \mathrm{Si}-5 \mathrm{Mo}-3 \mathrm{~W}$ and $\mathrm{Nb}-20 \mathrm{Si}-5 \mathrm{Hf}-5 \mathrm{Mo}-3 \mathrm{~W}$ (respectively, alloys YG5, YG6 and YG8 in [53]). Thus, the data suggest that the solubility of $\mathrm{W}$ in $\mathrm{Nb}_{5} \mathrm{Si}_{3}$ does not depend strongly on the alloying additions of $\mathrm{Al}, \mathrm{Cr}, \mathrm{Ge}, \mathrm{Mo}$, $\mathrm{Sn}$ and $\mathrm{Ti}$, when the latter elements are present simultaneously in $\mathrm{Nb}$-silicide-based alloys.

In both alloys there was precipitation of solid solution in the $\mathrm{Nb}_{5} \mathrm{Si}_{3}$ after the heat treatment (Figure 1e,f). Precipitation of $\mathrm{Nb}_{\mathrm{ss}}$ in $\alpha \mathrm{Nb}_{5} \mathrm{Si}_{3}$ grains has been reported after the heat treatment of the alloys Nb-24Ti-18Si-5Al (alloy KZ7 in [61]), KZ5 [61], JG1 [56], Nb-24Ti-18Si-5Ge-5Al (alloy ZF5 in [71]), the arc melted button and suction cast bars of the alloy CM1 [62] after heat treatment, the large arc melted ingots of the alloy CM1 before and after heat treatment [62] and the as-cast and heat-treated OFZ bars of the alloy CM1 grown at three different growth rates [62]. In Nb-24Ti-18Si-8Cr-4Al (alloy KZ2 in [72]) only the $\beta \mathrm{Nb}_{5} \mathrm{Si}_{3}$ was present in the cast microstructure and both the $\beta \mathrm{Nb}_{5} \mathrm{Si}_{3}$ and $\alpha \mathrm{Nb}_{5} \mathrm{Si}_{3}$ after the heat treatment with $\mathrm{Nb}_{\mathrm{ss}}$ precipitates in $\mathrm{Nb}_{5} \mathrm{Si}_{3}$ grains. For the Ti-rich $\mathrm{Nb}$-silicide-based alloys Zelenitsas and Tsakiropoulos attributed this precipitation of the $\mathrm{Nb}_{\mathrm{ss}}$ to the $\beta \mathrm{Nb}_{5} \mathrm{Si}_{3} \rightarrow \alpha \mathrm{Nb}_{5} \mathrm{Si}_{3}+$ $\mathrm{Nb}_{\mathrm{ss}}$ transformation [61].

For the $\mathrm{Nb}-\mathrm{xMo}-36 \mathrm{Si}$ and $\mathrm{Nb}-\mathrm{xMo}-37.5 \mathrm{Si}$ ( $\mathrm{x}=0$ to 10 at.\%) alloys (see above), Sekido et al. [69] reported (i) that $\mathrm{Nb}_{\mathrm{ss}}$ precipitates formed in both $\beta \mathrm{Nb}_{5} \mathrm{Si}_{3}$ and $\alpha \mathrm{Nb}_{5} \mathrm{Si}_{3}$ after heat treatment at $1300^{\circ} \mathrm{C}$ for $20 \mathrm{~h}$, (ii) that precipitation of $\mathrm{Nb}_{\mathrm{ss}}$ in $\beta \mathrm{Nb}_{5} \mathrm{Si}_{3}$ was not observed in the cast condition but after heat treatment at $1500{ }^{\circ} \mathrm{C}$ for $100 \mathrm{~h}$, and (iii) that in the $\alpha \mathrm{Nb}_{5} \mathrm{Si}_{3}$ that formed from the $\beta \mathrm{Nb}_{5} \mathrm{Si}_{3} \rightarrow$ $\alpha \mathrm{Nb}_{5} \mathrm{Si}_{3}$ transformation after heat treatment at $1500{ }^{\circ} \mathrm{C}$ for $100 \mathrm{~h}$ there was $\mathrm{Nb}_{\mathrm{ss}}$ precipitation in $\alpha \mathrm{Nb}_{5} \mathrm{Si}_{3}$. For the $\mathrm{Nb}_{\mathrm{ss}}$ precipitates, two orientation relationships were observed by Sekido et al., which were in agreement with the orientation relationships reported for eutectoid $\mathrm{Nb}_{\mathrm{ss}} / \alpha \mathrm{Nb}_{5} \mathrm{Si}_{3}$ lamellae by Sekido et al. [73] and Miura et al. [74]. Sekido et al. suggested that the $\beta \mathrm{Nb}_{5} \mathrm{Si}_{3} \rightarrow \alpha \mathrm{Nb}_{5} \mathrm{Si}_{3}$ transformation occurred either before the $\mathrm{Nb}_{\text {ss }}$ precipitated or simultaneously [69]. The results for the alloys KZ7, KZ5, JG1, ZF5 and CM1 (see the Abbreviations for the nominal compositions) are consistent with the precipitation of $\mathrm{Nb}_{\mathrm{ss}}$ in $\alpha \mathrm{Nb}_{5} \mathrm{Si}_{3}$, whereas according to the results of Sekida et al. precipitation of $\mathrm{Nb}_{\mathrm{ss}}$ is also possible in $\beta \mathrm{Nb}_{5} \mathrm{Si}_{3}$. It should be noted that precipitation of $\mathrm{Nb}_{\mathrm{ss}}$ was also observed in $\mathrm{Nb}_{5} \mathrm{Si}_{3}$ grains in JZ3-HT and [JZ3+]-HT [47] as well as in $\mathrm{Nb}_{5} \mathrm{Si}_{3}$ grains in the heat-treated alloys Nb-24Ti-18Si-6Ta-5Al-5Cr and Nb-24Ti-18Si-6Ta-8Cr-4Al (respectively, alloys KZ6 and KZ8 in [72]), which would suggest that $\mathrm{Ta}$, similarly to Mo, promotes the aforementioned phenomenon.

The hardness of the as-cast alloys JZ4 and JZ5 was $862 \mathrm{HV}$ and $838 \mathrm{HV}$, which gives room temperature strengths of $2816 \mathrm{MPa}$ and $2737 \mathrm{MPa}$, and specific room temperature strengths of 387 and $396 \mathrm{MPa} \mathrm{cm}^{3} \mathrm{~g}^{-1}$, respectively. After the heat treatment the room temperature strength was $2724 \mathrm{MPa}$ and $2633 \mathrm{MPa}$, respectively for JZ4 and JZ5. Both the room temperature strength and specific strength were higher than other RCCAs [1,2] and comparable with those of boron containing Nb-silicide-based alloys [1].

The $(\mathrm{Nb}, \mathrm{Ti}, \mathrm{Hf})_{3}(\mathrm{Si}, \mathrm{Sn}, \mathrm{Al})$ and $(\mathrm{Nb}, \mathrm{Ti}, \mathrm{Cr}, \mathrm{Hf})_{3}(\mathrm{Si}, \mathrm{Sn}, \mathrm{Al}) \mathrm{A} 15$ compounds have more than double the hardness of $\mathrm{Nb}_{3} \mathrm{Sn}(450 \mathrm{HV})$ [21]. The alloys JZ4 and JZ5 had lower vol.\% A15 compared with JZ3 and 
$\mathrm{JZ3}+[47]$, particularly the alloy JZ4, and the alloy JZ5 had lower vol.\% $\mathrm{Nb}_{\mathrm{ss}}$ than JZ3+. The hardness of the solid solution was the same in both alloys $(850 \mathrm{HV})$ but in the alloy JZ5 the contribution to hardness of $\mathrm{Al}, \mathrm{Cr}$ and $\mathrm{Ti}$ was 58\% higher compared with JZ4 (372 HV and $236 \mathrm{HV}$, respectively (calculations used data for binary $\mathrm{Nb}-\mathrm{X}(\mathrm{X}=\mathrm{Al}, \mathrm{Cr}, \mathrm{Ti})$ from $[27,31])$, in other words, the smaller contribution of Mo and $\mathrm{W}$ to the hardness of the solid solution, owing to the lower $\mathrm{Mo}+\mathrm{W}$ concentration in the $(\mathrm{Nb}, \mathrm{W})_{\mathrm{ss}}$ in JZ5-HT, was compensated by the higher concentrations of $\mathrm{Al}, \mathrm{Cr}$ and Ti. The hardness of the $\mathrm{Nb}_{5} \mathrm{Si}_{3}$ was higher than that of the binary silicide [63]. In spite of the fact that the microstructures of both alloys consisted of phases that had high hardness, microcracking was not observed in the as-cast buttons and after specimen preparation. The $\beta \mathrm{Nb}_{5} \mathrm{Si}_{3}$ has lower hardness and Young's modulus and higher CTE anisotropy than $\alpha \mathrm{Nb}_{5} \mathrm{Si}_{3}$ and alloying with Mo reduces the CTE anisotropy [63]. To the authors' knowledge there are no data about the effect of Ta on the CTE anisotropy of $\mathrm{Nb}_{5} \mathrm{Si}_{3}$. Suppression/elimination of microcracking after solidification and specimen preparation would benefit from lower CTE anisotropy, and the lower hardness of the $\mathrm{Nb}_{5} \mathrm{Si}_{3}$ in JZ4 and JZ5 compared with $\mathrm{JZ3}+$ [47]. Precipitation of $\mathrm{Nb}_{\mathrm{Ss}}$ in $\mathrm{Nb}_{5} \mathrm{Si}_{3}$ significantly improved the toughness of the silicide in both JZ4-HT and JZ5-HT (results not shown).

NICE [20] correctly predicted the vol.\% $\mathrm{Nb}_{\mathrm{ss}}$ in JZ4-AC and JZ5-AC (zero in both alloys) (Table 1) as well as the dependence of the vol. $\% \mathrm{Nb}_{\mathrm{ss}}$ on the $\mathrm{Sn} / \mathrm{Ge}$ ratio in the cast alloys JZ2, JZ3, JZ3+, JZ4 and $\mathrm{JZ}$, although the $\mathrm{R}^{2}$ values for linear fit of data are less than 0.9 (Figure $9 \mathrm{~b}$ ). The vol.\% $\mathrm{Nb}_{\mathrm{ss}}$ decreased with increasing $\mathrm{Sn} / \mathrm{Ge}$ ratio and $\mathrm{Sn}+\mathrm{Ge}$ sum in the alloys JZ2 to JZ5 (Figure 9).
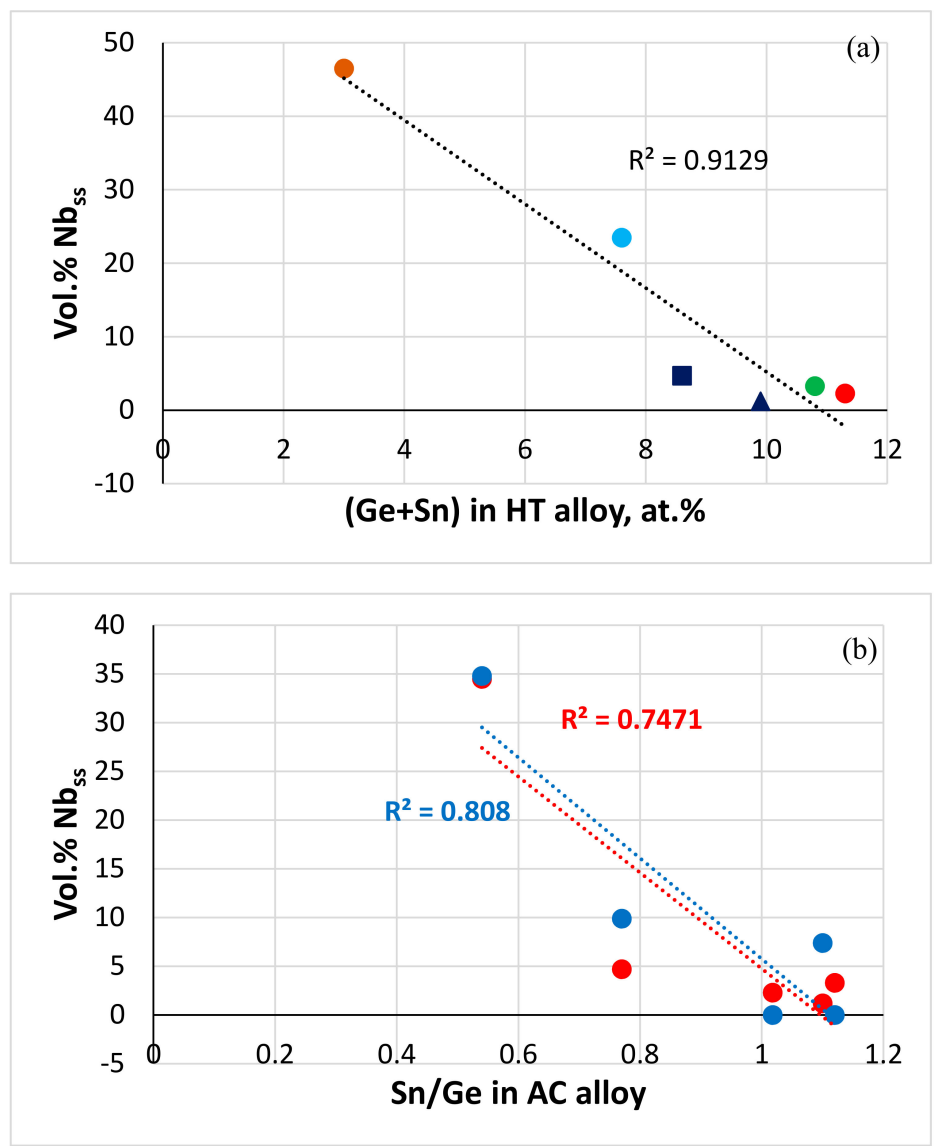

Figure 9. Volume fraction $\mathrm{Nb}_{\mathrm{ss}}$ as function (a) of $\mathrm{Ge}+\mathrm{Sn}$ in heat-treated alloys and (b) of $\mathrm{Sn} / \mathrm{Ge}$ in as-cast alloys. In (a) data for HT alloys, JZ1, JZ2 [46], JZ3, JZ3+ [47], with red for JZ5, green for JZ4, triangle for JZ3+, square for JZ3, blue for JZ2, and brown for JZ1. All data $\mathrm{R}^{2}=0.9129$, and data for Ta-containing alloys $\mathrm{R}^{2}=0.942$. In (b) data for cast alloys JZ2 to JZ5, red filled circles for experimental data, and blue circles for calculated data using NICE. AC $=$ as cast, HT = heat treated. 
The compositions of the solid solutions in the alloys JZ4 and JZ5 that were calculated by NICE [20], respectively, were $36 \mathrm{Nb}-6.4 \mathrm{Ti}-0 \mathrm{Si}-20.2 \mathrm{Mo}-21.2 \mathrm{~W}-0.7 \mathrm{Sn}-0.4 \mathrm{Ge}-0.8 \mathrm{Hf}-3.6 \mathrm{Al}-10.7 \mathrm{Cr}$ and 24.7Nb-10.5Ti-0Si-26.3Mo-18.8W-1.4Sn-0.6Ge-0.8Hf-4Al-12.9Cr. Compared with the experimental data (Tables S1 and S2), NICE underestimated the $\mathrm{W}$ and $\mathrm{Cr}$, and overestimated the $\mathrm{Nb}$ content in the $\mathrm{Nb}_{\mathrm{ss}}$ of JZ4 and underestimated the $\mathrm{Cr}$ and Ge, and overestimated the $\mathrm{Nb}$ and Mo contents in the $\mathrm{Nb}_{\mathrm{ss}}$ of JZ5. Bearing in mind the accuracy of chemical analysis data and the luck of thermodynamic data for ternary systems that are relevant to the studied alloys [1,20], we consider the agreement between experimental and calculated $\mathrm{Nb}_{\mathrm{ss}}$ to be good.

The parameters VEC, $\Delta \chi$ and $\delta$ of the $\mathrm{Nb}$-silicide-based alloys and their solid solutions $[7,50]$ are key for the calculations in NICE [20]. The experimental and calculated VEC, $\Delta \chi$ and $\delta$ parameters of the $\mathrm{Nb}_{\mathrm{ss}}$ in JZ4, respectively, were $5.499,0.337,4.574$ and 5.366, $0.33,4.596$, and of the $\mathrm{Nb}_{\mathrm{ss}}$ in JZ5, respectively, were 5.341, 0.321, 5.463 and 5.367, 0.327, 5.09. Compared with the data for the $\mathrm{Nb}_{\mathrm{ss}}$ in $\mathrm{Nb}$-silicide-based alloys in [7], the data for the experimental compositions of the solid solutions show that the range of VEC is expanded from 4.4-5.4 to 4.4-5.5. The data for the alloy JZ3+ [47] showed that the range of $\Delta x$ also changed from $0.039-0.331$ to $0.039-0.369$. The $\Delta \chi$ values of the $\mathrm{Nb}_{\mathrm{ss}}$ in JZ4 and JZ5 are in the latter range. In $[1,7,20]$ it was discussed that $\mathrm{Si}$-free $\mathrm{Nb}_{\mathrm{ss}}$ in $\mathrm{Nb}$-silicide-based alloys has $\delta$ less than approximately 5 . This is supported by the results of this study.

The chemical composition of the $\mathrm{Nb}_{5} \mathrm{Si}_{3}$ silicide calculated by NICE [20] was $50.8(\mathrm{Nb}, \mathrm{Mo}, \mathrm{W})$ 9.4Ti-27.2Si-1.6Sn-5.9Ge-1.4Hf-1.9Al-1.8Cr and 44.9(Nb, Mo, W)-15.4Ti-26.5Si-1.6Sn-6.1Ge-1.9Hf-2.4Al $-1.2 \mathrm{Cr}$, respectively, in the cast alloys JZ4 and JZ5. Owing to the limited data about Mo and W in the NICE database, the total RM concentration was calculated instead of the concentration of each RM. Compared with the experimental data (Tables S1 and S2) NICE underestimated and overestimated, respectively, $\mathrm{Si}$ and $\mathrm{Hf}$ in the $\mathrm{Nb}_{5} \mathrm{Si}_{3}$ in JZ5. We consider the agreement between experimental and calculated data to be good.

The parameters VEC, $\Delta x, \delta$ and the ratios $\mathrm{sd} / \mathrm{sp}$ (sd electronic configuration elements over $\mathrm{sp}$ electronic configuration elements) and $\mathrm{Nb} /(\mathrm{Ti}+\mathrm{Hf}$ ) of the alloys JZ4 and JZ5, respectively, were 4.618, $0.2165,9.42,1.96,2.87$ and $4.517,0.2099,9.66,1.89,1.5$. The parameters VEC, $\Delta x$ and $\delta$ fall in the ranges of the parameters of $\mathrm{Nb}$-silicide-based alloys [50]. NICE can calculate the creep rate due to intrinsic resistances to dislocation motion $[1,20]$ and, together with calculations linked with oxidation behaviour, can point out whether a designed/selected alloy is worthy of further investigation after considering its creep and oxidation. The calculated creep rates at $1200{ }^{\circ} \mathrm{C}$ and $170 \mathrm{MPa}$ using the above parameters and ratios were in the ranges $3 \times 10^{-6} \mathrm{~s}^{-1}$ to $8.5 \times 10^{-10} \mathrm{~s}^{-1}$, and $1.7 \times 10^{-4} \mathrm{~s}^{-1}$ to $2.7 \times 10^{-9} \mathrm{~s}^{-1}$, with average creep rates $4.5 \times 10^{-7} \mathrm{~s}^{-1}$ and $2.7 \times 10^{-6} \mathrm{~s}^{-1}$, respectively, for the alloys JZ4 and JZ5. The average creep rate of JZ4 was lower than that of JZ5, as would be expected when considering the $\mathrm{Nb} /(\mathrm{Ti}+\mathrm{Hf})$ ratios [6]. The average creep rates were lower than the creep rate of the single crystal Ni-based superalloy CMSX-4 for the same conditions $\left(5.6 \times 10^{-5} \mathrm{~s}^{-1}\right)$, but higher than the creep rate of $1 \times 10^{-7} \mathrm{~s}^{-1}$ that is the criterion in NICE to decide whether it is likely for a designed/selected alloy to meet the creep goal [20]. However, it should be noted that the lowest values of the calculated creep rates for both alloys were lower than $1 \times 10^{-7} \mathrm{~s}^{-1}$.

\subsection{Oxidation}

\subsubsection{Oxidation at $800^{\circ} \mathrm{C}$}

The Figures 2 and 3 showed (i) that the substitution of Ta by Mo resulted in significant improvement of oxidation at $800{ }^{\circ} \mathrm{C}$ in both alloys, as did the increase in the Ti concentration in the alloy JZ5, and (ii) confirmed the beneficial effect of both $\mathrm{Mo}$ and $\mathrm{Ti}$ on the oxidation resistance of $\mathrm{Nb}$-silicide-based alloys that was reported in [68].

The alloys JZ4 and JZ5 exhibited the best oxidation resistance at $800{ }^{\circ} \mathrm{C}$ (Figure 2a), gained the lowest weight compared with the alloys JZ1 to JZ3+ [46,47], the oxidation specimens retained their shapes, did not pest (Figure $3 \mathrm{a}, \mathrm{b}$ ) and formed thin oxide scales. Their oxidation at $800{ }^{\circ} \mathrm{C}$ followed 
parabolic oxidation kinetics similar to the single crystal Ni superalloy CMSX-4 that gained $0.04 \mathrm{mg} / \mathrm{cm}^{2}$ after $50 \mathrm{~h}$ and had $k_{\mathrm{p}}=4 \times 10^{-14} \mathrm{~g}^{2} \mathrm{~cm}^{-4} \mathrm{~s}^{-1}$ [1].

Compared with the alloy JZ3 [47], the substitution of Ta by Mo in JZ4 changed the oxidation kinetics at $800{ }^{\circ} \mathrm{C}$ from linear to parabolic, decreased the weight change by $94.5 \%$ and eradicated cracks in the scale. Compared with the alloy JZ3+ the weight change decrease was similar (96\%) at $800^{\circ} \mathrm{C}$ and the pest oxidation was suppressed [47].

The effect of Mo with $\mathrm{Al}$ and $\mathrm{Cr}$ on the oxidation resistance at $800{ }^{\circ} \mathrm{C}$ of Nb-24Ti-18Si-based alloys without Sn and $\mathrm{Hf}$ additions was reported by Geng et al. [68], who showed that the addition of 2 at.\% Mo was more beneficial than 5 at.\%. Pest oxidation was eliminated in the Nb-24Ti-18-Si-5Al-5Cr-5Hf-5Sn-2Mo alloy with the addition of Hf and Sn. Comparison of the TG data of the JG series of alloys $[56,68]$ and the alloys JZ1 and JZ2 [46], JZ3 and JZ3+ [47], JZ4 and JZ5 shows (i) that the beneficial effect of the synergy of Mo with Sn, Ge, Al, Cr, Ti and Hf and W was stronger than that of Ta with the same elements and (ii) that the detrimental effect of Mo addition at high concentration on the oxidation of $\mathrm{Nb}-25 \mathrm{Ti}-18 \mathrm{Si}-5 \mathrm{Al}-5 \mathrm{Cr}$-based alloys was compensated with the addition of Sn and Ge with Hf, Ti and W. This is encouraging news because (a) Mo has a lower density and is a better solid solution strengthener than Ta $[1,27,28,31]$ and (b) points to the synergy of Mo and $\mathrm{W}$ in Nb-silicide-based alloys and in RCCAs being more desirable than that of Ta and $\mathrm{W}$ for achieving a balance of strength and oxidation, and/or properties closer to the property goals [1].

The starting microstructures of the oxidation specimens of the alloys JZ4 and JZ5 were slightly different compared with the alloys JZ3 and JZ3+, in that the $\mathrm{TM}_{5} \mathrm{Sn}_{2} \mathrm{X}$ compound was present and the volume fraction of the Laves phase was higher than those in the alloys JZ3 and JZ3+ [47]. The microcracking that was observed in JZ3+ was not noted in JZ4 and JZ5. There was no apparent change in the compositions of the phases in the alloys JZ4 and JZ5 after the oxidation, compared with the cast alloys. Considering the data for the composition of phases in the bulk of the alloys JZ3 [47], $\mathrm{JZ4}$ and JZ5 after oxidation at $800{ }^{\circ} \mathrm{C}$, (i) the parameters $<\mathrm{Si}>, \mathrm{RM} / \mathrm{W}$ and the Ti content of the A15 in JZ5 were the highest (Figure 10a), (ii) the $\mathrm{RM} /\left(\mathrm{Ti}+\mathrm{Hf}\right.$ ) ratio of the $\mathrm{Nb}_{5} \mathrm{Si}_{3}$ and Ti-rich $\mathrm{Nb}_{5} \mathrm{Si}_{3}$ were the lowest for JZ5 (Figure 10b) and (iii) the Laves phase was the poorest in $\mathrm{Al}$ and richest in Si in JZ3, and had the highest RM/W and Ti + Hf content, respectively, in JZ3 and JZ5 (Figure 10c). Considering that the Laves phase plays a minor role in the oxidation of Nb-silicide-based alloys at $800{ }^{\circ} \mathrm{C}$ [75] and that the $\mathrm{TM}_{5} \mathrm{Sn}_{2} \mathrm{X}$ compound was present only with a small volume fraction in JZ4 and JZ5, it is suggested that the good oxidation resistance of the alloys JZ4 and JZ5 at $800{ }^{\circ} \mathrm{C}$ is attributed to the low volume fraction of the $\mathrm{A} 15$, the absence of $\mathrm{Nb}_{\mathrm{ss}}$ in the starting microstructure and the aforementioned parameters (Figure 10).

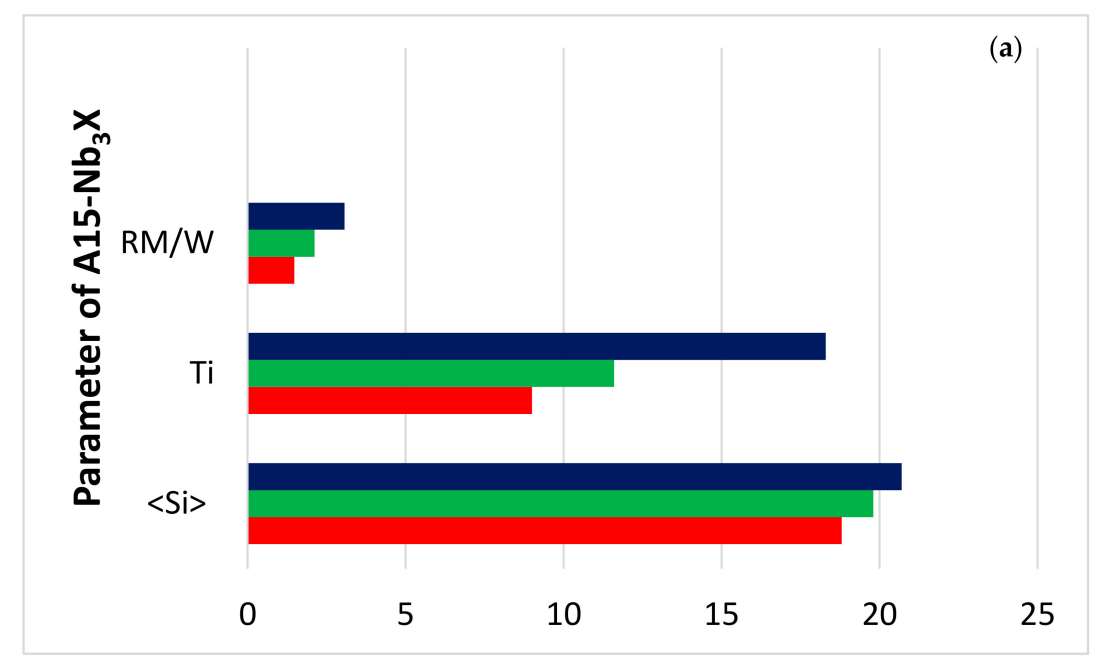

Figure 10. Cont. 

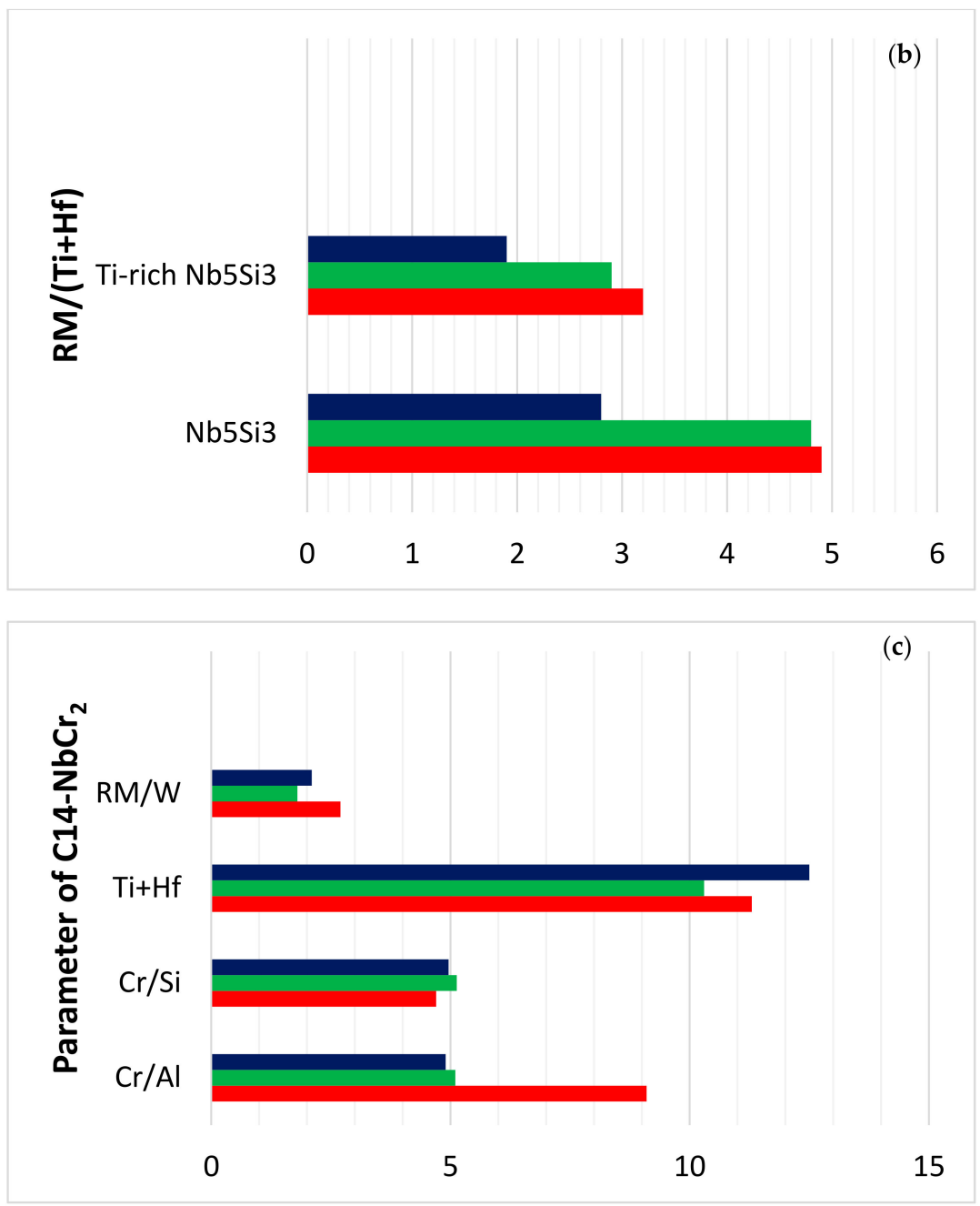

Figure 10. Parameters of different phases for the bulk of oxidised specimens at $800{ }^{\circ} \mathrm{C}$, red JZ3, green JZ4, blue JZ5. (a) Data for $\mathrm{A} 15-\mathrm{Nb}_{3} \mathrm{X}$, parameters $<\mathrm{Si}>$ (at.\%), $\mathrm{RM} / \mathrm{W}$, concentration of Ti (at.\%), (b) data for $\mathrm{Nb}_{5} \mathrm{Si}_{3}$, parameter $\mathrm{RM} /\left(\mathrm{Ti}+\mathrm{Hf}\right.$ ), (c) data for $\mathrm{C} 14-\mathrm{NbCr}_{2}$, parameters $\mathrm{Cr} / \mathrm{Al}, \mathrm{Cr} / \mathrm{Si}, \mathrm{Ti}+\mathrm{Hf}, \mathrm{RM} / \mathrm{W}$. $\mathrm{RM}=\mathrm{Mo}$ or $\mathrm{Ta},<\mathrm{Si}>=\mathrm{Al}+\mathrm{Ge}+\mathrm{Si}+\mathrm{Sn}$.

It should be noted that some of the A15 phase immediately below the oxide scale was oxidised in the alloy JZ4 (Figure 4a). This was not observed in the alloy JZ5. The better oxidation resistance of the A15 phase in the alloy JZ5 at $800{ }^{\circ} \mathrm{C}$ was attributed to the increase in its $<\mathrm{Si}>$ and Ti contents and the decrease in the concentration of W (Figure 10a).

\subsubsection{Oxidation at $1200{ }^{\circ} \mathrm{C}$}

Compared with the alloy JZ3 [47], the substitution of Ta by Mo in JZ4 (i) changed the oxidation kinetics from linear for the majority of the duration of the oxidation experiment in JZ3 to parabolic for the whole experiment in JZ4, (ii) reduced the weight change by $44.5 \%$, (iii) eliminated edge cracking of the scale and (iv) supressed scale spallation at $1200{ }^{\circ} \mathrm{C}$. Compared with the alloy JZ3+ [47], (v) the weight gain of JZ4 was reduced only slightly (4\%) and (vi) there was no scale spallation in JZ4 and JZ5. The reduction by $37 \%$ in the weight gain of the alloy JZ5 compared with the alloy JZ4 was attributed to the beneficial effect of the increased concentration of Ti on the oxidation resistance, in agreement with [68]. Furthermore, the increase in Ti content in JZ5 did not affect the adherence of the scale. In other words, the substitution of Ta by Mo notably improved the oxidation at both temperatures. The parabolic rate constants of the polycrystalline alloys JZ3+ [47], JZ4 and JZ5, all of which did 
not suffer from scale spallation, were the closest to that of the single crystal Ni superalloy CMSX-4, which gained $0.4 \mathrm{mg} / \mathrm{cm}^{2}$ after $50 \mathrm{~h}$ and had $\mathrm{k}_{\mathrm{p}} \approx 4 \times 10^{-12} \mathrm{~g}^{2} \mathrm{~cm}^{-4} \mathrm{~s}^{-1}$ at $1200{ }^{\circ} \mathrm{C}$ [1].

When Sn was added (2-8 at.\%) to the MASC alloy Nb-25Ti-16Si-8Hf-2Al-2Cr, all alloys gained more than $50 \mathrm{mg} / \mathrm{cm}^{2}$ after $50 \mathrm{~h}$ exposure at $1200{ }^{\circ} \mathrm{C}$ [44]. The addition of 5 at.\% Sn to $\mathrm{Nb}-24 \mathrm{Ti}-18 \mathrm{Si}-2 \mathrm{Mo}-5 \mathrm{Al}-5 \mathrm{Cr}-5 \mathrm{Hf}$ reduced the rate constant at $1200^{\circ} \mathrm{C}$ but the weight gain was high, about $90 \mathrm{mg} / \mathrm{cm}^{2}$ after $100 \mathrm{~h}$ exposure. A mass gain of about $40 \mathrm{mg} / \mathrm{cm}^{2}$ was observed in the alloy $\mathrm{Nb}-24 \mathrm{Ti}-18 \mathrm{Si}-5 \mathrm{Ge}-5 \mathrm{Al}-5 \mathrm{Cr}$ after $100 \mathrm{~h}$ at $1200^{\circ} \mathrm{C}$ [43]. Comparison of the data of the alloys mentioned above with that for JZ3+ [47], JZ4 and JZ5 shows (1) that the oxidation resistance of Nb-silicide-based alloys at $1200^{\circ} \mathrm{C}$ was enhanced dramatically when $\mathrm{Sn}$ and Ge were added together with $\mathrm{Al}, \mathrm{Ce}, \mathrm{W}$ and Ta or Mo, and with Hf at low ( $\leq 1$ at.\%) concentration and (2) that the oxidation improved with the increase in the Sn and/or Ti concentrations in the alloys.

Changes in the chemical composition of the $(\mathrm{Nb}, \mathrm{W})_{\mathrm{ss}}, \mathrm{Nb}_{5} \mathrm{Si}_{3}$ and $\mathrm{A} 15-\mathrm{Nb}_{3} \mathrm{X}$ phases in the diffusion zone and bulk of the oxidised specimens of the alloys JZ4 and JZ5 are compared with the bulk of the heat-treated alloys in Figure 11a-c. In both alloys, the (Mo + W)/Ti ratio of the solid solution was highest in the diffusion zone, owing to the depletion of its Ti for the formation of the Ti-rich oxide in the scale and the increase in its Mo and W contents (Tables S5 and S6 and Table 6), and the $<\mathrm{Si}>$ content was lowest in the diffusion zone of JZ5, which indicates a stronger contribution of $\mathrm{Al}, \mathrm{Ge}, \mathrm{Si}, \mathrm{Sn}$ in the formation of the scale compared with JZ4, where $<\mathrm{Si}>$ did not change significantly (Figure 11a). Note that in Table 6, two sets of data for given for the bulk, namely data for the bulk of the oxidised specimen and below this are the data in italics for the heat-treated alloy. In both the alloys of this study, the $\mathrm{Nb}_{5} \mathrm{Si}_{3}$ contributed $\mathrm{Ti}$ and $\mathrm{Al}, \mathrm{Ge}, \mathrm{Si}, \mathrm{Sn}$ towards the formation of the scale, the latter contribution was stronger in JZ5 compared with JZ4 (Figure 11b, Table 6). Owing to segregation of solutes in the diffusion zone, the $<\mathrm{Si}>$ content and the $\mathrm{Mo} / \mathrm{W}$ ratio of the $\mathrm{A} 15-\mathrm{Nb}_{3} \mathrm{X}$ increased in the diffusion zone of both alloys, particularly in the alloy JZ5 that exhibited a stronger trend compared with the Ta/W ratio of the alloy JZ3 (Figure 11c,d, Table 6). Considering the alloys JZ3, JZ3+ [47], $\mathrm{JZ4}$ and JZ5, the trend in the $<\mathrm{Si}>$ content in the diffusion zone was essentially the same, with the lowest $<\mathrm{Si}>$ for JZ5 (Figure 11e) and the $\mathrm{RM} /\left(\mathrm{Ti}+\mathrm{Hf}\right.$ ) ratio of the $\mathrm{Nb}_{5}(\mathrm{Si}, \mathrm{Sn})_{3}$ in JZ5 was the lowest owing to its high Ti and Sn concentrations (Figure 11e and Table 6). It should be noted that both Sn and Ti reduce the hardness of $\mathrm{Nb}_{5} \mathrm{Si}_{3}$ [63]. It is suggested that the formation of thin oxide scales with low stresses due to the growth of the oxides in the scales, the presence of $\mathrm{Nb}_{5}(\mathrm{Si}, \mathrm{Sn})_{3}$ in the diffusion zone and the low vol.\% of the $(\mathrm{Nb}, \mathrm{W})_{\mathrm{ss}}$ contributed to increase the deformation capability of the area around the scale/substrate interface and thus improved the adhesion of the scales in the alloys JZ3, JZ3+ [47], JZ4 and JZ5, particularly in the latter three alloys.

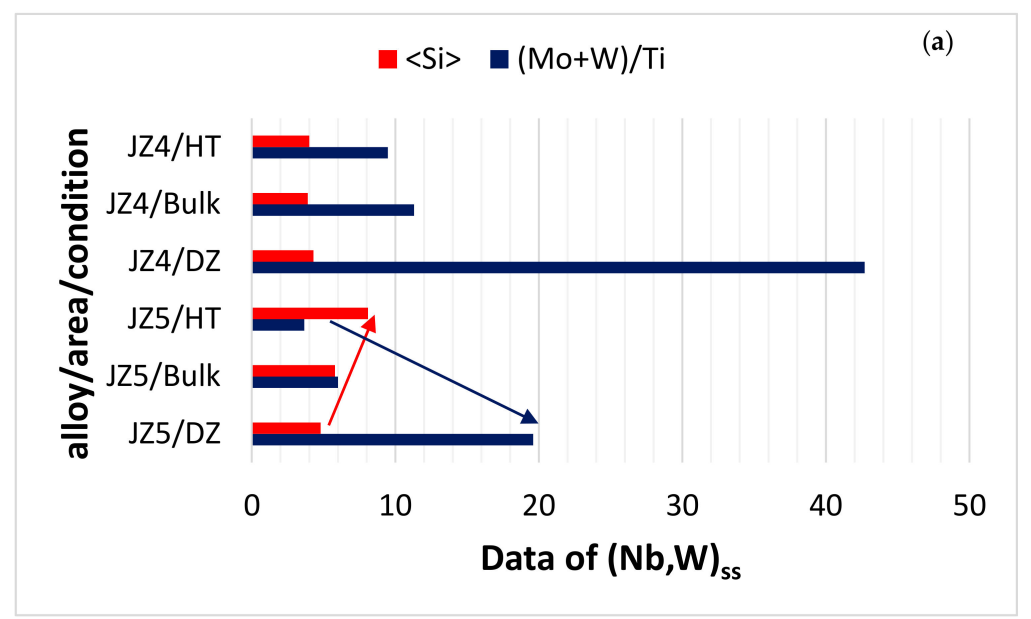

Figure 11. Cont. 


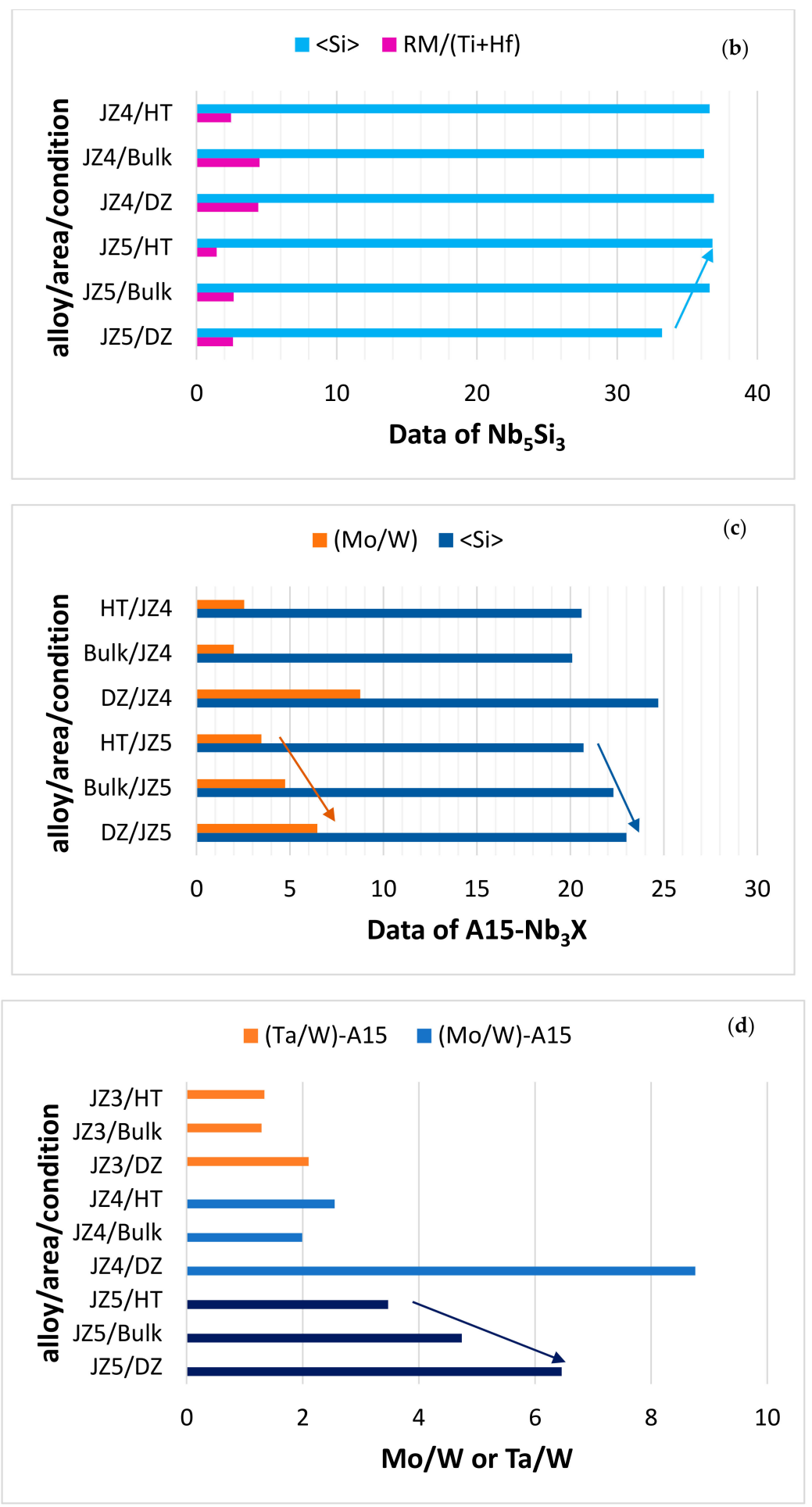

Figure 11. Cont. 


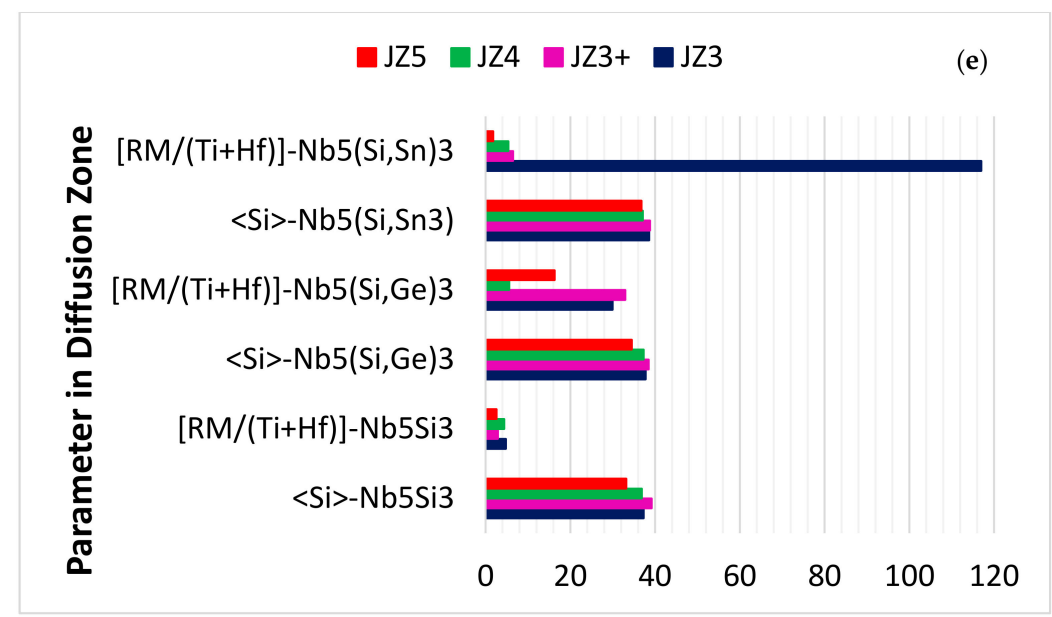

Figure 11. Data for $1200{ }^{\circ} \mathrm{C}$ for phases in different alloys. (a) Data for $(\mathrm{Nb}, \mathrm{W})_{\mathrm{ss}}$, parameters $<\mathrm{Si}>$, (Mo $+\mathrm{W}) / \mathrm{Ti}$, (b) data for $\mathrm{Nb}_{5} \mathrm{Si}_{3}$, parameters $<\mathrm{Si}>, \mathrm{RM} /(\mathrm{Ti}+\mathrm{Hf})$, (c) data for $\mathrm{A} 15-\mathrm{Nb}_{3} \mathrm{X}$, parameters $<\mathrm{Si}>$, $\mathrm{Mo} / \mathrm{W}$, (d) data for $\mathrm{A} 15-\mathrm{Nb}_{3} \mathrm{X}$, parameters $\mathrm{Ta} / \mathrm{W}$ or $\mathrm{Mo} / \mathrm{W}$, (e) data for phases in the diffusion zone of the alloys JZ3, JZ3 + [27], JZ4 and JZ5. $\mathrm{RM}=\mathrm{Mo}$ or $\mathrm{Ta},<\mathrm{Si}>=\mathrm{Al}+\mathrm{Ge}+\mathrm{Si}+\mathrm{Sn}$. Note that $<\mathrm{Si}>=\mathrm{Al}+$ $\mathrm{Ge}+\mathrm{Si}+\mathrm{Sn}$ when used for the A15 phase.

Table 6. Phases in the diffusion zones and in the bulk of the alloys JZ3 and JZ3+ [47] and JZ4 and JZ5 after isothermal oxidation at $1200{ }^{\circ} \mathrm{C}$. In italics are data for specific phases in heat-treated alloys.

\begin{tabular}{|c|c|c|c|c|}
\hline \multirow{2}{*}{$\begin{array}{c}\text { Phase } \\
\text { Diffusion Zone }\end{array}$} & \multicolumn{4}{|c|}{ Alloy } \\
\hline & JZ3 & $\mathrm{JZ3+}$ & JZ4 & JZ5 \\
\hline$(\mathrm{Nb}, \mathrm{W})_{\mathrm{ss}}$ & $\begin{array}{c}\mathrm{W} / \mathrm{Ta}=3.15 \\
(\mathrm{Ta}+\mathrm{W}) / \mathrm{Ti}=152 \\
<\mathrm{Si}>=5.5\end{array}$ & $\begin{array}{c}\mathrm{W} / \mathrm{Ta}=3.64 \\
(\mathrm{Ta}+\mathrm{W}) / \mathrm{Ti}=258 \\
<\mathrm{Si}>=4.2\end{array}$ & $\begin{array}{c}\mathrm{W} / \mathrm{Mo}=1.48 \\
(\mathrm{Mo}+\mathrm{W}) / \mathrm{Ti}=42.7 \\
<\mathrm{Si}>=4.3\end{array}$ & $\begin{array}{c}\mathrm{W} / \mathrm{Mo}=1.24 \\
(\mathrm{Mo}+\mathrm{W}) / \mathrm{Ti}=19.6 \\
<\mathrm{Si}>=4.8\end{array}$ \\
\hline $\mathrm{A} 15-\mathrm{Nb}_{3} \mathrm{X}$ & $\begin{array}{l}<\mathrm{Si}>=25.8 \\
\mathrm{Ta} / \mathrm{W}=2.1\end{array}$ & $\begin{array}{l}<\mathrm{Si}>* \\
\mathrm{Ta} / \mathrm{W}\end{array}$ & $\begin{array}{c}<\mathrm{Si}>=24.7 \\
\mathrm{Mo} / \mathrm{W}=8.76\end{array}$ & $\begin{aligned}<\mathrm{Si}> & =23 \\
\mathrm{Mo} / \mathrm{W} & =6.46\end{aligned}$ \\
\hline $\mathrm{Nb}_{5}(\mathrm{Si}, \mathrm{Ge})_{3}$ & $\begin{array}{c}<\mathrm{Si}>=37.8 \\
\mathrm{RM} /(\mathrm{Ti}+\mathrm{Hf})=30\end{array}$ & $\begin{array}{c}<\mathrm{Si}>=38.5 \\
\mathrm{RM} /(\mathrm{Ti}+\mathrm{Hf})=33\end{array}$ & $\begin{array}{c}<\mathrm{Si}>=37.3 \\
\mathrm{RM} /(\mathrm{Ti}+\mathrm{Hf})=5.6\end{array}$ & $\begin{array}{c}<\mathrm{Si}>=34.5 \\
\mathrm{RM} /(\mathrm{Ti}+\mathrm{Hf})=16.3\end{array}$ \\
\hline $\mathrm{Nb}_{5} \mathrm{Si}_{3}$ & $\begin{array}{c}<\mathrm{Si}>=37.3 \\
\mathrm{RM} /(\mathrm{Ti}+\mathrm{Hf})=4.8\end{array}$ & $\begin{array}{c}<\mathrm{Si}>=39.2 \\
\mathrm{RM} /(\mathrm{Ti}+\mathrm{Hf})=2.9\end{array}$ & $\begin{array}{c}<\mathrm{Si}>=36.9 \\
\mathrm{RM} /(\mathrm{Ti}+\mathrm{Hf})=4.4\end{array}$ & $\begin{array}{c}<\mathrm{Si}>=33.2 \\
\mathrm{RM} /(\mathrm{Ti}+\mathrm{Hf})=2.6\end{array}$ \\
\hline $\mathrm{Nb}_{5}(\mathrm{Si}, \mathrm{Sn})_{3}$ & $\begin{array}{c}<\mathrm{Si}>=38.6 \\
\mathrm{RM} /(\mathrm{Ti}+\mathrm{Hf})=117\end{array}$ & $\begin{array}{c}<\mathrm{Si}>=38.8 \\
\mathrm{RM} /(\mathrm{Ti}+\mathrm{Hf})=6.5\end{array}$ & $\begin{array}{c}<\mathrm{Si}>=37.1 \\
\mathrm{RM} /(\mathrm{Ti}+\mathrm{Hf})=5.4\end{array}$ & $\begin{array}{c}<\mathrm{Si}>=36.8 \\
\mathrm{RM} /(\mathrm{Ti}+\mathrm{Hf})=1.8\end{array}$ \\
\hline Bulk & JZ3 & $\mathrm{JZ3+}$ & JZ4 & JZ5 \\
\hline$(\mathrm{Nb}, \mathrm{W})_{\mathrm{ss}}$ & $\begin{array}{c}W / T a=1.37^{+} \\
(T a+W) / T i=3.2^{+} \\
<S i>=7.3^{+}\end{array}$ & $\begin{array}{c}W / T a=2.64^{+} \\
(T a+W) / T i=14.1^{+} \\
<S i>=3.9^{+}\end{array}$ & $\begin{array}{c}\mathrm{W} / \mathrm{Mo}=1.4 \\
(\mathrm{Mo}+\mathrm{W}) / \mathrm{Ti}=11.3 \\
<\mathrm{Si}>=3.9 \\
W / \mathrm{Mo}=1.35^{+} \\
(\mathrm{Mo}+\mathrm{W}) / \mathrm{Ti}=9.48^{+} \\
<\mathrm{Si}>=4^{+}\end{array}$ & $\begin{array}{c}\mathrm{W} / \mathrm{Mo}=1.08 \\
(\mathrm{Mo}+\mathrm{W}) / \mathrm{Ti}=6 \\
<\mathrm{Si}>=5.8 \\
W / \mathrm{Mo}=0.77^{+} \\
(\mathrm{Mo}+\mathrm{W}) / \mathrm{Ti}=3.66^{+} \\
<\mathrm{Si}>=8.1^{+}\end{array}$ \\
\hline $\mathrm{A} 15-\mathrm{Nb}_{3} \mathrm{X}$ & $\begin{array}{c}<\mathrm{Si}>=19.7 \\
\mathrm{Ta} / \mathrm{W}=1.29 \\
<\mathrm{Si}>=20.7^{+} \\
\mathrm{Ta} / \mathrm{W}=1.34^{+}\end{array}$ & $\begin{array}{c}<\mathrm{Si}>=20.3 \\
\mathrm{Ta} / \mathrm{W}=0.96 \\
<\mathrm{Si}>=20.5^{+} \\
\mathrm{Ta} / \mathrm{W}=1.26^{+}\end{array}$ & $\begin{array}{c}<\mathrm{Si}>=20.1 \\
\mathrm{Mo} / \mathrm{W}=1.99 \\
<\mathrm{Si}>=20.6^{+} \\
\mathrm{Mo} / \mathrm{W}=2.55^{+}\end{array}$ & $\begin{array}{c}<\mathrm{Si}>=22.3 \\
\mathrm{Mo} / \mathrm{W}=4.74 \\
<\mathrm{Si}>=20.7^{+} \\
\mathrm{Mo} / \mathrm{W}=3.47^{+}\end{array}$ \\
\hline $\mathrm{Nb}_{5} \mathrm{Si}_{3}$ & $\begin{array}{c}<\mathrm{Si}>=38 \\
\mathrm{RM} /(\mathrm{Ti}+\mathrm{Hf})=4.6 \\
<\mathrm{Si}>=38.6^{+} \\
R M /(\mathrm{Ti}+\mathrm{Hf})=4.82^{+}\end{array}$ & $\begin{array}{c}<\mathrm{Si}>=38.9 \\
\mathrm{RM} /(\mathrm{Ti}+\mathrm{Hf})=4.98 \\
<\mathrm{Si}>=37.9^{+} \\
\mathrm{RM} /(\mathrm{Ti}+\mathrm{H} f)=3.23^{+}\end{array}$ & $\begin{array}{c}<\mathrm{Si}>=36.2 \\
\mathrm{RM} /(\mathrm{Ti}+\mathrm{Hf})=4.5 \\
<\mathrm{Si}>=36.6^{+} \\
\mathrm{RM} /(\mathrm{Ti}+\mathrm{Hf})=2.46^{+}\end{array}$ & $\begin{array}{c}<\mathrm{Si}>=36.6 \\
\mathrm{RM} /(\mathrm{Ti}+\mathrm{Hf})=2.65 \\
<\mathrm{Si}>=36.8^{+} \\
R M /(\mathrm{Ti}+\mathrm{Hf})=1.44^{+}\end{array}$ \\
\hline Ti-rich $\mathrm{Nb}_{5} \mathrm{Si}_{3}$ & $\begin{array}{c}<\mathrm{Si}>=37.9 \\
\mathrm{RM} /(\mathrm{Ti}+\mathrm{Hf})=2.99 \\
<\mathrm{Si}>=38.4^{+} \\
\mathrm{RM} /(\mathrm{Ti}+\mathrm{Hf})=2.48^{+}\end{array}$ & $\begin{array}{c}<\mathrm{Si}>=36.4 \\
\mathrm{RM} /(\mathrm{Ti}+\mathrm{Hf})=1.9 \\
<\mathrm{Si}>=38.4^{+} \\
R M /(\mathrm{Ti}+\mathrm{H} f)=2.06^{+}\end{array}$ & $\begin{array}{c}<\mathrm{Si}>=35.9 \\
\mathrm{RM} /(\mathrm{Ti}+\mathrm{Hf})=1.87 \\
<\mathrm{Si}>=38.1^{+} \\
R M /(\mathrm{Ti}+\mathrm{H} f)=1.84\end{array}$ & $\begin{array}{c}<\mathrm{Si}>=36.6 \\
\mathrm{RM} /(\mathrm{Ti}+\mathrm{Hf})=1.17 \\
<\mathrm{Si}>=37.9^{+} \\
R M /(\mathrm{Ti}+\mathrm{Hf})=1.08^{+}\end{array}$ \\
\hline $\mathrm{C} 14-\mathrm{NbCr}_{2}$ & $\begin{array}{c}<\mathrm{Cr}>=61.7 \\
\mathrm{Ta}+\mathrm{W}=12.3 \\
<\mathrm{Cr}>/ \mathrm{LFE}=1.77 \\
<\mathrm{Cr}>=63.3^{+} \\
\mathrm{Ta}+W=12.2^{+} \\
<\mathrm{Cr}>/ \mathrm{LFE}=1.94^{+}\end{array}$ & $\begin{array}{c}<\mathrm{Cr}>=60.8 \\
\mathrm{Ta}+\mathrm{W}=14.1 \\
<\mathrm{Cr}>/ \mathrm{LFE}=1.75 \\
<\mathrm{Cr}>=62.1^{+} \\
\mathrm{Ta}+W=14.8^{+} \\
<\mathrm{C} r>/ \mathrm{LFE}=1.9^{+}\end{array}$ & $\begin{array}{c}<\mathrm{Cr}>=59.6 \\
\mathrm{Mo}+\mathrm{W}=7 \\
<\mathrm{Cr}>/ \mathrm{LFE}=1.78 \\
<\mathrm{Cr}>=61.3^{+} \\
M o+W=7.5^{+} \\
<\mathrm{Cr}>/ \mathrm{LFE}=1.79^{+}\end{array}$ & $\begin{array}{c}<\mathrm{Cr}>=60.1 \\
\mathrm{Mo}+\mathrm{W}=7.9 \\
<\mathrm{Cr}>/ \mathrm{LFE}=1.88 \\
-\end{array}$ \\
\hline
\end{tabular}

* See [47], + data for HT alloy, $<\mathrm{Si}>=\mathrm{Al}+\mathrm{Ge}+\mathrm{Si}+\mathrm{Sn},<\mathrm{Cr}>=\mathrm{Cr}+\mathrm{Al}+\mathrm{Ge}+\mathrm{Si}+\mathrm{Sn}, \mathrm{RM}=\mathrm{Nb}, \mathrm{Mo}, \mathrm{Ta}, \mathrm{W}$, $\mathrm{LFE}=\mathrm{C} 14$-Laves forming element $(\mathrm{Hf}, \mathrm{Nb}, \mathrm{Ta}, \mathrm{Ti})$. 
Geng et al. [56], Vellios [76], Knittel et al. [44] and Xu et al. [41,42] reported that in their Sn-containing alloys the $\mathrm{Sn}$ segregated at the oxide scale/diffusion zone interface at $1200{ }^{\circ} \mathrm{C}$ where the $\mathrm{Nb}_{3} \mathrm{Sn}$ and $\mathrm{Nb}_{5} \mathrm{Sn}_{2} \mathrm{Si}$ compounds were formed. The latter compound is not stable at $120{ }^{\circ} \mathrm{C}$ according to [66]. The stability of the $\mathrm{Nb}_{5} \mathrm{Sn}_{2} \mathrm{Si}$ compound at $1200{ }^{\circ} \mathrm{C}$ has also been confirmed in oxidised $\mathrm{Nb}-24 \mathrm{Ti}-18 \mathrm{Si}-5 \mathrm{Al}-5 \mathrm{Cr}-5 \mathrm{Sn}$ [42]. In other words, prior to this work, the formation of $\mathrm{Nb}_{5} \mathrm{Sn}_{2} \mathrm{Si}$ at $1200^{\circ} \mathrm{C}$ had been confirmed only in oxidised $\mathrm{Nb}$-silicide-based alloys where $\mathrm{Al}, \mathrm{Cr}$ and $\mathrm{Sn}$ were present simultaneously, which would suggest that contamination by oxygen could stabilise this compound at the said temperature. The $\mathrm{TM}_{5} \mathrm{Sn}_{2} \mathrm{X}$ compound that formed in JZ4-AC and JZ5-AC was not stable in the heat-treated alloys and in the oxidised alloys at $1200^{\circ} \mathrm{C}$. This would suggest that the simultaneous addition of Ge and $\mathrm{Sn}$ with Mo and $\mathrm{W}$ was also key to $\mathrm{TM}_{5} \mathrm{Sn}_{2} \mathrm{X}$ not being stable at $120{ }^{\circ} \mathrm{C}$.

A common observation in the alloys JZ3, JZ3+ [47], JZ4 and JZ5 was the segregation of Ge and Sn below the scale/substrate interface (Figure 7) and formation of Sn and Ge containing intermetallic phases in the diffusion zone (Table 6). Segregation of solutes in the substrate just below the scale/substrate interface has been studied in $[41,42,45,56,76]$. Table 7 shows the solutes that are predicted to segregate to the surfaces of binary $\mathrm{Nb}-\mathrm{X}$ alloys. Note that Table 7 is an expansion of the Table 7 in [41] to include data for Ge, Mo and Hf.

Table 7. Solutes in $\mathrm{Nb}-\mathrm{X}$ binary alloys predicted to segregate to the surface.

\begin{tabular}{ccccccccc}
\hline Theory & \multicolumn{7}{c}{ Surface Segregating Element } \\
\hline $\mathrm{A}$ & $\mathrm{Al}$ & $\mathrm{Cr}$ & $\mathrm{Si}$ & $\mathrm{Sn}$ & $\mathrm{Ge}$ & $\mathrm{Mo}$ & $\mathrm{Hf}$ & $\mathrm{Ti}$ \\
\hline $\mathrm{B}$ & $\mathrm{Al}$ & - & - & $\mathrm{Sn}$ & $\mathrm{Ge}$ & - & - & $\mathrm{Ti}$ \\
\hline $\mathrm{C}$ & - & $\mathrm{Cr}$ & $\mathrm{Si}$ & $\mathrm{Sn}$ & $\mathrm{Ge}$ & - & - & - \\
\hline $\mathrm{D}$ & $\mathrm{Al}$ & $\mathrm{Cr}$ & $\mathrm{Si}$ & $\mathrm{Sn}$ & $\mathrm{Ge}$ & - & $\mathrm{Hf}$ & $\mathrm{Ti}$ \\
\hline
\end{tabular}

According to theory A, the solute of the alloy with lower heat of sublimation should segregate to the surface; according to theory $\mathrm{B}$, the larger the solute atom relative to the solvent, the stronger the surface segregation; according to theory $C$, surface segregation should occur when, owing to solute distribution (partitioning), the melt is richer in solute than the solid, and according to theory D, the element with the lower surface energy segregates.

Ge- and $\mathrm{Sn}$-containing intermetallics and $\mathrm{Nb}_{\mathrm{ss}}$ rich in refractory metals formed in the diffusion zones of the alloys JZ3, JZ3+ [47], JZ4 and JZ5 at $1200{ }^{\circ} \mathrm{C}$. The solid solution in the alloys JZ3 and $\mathrm{JZ3}+$ was very rich in $\mathrm{W}$ and extremely poor in Ti (see Table 6 and [47]). Segregation of W or Ta to the surface is not expected in binary $\mathrm{Nb}-\mathrm{X}(\mathrm{X}=\mathrm{Ta}, \mathrm{W})$ alloys.

The Ti concentration in the solid solution decreased with increasing (i) W concentration [62], (ii) $\mathrm{W} / \mathrm{RM}$ ratio and (iii) $\mathrm{RM}+\mathrm{W}$ content $(\mathrm{RM}=\mathrm{Mo}$,Ta) (Figure 12a-c). The $\mathrm{Al}+\mathrm{Cr}$ concentration of the solid solution did not depend on its $\mathrm{Sn} / \mathrm{Ge}$ ratio in the Ta-containing alloys and was highest in JZ5 (Figure 12d), and the $\mathrm{Cr} / \mathrm{Al}$ ratio increased with its $\mathrm{RM}+\mathrm{W}$ content $(\mathrm{RM}=\mathrm{Mo}, \mathrm{Ta})$ (Figure 12e). In the diffusion zone, as the concentration of Ti decreased in the phases owing to its consumption for the formation of the scale, in the poorer Ti solid solution the $\mathrm{W}$ and $\mathrm{Mo}+\mathrm{W}$ contents and the W/Mo ratio increased. The $\mathrm{Al}$ and $\mathrm{Cr}$ concentrations in the solid solution were also affected, particularly in JZ4 and JZ5, where the dependence of the $\mathrm{Al}+\mathrm{Cr}$ content on the $\mathrm{Sn} / \mathrm{Ge}$ ratio was stronger than in the Ta-containing alloys. The $\mathrm{Cr} / \mathrm{Al}$ ratio in the solid solution increased because of the increased $\mathrm{Mo}+\mathrm{W}$ content, and the decrease in the $\mathrm{Al}$ content was more severe compared with that of $\mathrm{Cr}$ (Tables S5 and S6) because decrease in the Ti concentration in $\mathrm{Nb}_{\mathrm{ss}}$ results to lower $\mathrm{Al}$ and $\mathrm{Cr}$ concentrations [77]. $\mathrm{The} \mathrm{Al}+\mathrm{Ge}+\mathrm{Si}+\mathrm{Sn}$ content of the A15 increased with that of the alloy (Figure 13). Compared with JZ5-HT, the Mo/W and Al $+\mathrm{Ge}+\mathrm{Si}+\mathrm{Sn}$ content of the A15 increased in the bulk of the oxidised alloy and its diffusion zone (Table 6) and the Mo/W ratio was higher than the Ta/W ratio of JZ3 [47] owing to the lower solubility of Ta in the A15 phase than that of Mo. 

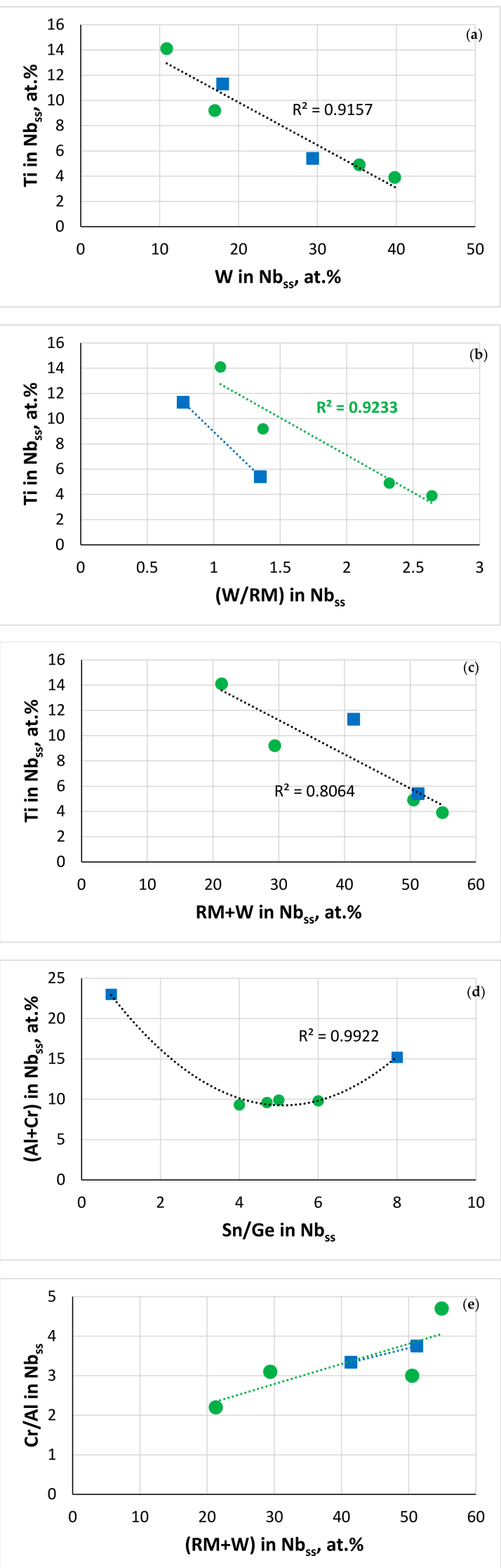

Figure 12. Data for the chemical composition of the solid solution. Squares for the alloys JZ4, JZ5, circles for Ta-containing alloys JZ1, JZ2 [46], JZ3, JZ3+ [47]. (a) Ti versus $\mathrm{W}$ in $\mathrm{Nb}_{\mathrm{ss}}$, (b) Ti versus W/RM in $\mathrm{Nb}_{\mathrm{ss}}$, (c) Ti versus $\mathrm{RM}+\mathrm{W}$ in $\mathrm{Nb}_{\mathrm{ss}}$, (d) $\mathrm{Al}+\mathrm{Cr}$ in $\mathrm{Nb}_{\mathrm{ss}}$ versus $\mathrm{Sn} / \mathrm{Ge}$ in $\mathrm{Nb}_{\mathrm{ss}}$, (e) $\mathrm{Cr} / \mathrm{Al}$ in $\mathrm{Nb}_{\mathrm{ss}}$ versus $\mathrm{RM}+\mathrm{W}$ in $\mathrm{Nb}_{\mathrm{ss}}$. $\mathrm{RM}=\mathrm{Mo}$ or $\mathrm{Ta}$, in $(\mathbf{e}) \mathrm{R}^{2}=0.6404$ for linear fit of all data. 


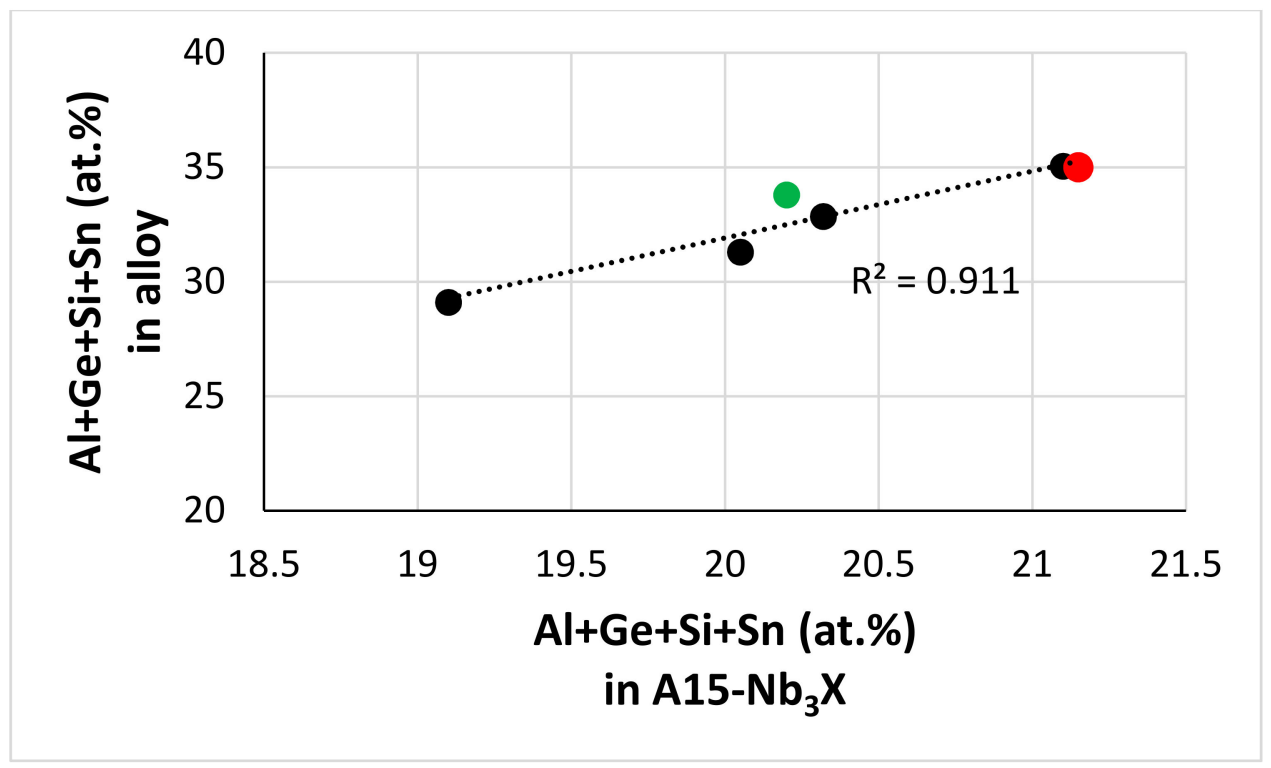

Figure 13. Relationship between the $\mathrm{Al}+\mathrm{Ge}+\mathrm{Si}+\mathrm{Sn}$ content in alloys and $\mathrm{A} 15-\mathrm{Nb}_{3} \mathrm{X}$. Data for the alloys JZ2 [46], JZ3, JZ3+ [47], JZ4 and JZ5. Red for JZ5, green for JZ4.

The solid solution is the Achilles heel of $\mathrm{Nb}$-silicide-based alloys regarding their oxidation [68,75]. The exceptional oxidation resistance of the alloys JZ4 and JZ5 at both temperatures benefited from the very low vol. $\%$ of $(\mathrm{Nb}, \mathrm{W})_{\mathrm{ss}}$ that resulted from the increased $\mathrm{Ge}+\mathrm{Sn}$ content in each alloy (Figure 9). The oxidation of the $\mathrm{Nb}_{5} \mathrm{Si}_{3}$ silicide is superior to that of $\mathrm{Nb}$. One would expect the precipitation of $\mathrm{Nb}_{\mathrm{ss}}$ in $\mathrm{Nb}_{5} \mathrm{Si}_{3}$ to decrease the oxidation resistance of the latter if it were to be contaminated by oxygen. This was not observed, as both alloys were not contaminated by oxygen after the heat treatment and after isothermal oxidation at 800 and $1200{ }^{\circ} \mathrm{C}$. The inferior oxidation of the Ta-containing alloys JZ3 and $\mathrm{JZ3}+[47]$, which also had low vol.\% $(\mathrm{Nb}, \mathrm{W})_{\mathrm{ss}}$, the same phases in the diffusion zone and precipitates of $\mathrm{Nb}_{\mathrm{ss}}$ in $\mathrm{Nb}_{5} \mathrm{Si}_{3}$, would suggest that the chemical composition of the phases (Tables S3-S6 and Table 6, Figures 10-13) played a key role regarding the control of the contamination by oxygen and the reduction of the diffusivity of oxygen in the alloys.

\subsection{Further Comments on Experimental Data and NICE Calculations}

The alloys JZ4 and JZ5, and the other alloys in Table 4, with the exception of JZ3+, did not pest at $800{ }^{\circ} \mathrm{C}$. The alloys JZ4 and JZ5 followed parabolic kinetics with rate constants that were of the same order as the best Ti-rich Nb-silicide-based alloys based on KZ5 (Nb-24Ti-18Si-5Al-5Cr) (Table 3 in [1]) and two orders higher than the $\mathrm{k}_{\mathrm{p}}$ of CMSX-4 at $815^{\circ} \mathrm{C}$ [1]. It is remarkable that their oxidation in the pest regime is better than that of boron containing Ti-rich $\mathrm{Nb}$-silicide-based alloys that follow linear kinetics at $800{ }^{\circ} \mathrm{C}$ (Table 3 in [1]). Furthermore, it is noteworthy that the oxidation behaviour in the pest regime of all the alloys in Table 4, which are also RCCAs, is much better than that of the RCCAs that were recently reviewed in [2].

At $1200{ }^{\circ} \mathrm{C}$, the oxidation resistance of the alloys JZ4 and JZ5 (and JZ3+) was also better than that of the other alloys in the Table 4. Both alloys (and JZ3+) followed parabolic kinetics with rate constants better than or of the same order compared with Boron containing Ti-rich $\mathrm{Nb}$-silicide-based alloys (Table 3 in [1]). The alloy JZ5 exhibited the lowest $k_{p}$ that was two orders of magnitude higher than that of CMSX-4 at at $1200{ }^{\circ} \mathrm{C}$.

In our opinion, it is remarkable that the two alloys of this study with (i) RM additions, (ii) low densities (albeit higher than the densities of Boron containing Ti-rich $\mathrm{Nb}$-silicide-based alloys based on KZ5 ( $\left.\rho \leq 6.8 \mathrm{~g} / \mathrm{cm}^{3}[1]\right)$ and (iii) probably good creep at the creep goal conditions (Section 5.3), 
surpass or match up with the oxidation properties of Ti-rich $\mathrm{Nb}$-silicide-based alloys with or without Boron addition.

The oxidation of the alloy OHS1 [45] was the stimulus for the study of the alloys discussed in this paper (Sections 1 and 2) and in [47]. The oxidation of JZ4 and JZ5 at 800 and $1200{ }^{\circ} \mathrm{C}$ was better than that of the alloy OHS1 (Table 4). The parameters VEC, $\Delta x, \delta$ are key in the alloy design methodology NICE [20]. Maps based on these parameters describe alloying behaviour of alloys and their phases $[1,7,21,47,50,63,64]$. Figure 14 shows the $\delta$ versus VEC and $\Delta \chi$ versus VEC maps of $\mathrm{Nb}$-silicide-based alloys with Ge or Sn or Ge $+\mathrm{Sn}$ additions and with or without RM (=Mo, Ta, W) addition. Note that the alloys included in the Figure 14 are also RCCAs. The maps in the Figure 14 clearly separate the alloys without W addition (on the left hand side of OHS1) from those with Mo and $\mathrm{W}$ or Ta and $\mathrm{W}$ addition (on the right hand side of OHS1), and show (i) that the addition of Mo, W in JZ4 and JZ5 (and of Ta, W in JZ3+) increase both VEC and $\delta$ compared with OHS1 and (ii) that all the alloys fall in the same line in the $\Delta \chi$ versus VEC map (Figure $14 \mathrm{~b}$ ). The latter figure also shows that the addition of Mo, W in JZ4 and JZ5 and Ta, W in JZ3 and JZ3+ increased VEC and $\Delta x$.
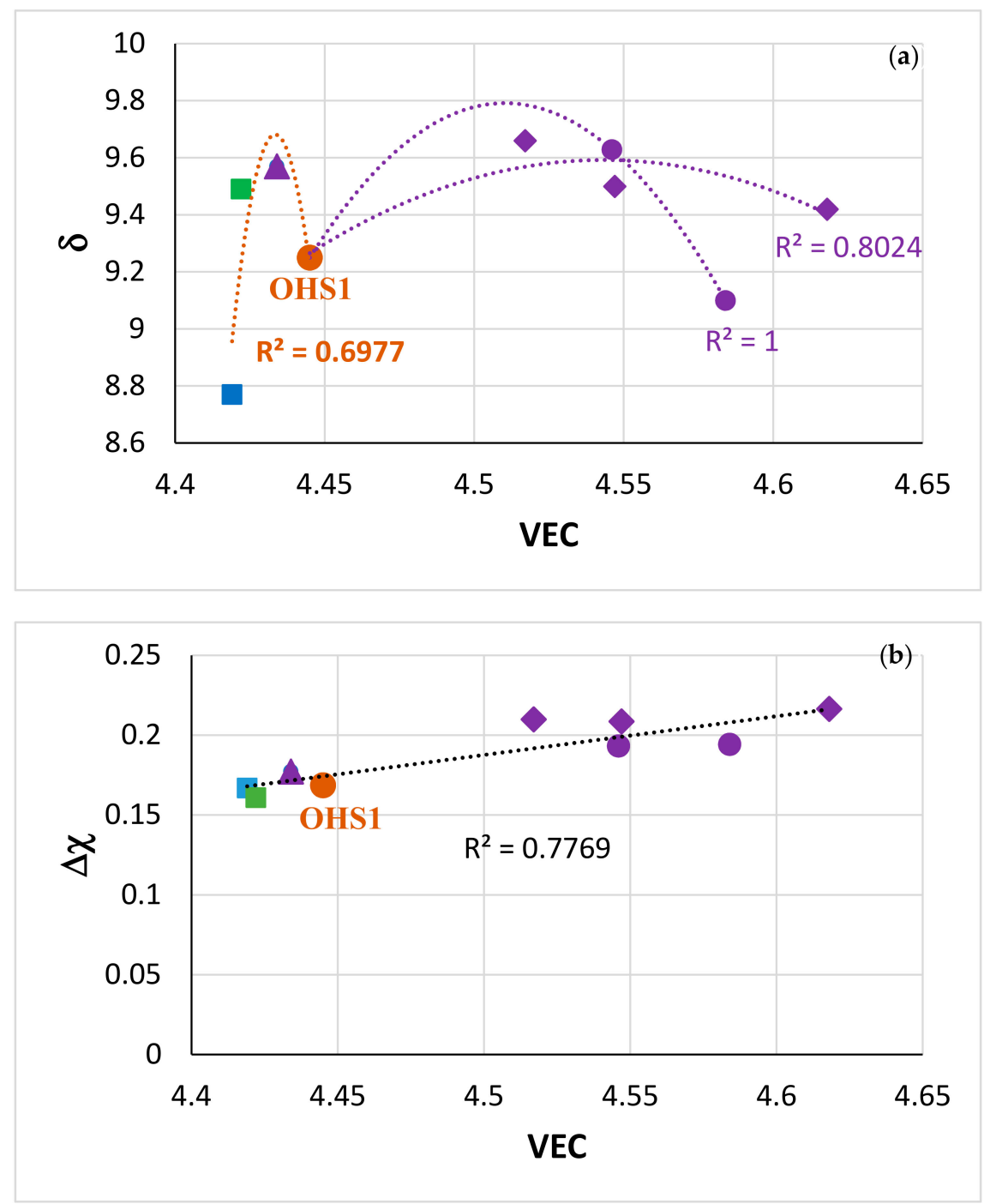

Figure 14. (a) $\delta$ versus VEC map and (b) $\Delta \chi$ versus VEC map of Nb-silicide/RCCA alloys, data for the alloys OHS1 [45], JZ3, JZ3+ [47], JG6 [56], EZ8 [58], ZF9 [59], for nominal compositions see Abbreviations. Diamonds for alloys JZ4, JZ5, NT1 [78], purple circles for alloys JZ3, JZ3+, triangle JG6, green square EZ8, blue square ZF9, brown circle OHS1. 
Trends of the aforementioned parameters are linked with the improvement of specific properties [20], for example NICE predicts that oxidation resistance increases with decreasing VEC and increasing $\delta$. The data in the Figure $15 \mathrm{a}$ are for oxidation at $800{ }^{\circ} \mathrm{C}$ and show the decrease in $\triangle$ W/A with decreasing VEC, in agreement with NICE. All the alloys in this figure are also RCCAs. The two lines, which are consistent with the linear fit of data, cross at the data point of the alloy ZF9 (Nb-24Ti-18Si-5Al-5Cr-5Ge-5Hf [43,59]). The red line is for Ti-rich Nb-silicide-based alloys. Note (i) that the simultaneous addition of Ge and Sn in OHS1 increased the weight gain at $800{ }^{\circ} \mathrm{C}$ [45] and VEC (indicated by the orange arrow) (ii) that the addition of Mo and W in JZ4 and the decrease in the Ti content, compared with OHS1, caused the clockwise shift in the map from OHS1 to JZ4, which is indicated by the green arrow, (iii) that the increase in the Ti content in JZ5 reduced both the $\triangle$ W/A and VEC compared with JZ4, which is indicated by the blue arrow and (iv) that the slope of the blue line is significantly lower than that of the red line. The data in the Figure $15 \mathrm{~b}$ are for oxidation at $1200{ }^{\circ} \mathrm{C}$ and show the decrease in $\triangle$ W/A with increasing $\delta$, in agreement with NICE. In this map, all the alloys fall in the same line with $R^{2}=0.8381$. The dashed vertical and horizontal lines delineate the area of $\mathrm{Nb}$-silicide-based alloys with scale spallation. Compared with OHS1, the addition of RMs in JZ3+, JZ4 and JZ5 reduced both weight gain and $\delta$.

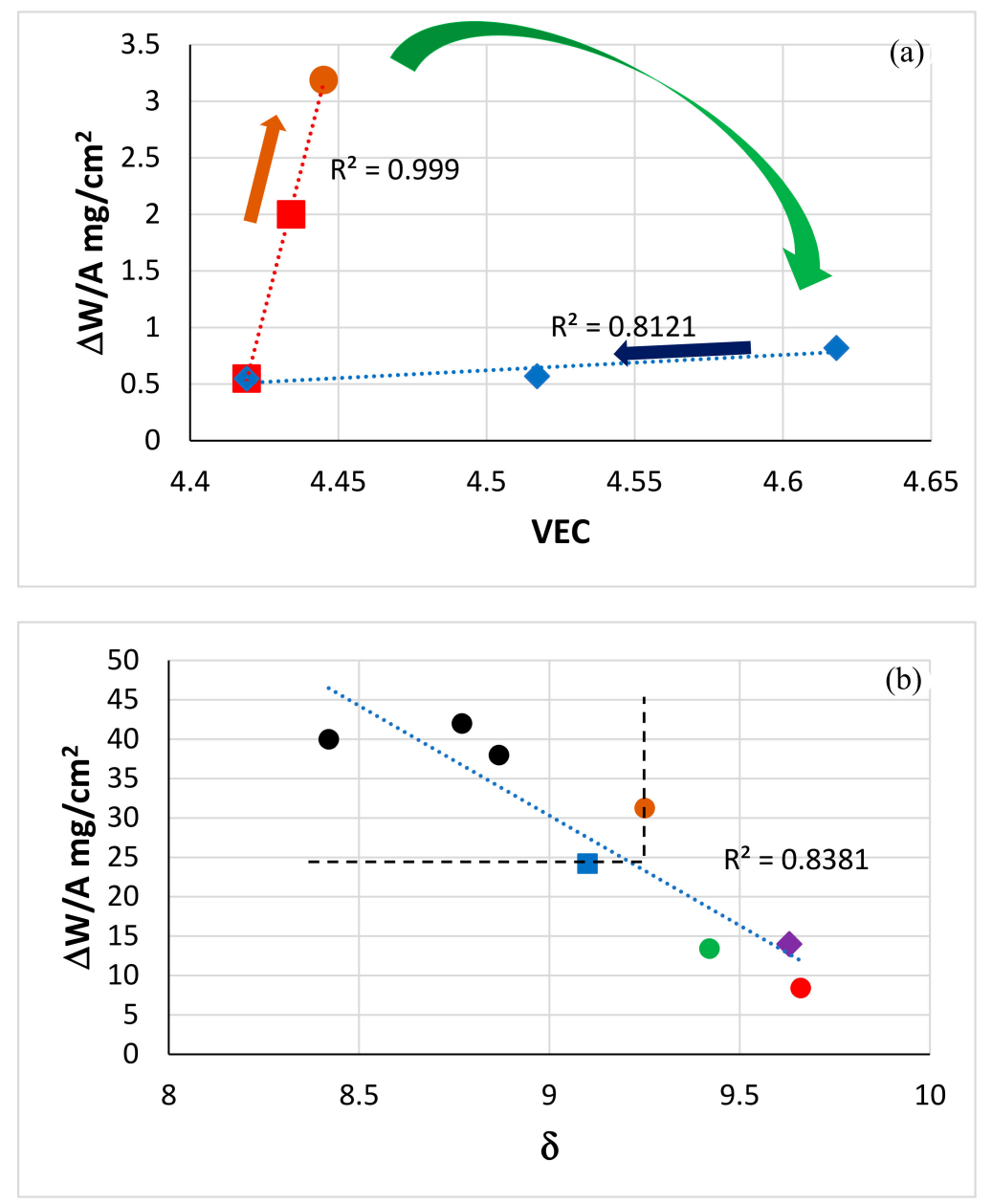

Figure 15. Weight change $\Delta W / A$ versus (a) VEC and (b) $\delta$ at (a) $800{ }^{\circ} \mathrm{C}$ and (b) $1200{ }^{\circ} \mathrm{C}$. In (a) the two lines cross at the data point of the alloy ZF9 [59]. Red ZF9, JG6 [56], orange OHS1 [45], blue ZF9, JZ4 and JZ5. In (b) the data are for the alloys ZF6 [59], ZX8 [42], ZF9, OHS1, JZ3, JZ3+ [47], JZ4, JZ5. Red JZ5, green JZ4, square JZ3, diamond JZ3+, orange OHS1. For all data $\mathrm{R}^{2}=0.8381$, for the alloys OHS1, JZ4 and JZ5 $\mathrm{R}^{2}=0.8395$. For nominal compositions of alloys see Abbreviations. For dashed lines see text. 
Figure 15 showed that the experimental data corroborated the trends of the parameters VEC and $\delta$ predicted by NICE for oxidation resistance in $\mathrm{Nb}$-silicide-based alloys. Note that these trends were followed for alloys that are also RCCAs. Figure 16 compares the experimental data about weight change at 800 and $1200{ }^{\circ} \mathrm{C}$ with the calculated $\triangle \mathrm{W} / \mathrm{A}$ using NICE. The weight change decreases with the $\mathrm{Sn}+\mathrm{Ge}$ content (Figure 16a,b) and the Sn/Ge ratio (Figure 16c) in the alloys. The agreement between calculations and experiment is considered good for both temperatures. Note the link between $\mathrm{Sn}+\mathrm{Ge}$ or $\mathrm{Sn} / \mathrm{Ge}$ with the vol. $\% \mathrm{Nb}_{\mathrm{ss}}$ in the alloys, and the link between the $\mathrm{Al}+\mathrm{Cr}$ content in $\mathrm{Nb}_{\mathrm{ss}}$ with the $\mathrm{Sn} / \mathrm{Ge}$ ratio, which were discussed earlier (see also Figures 9 and 12).
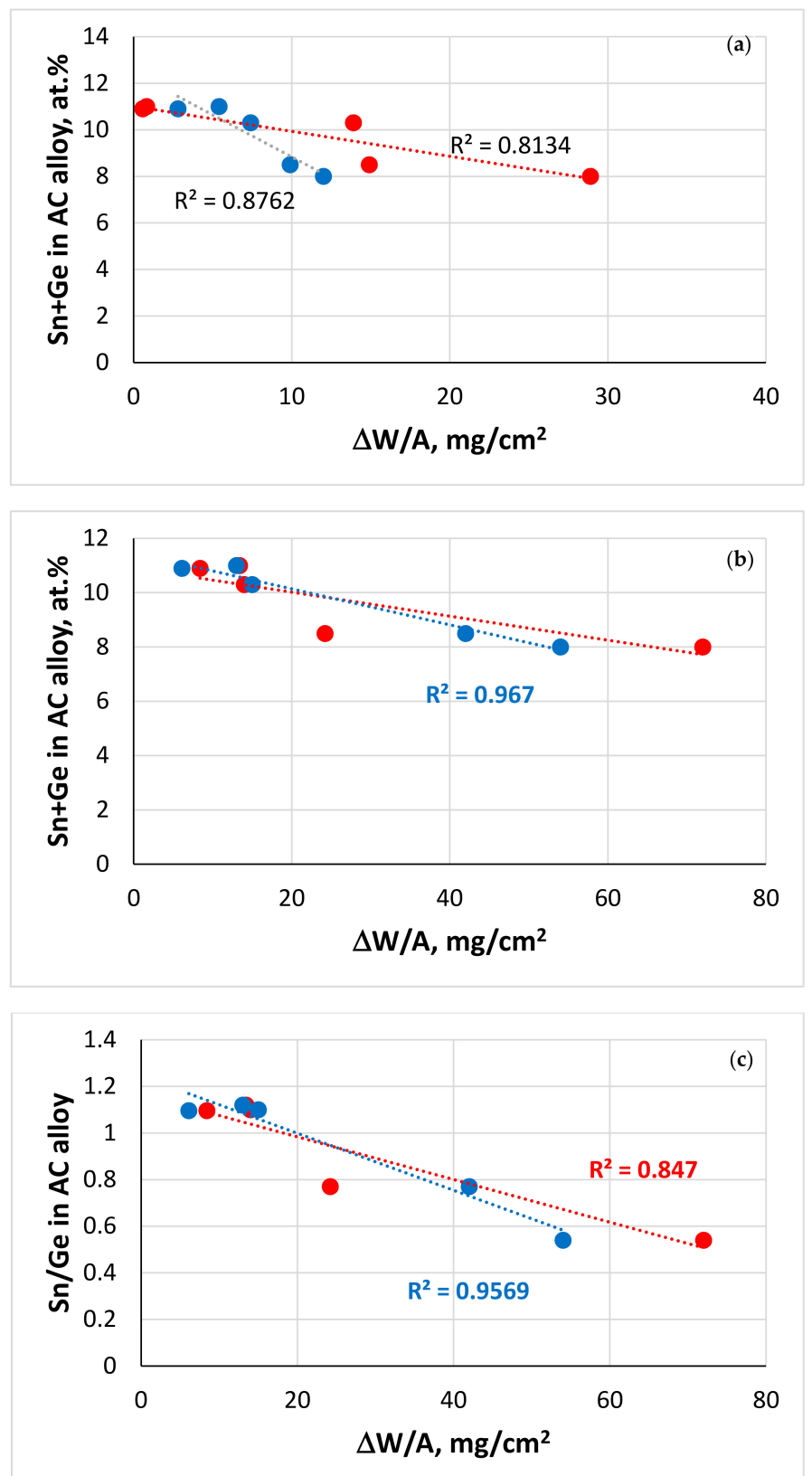

Figure 16. Weight change $\Delta W / A$ versus $(\mathbf{a}, \mathbf{b}) \mathrm{Sn}+\mathrm{Ge}$ and (c) $\mathrm{Sn} / \mathrm{Ge}$ in as-cast alloys JZ2 [46], JZ3, $\mathrm{JZ3}+$ [47], JZ4 and JZ5 at (a) $800{ }^{\circ} \mathrm{C}$ and $(\mathbf{b}, \mathbf{c}) 1200{ }^{\circ} \mathrm{C}$. Experimental data shown with red colour, calculated data by NICE [20] shown with blue colour. AC $=$ as cast. 


\section{Summary, and Suggestion for Future Work}

We studied the microstructures, MACSi and isothermal oxidation of the alloys JZ4 and JZ5, calculated their average creep rate due to intrinsic resistances for the creep goal conditions, and compared experimental data with the calculations of the alloy design methodology NICE. We also compared properties of the alloys with those of other RCCAs studied to date and reviewed in [2]. The densities of both alloys were less than $7.3 \mathrm{~g} / \mathrm{cm}^{3}$ and lower than the density of multiphase RCCAs with bcc solid solution $+\mathrm{M}_{5} \mathrm{Si}_{3}$ silicide(s) in their microstructure. There was macrosegregation of $\mathrm{Si}$ in both alloys. The latter had the same phases in their as-cast microstructures, namely $\mathrm{\beta Nb}_{5} \mathrm{Si}_{3}$, $\alpha \mathrm{Nb}_{5} \mathrm{Si}_{3}, \mathrm{~A} 15-\mathrm{Nb}_{3} \mathrm{X}(\mathrm{X}=\mathrm{Al}, \mathrm{Ge}, \mathrm{Si}, \mathrm{Sn}), \mathrm{TM}_{5} \mathrm{Sn}_{2} \mathrm{X}(\mathrm{X}=\mathrm{Al}, \mathrm{Ge}, \mathrm{Si}), \mathrm{C} 14-\mathrm{Cr}_{2} \mathrm{Nb}$, and no solid solution. After the heat treatment at $1500{ }^{\circ} \mathrm{C}$ for $100 \mathrm{~h}$ a low volume fraction of an Mo- and W-rich solid solution was observed in both alloys together with $\beta \mathrm{Nb}_{5} \mathrm{Si}_{3}, \alpha \mathrm{Nb}_{5} \mathrm{Si}_{3}$ and $\mathrm{A} 15-\mathrm{Nb}_{3} \mathrm{X}$ but not the $\mathrm{TM}_{5} \mathrm{Sn}_{2} \mathrm{X}$, whereas the Laves phase was stable only in JZ4. At $800^{\circ} \mathrm{C}$ both alloys did not pest, and there was no spallation of their scales at $1200{ }^{\circ} \mathrm{C}$. At both temperatures, both alloys followed parabolic oxidation kinetics and their weight changes were lower than those of Ti-rich $\mathrm{Nb}$-silicide-based alloys. The oxidation of both alloys was superior to that of other RCCAs studied to date [2]. Calculated Si macrosegregation, solid solution volume fractions, chemical compositions of solid solution and $\mathrm{Nb}_{5} \mathrm{Si}_{3}$, and weight changes in isothermal oxidation at 800 and $1200^{\circ} \mathrm{C}$ using the alloy design methodology NICE agreed well with the experimental results.

Considering the experimental data for oxidation, MACSi and room temperature strength and the calculated data for oxidation, MACSi and creep rates of the alloys JZ4 and JZ5, it is suggested that both alloys are worthy further investigations that could consider (i) evaluation of their cyclic oxidation, (ii) assessment of their creep properties, and (iii) the scale up of alloy making to large buttons and ingots $[1,62]$ to confirm reproducibility of properties. In our opinion, ultra-high temperature $\mathrm{Nb}-\mathrm{Mo}-\mathrm{W}-\mathrm{Ti}-\mathrm{Cr}-\mathrm{Hf}-\mathrm{Al}-\mathrm{Ge}-\mathrm{Si}-\mathrm{Sn}$ RMICs, RCCAs and RHEAs are worthy of development owing to their promise to meet property goals and/or offer a balance of properties. The alloys JZ4 and JZ5 are a good basis for the design of new alloys.

In the introduction we discussed that RMICs, RCCAs and RHEAs intended for application in aero engines would require environmental coatings (ECs) of the BC/TGO/TC type [36,79]. BC Nb-Ti-Si-Al-Hf HEAs forming $\alpha \mathrm{Al}_{2} \mathrm{O}_{3}$ TGO [80,81] could be suitable and compatible with $\mathrm{Nb}-\mathrm{Mo}-\mathrm{W}-\mathrm{Ti}-\mathrm{Cr}-\mathrm{Hf}-\mathrm{Al}-\mathrm{Ge}-\mathrm{Si}-\mathrm{Sn}$ UHTMs. A good starting point for the design of HEA and/or "conventional" alloys for BC application in ECs could be the $(\mathrm{Al} / \mathrm{Si})_{\text {alloy }}$ versus $[\mathrm{Nb} /(\mathrm{Ti}+\mathrm{Hf})]_{\text {alloy }}$ maps in Figure 13 in [81], and the $\Delta \chi$ versus VEC, $\delta$ versus VEC and $\Delta \chi$ versus $\delta$ maps in Figure 13 in [82].

Supplementary Materials: The following are available online at http:/www.mdpi.com/1996-1944/13/20/4548/s1, Figure S1: X-ray diffractograms of the (a) as cast and (b) heat treated alloy, Figure S2: X-ray diffractograms of the (a) as cast and (b) heat treated alloy JZ5, Table S1: EDS analysis data (at.\%) of the alloy JZ4, Table S2: EDS analysis data (at.\%) for the alloy JZ5, Table S3: EDS analysis data (at.\%) of phases in the alloy JZ4 after oxidation at $800{ }^{\circ} \mathrm{C}$ for $100 \mathrm{~h}$, Table S4: EDS analysis data (at.\%) of phases in the alloy JZ5 after oxidation at $800{ }^{\circ} \mathrm{C}$ for $100 \mathrm{~h}$, Table S5: EDS analysis data (at.\%) of phases in the alloy JZ4 after oxidation at $120{ }^{\circ} \mathrm{C}$ for $100 \mathrm{~h}$, Table S6: EDS analysis data (at.\%) of phases in the alloy JZ5 after oxidation at $1200{ }^{\circ} \mathrm{C}$ for $100 \mathrm{~h}$.

Author Contributions: Experimental work, J.Z., C.U., Supervision, C.U. and P.T., Formal analysis J.Z., C.U. and P.T., Draft preparation, J.Z., Review P.T. and C.U., Final paper, P.T., C.U., J.Z. All authors have read and agreed to the published version of the manuscript.

Funding: This research was funded by the EPSRC (EP/H500405/1, EP/L026678/1) and Rolls-Royce Plc.

Acknowledgments: The support of this work by the University of Sheffield, Rolls-Royce Plc and EPSRC (EP/H500405/1, EP/L026678/1) is gratefully acknowledged.

Conflicts of Interest: The authors declare no conflict of interest. 


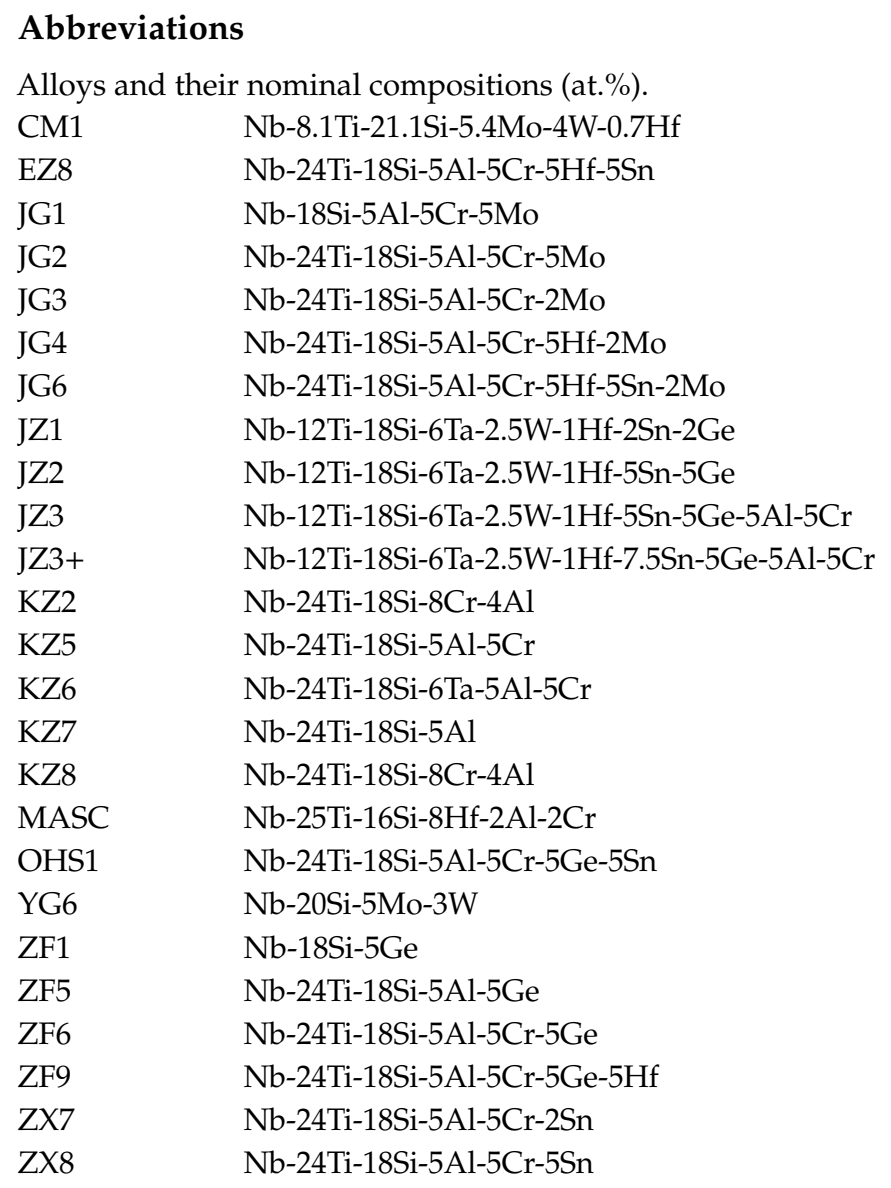

\section{Appendix A}

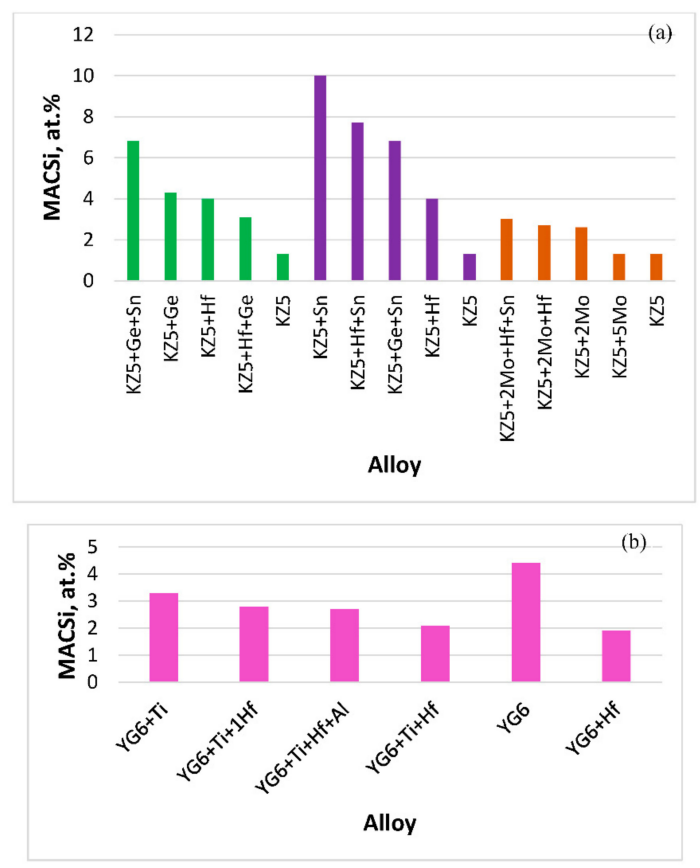

Figure A1. Si macrosegregation (MACSi) in (a) Ti-rich (Ti concentration about 24 at.\%) and (b) Ti-poor (Ti concentration about 11 at.\%) Nb-silicide-based alloys. Base alloy in (a,b), respectively, KZ5 (Nb-24Ti-18Si-5Al-5Cr [1,61]) and YG6 (Nb-20Si-5Mo-3W) [1,53]. 


\section{References}

1. Tsakiropoulos, P. Alloys for application at ultra-high temperatures: Nb-silicide in situ composites. Challenges, breakthroughs and opportunities. Prog. Mater. Sci. 2020, 100714. [CrossRef]

2. Senkov, O.; Miracle, D.B.; Chaput, K.J.; Couzinie, J.-P. Development and exploration of refractory high entropy alloys-A review. J. Mater. Res. 2018, 33, 3092-3128. [CrossRef]

3. Bewlay, B.P.; Jackson, M.R.; Gigliotti, M.F.X. Niobium Silicide High Temperature In Situ Composites. In Intermetallic Compounds_Principles and Practice; Wiley: Hoboken, NJ, USA, 2002; Volume 3, pp. 541-560.

4. Schneibel, J.H. Beyond Nickel-Base Superalloys. In Processing and Fabrication of Advanced Materials XIII; Stallion Press: Singapore, 2005; Volume 2.

5. Perepezko, J.H. The hotter the engine, the better. Science 2009, 326, 1068-1069. [CrossRef] [PubMed]

6. Bewlay, B.P.; Jackson, M.R.; Zhao, J.-C.; Subramanian, P.R.; Mendiratta, M.G.; Lewandowski, J.J. Ultrahigh-Temperature Nb-Silicide-Based Composites. MRS Bull. 2003, 28, 646-653. [CrossRef]

7. Tsakiropoulos, P. On the Nb silicide based alloys: Part I-The bcc Nb solid solution. J. Alloy. Compd. 2017, 708, 961-971. [CrossRef]

8. Mendiratta, M.; Dimiduk, D. Phase relations and transformation kinetics in the high $\mathrm{Nb}$ region of the $\mathrm{Nb}-\mathrm{Si}$ system. Scr. Met. Et Mater. 1991, 25, 237-242. [CrossRef]

9. Kassem, M.A.; Koch, C.C. Effect of Interstitials on the Phase Stability of Selected Intermetallics. In MRS Proceedings; Cambridge University Press: Cambridge, UK, 1990; Volume 213, pp. 801-806.

10. Jackson, M.R.; Bewlay, B.P.; Rowe, R.G.; Skelly, D.W.; Lipsitt, H.A. High-temperature refractory metal-intermetallic composites. JOM 1996, 48, 39-44. [CrossRef]

11. Samant, A.V.; Lewandowski, J.J. Effects of test temperature, grain size, and alloy additions on the cleavage fracture stress of polycrystalline niobium. Met. Mater. Trans. A 1997, 28, 389-399. [CrossRef]

12. Bewlay, B.; Briant, C.; Sylven, E.; Jackson, M.; Xiao, G. Creep Studies of Monolithic Phases in Nb-Silicide Based In-Situ Composites. In MRS Proceedings; Cambridge University Press: Cambridge, UK, 2000; Volume 646, p. 2.6.1.

13. Hirai, H.; Sha, J.; Ueno, H.; Hanada, S.; Tabaru, T.; Kitahara, A. High-Temperature Compression Strength of Directionally Solidified Nb-Mo-W-Ti-Si In-Situ Composites. In MRS Proceedings; Cambridge University Press: Cambridge, UK, 2000; Volume 646, p. 5.41.1.

14. Chan, K.S. Alloying effects on fracture mechanisms in Nb-based intermetallic in-situ composites. Mater. Sci. Eng. A 2002, A329-A331, 513-522. [CrossRef]

15. Bewlay, B.P.; Briant, C.L.; Sylven, E.T.; Jackson, M.R. The effects of substitutional additions on creep behaviour of tetragonal and hexagonal silicides. Mat. Res. Soc. Symp. Proc. 2003, 753, BB5.24.1-BB5.24.6. [CrossRef]

16. Chan, K.S. Cyclic-Oxidation Resistance of Niobium-Base in situ Composites: Modeling and Experimentation. Oxid. Met. 2004, 61, 165-194. [CrossRef]

17. Xiong, B.; Cai, C.; Wan, H.; Zheng, Y. Effects of Si, W and W-Mo on isothermal oxidation behaviour of $\mathrm{Nb} / \mathrm{Nb} 5 \mathrm{Si} 3$ in situ composites at high temperature. J. Alloys Compd. 2009, 604, 211-216. [CrossRef]

18. Liu, Y.; Shazly, M.; Lewandowski, J.J. Microstructural effects on crack path selection in bending and fatigue in a Nb-19Si-5Cr-3.5Hf-24Ti-0.75Sn-1W alloy. Mater. Sci. Eng. A 2010, 527, 1489-1500. [CrossRef]

19. Zhang, S.; Guo, X. Alloying effects on the microstructure and properties of $\mathrm{Nb}$-Si based ultrahigh temperature alloys. Intermetallics 2016, 70, 33-44. [CrossRef]

20. Tsakiropoulos, P. On Nb Silicide Based Alloys: Alloy Design and Selection. Materials 2018, 11, 844. [CrossRef]

21. Tsakiropoulos, P. Alloying and properties of $\mathrm{C} 14-\mathrm{NbCr}_{2}$ and $\mathrm{A} 15-\mathrm{Nb}_{3} \mathrm{X}(\mathrm{X}=\mathrm{Al}, \mathrm{Ge}, \mathrm{Si}, \mathrm{Sn})$ in $\mathrm{Nb}$-silicide based alloys. Materials 2018, 11,395. [CrossRef]

22. Thandorn, T.; Tsakiropoulos, P. Study of the role of B addition on the microstructure of the Nb-24Ti-18Si-8B alloy. Intermetallics 2010, 18, 1033-1038. [CrossRef]

23. Portillo, B.I.; Varma, S.K. Oxidation behaviour of Nb-20Mo-15Si-5B-20Ti alloy in air from 700 to $1300{ }^{\circ} \mathrm{C}$. J. Alloy. Compd. 2010, 497, 68-73. [CrossRef]

24. Zifu, L.; Tsakiropoulos, P. Study of the effects of Ge addition on the microstructure of $\mathrm{Nb}-18 \mathrm{Si}$ in situ composites. Intermetallics 2010, 18, 1072-1078. [CrossRef]

25. Liu, Y.; Kramer, M.J.; Thom, A.J.; Akinc, M. Oxidation behaviour of multiphase Nb-Mo-Si-B alloys. Metall. Mater. Trans. A 2005, 36, 601-607. [CrossRef] 
26. Bewlay, B.P.; Whiting, P.W.; Davis, A.W.; Briant, C.L. Creep Mechanisms in Niobium-Silicide Based In-Situ Composites. MRS Proc. 1998, 552, KK6.11.1. [CrossRef]

27. Begley, R.; Bechtold, J. Effect of alloying on the mechanical properties of niobium. J. Less Common Met. 1961, 3, 1-12. [CrossRef]

28. Prokoshkin, D.A.; Vasileva, E.V. Alloys of niobium, ed. A. M. Samarin, translated from Russian by N. Kaner; translation edited by Molly Gleiser, Jerusalem. Israel Program Sci. Transl. 1965.

29. Wilcox, B.A. Basic Strengthening Mechanisms in Refractory Metals. In Proceedings of the Refractory Metal Alloys Metallurgy and Technology; Springer Science and Business Media LLC.: Berlin, Germany, 1968; pp. 1-39.

30. Wadsworth, J.; Nieh, T.G.; Stephens, J.J. Recent advances in aerospace refractory metal alloys. Intern. Mater. Rev. 1988, 33, 131-150. [CrossRef]

31. Begley, R.T. Columbium alloy development at Westinghouse. In Evolution of Refractory Metals and Alloys; Dalder, E.N.C., Grobstein, T., Chen, C.S., Eds.; TMS: Warrendale, PA, USA, 1994; pp. $29-48$.

32. Bryant, R. The solubility of oxygen in transition metal alloys. J. Less Common Met. 1962, 4, 62-68. [CrossRef]

33. Jones, D.; McQuillan, A. Magnetic susceptibility and hydrogen affinity of B.C.C. alloys of Nb-Mo Nb-Re and Mo-Re. J. Phys. Chem. Solids 1962, 23, 1441-1447. [CrossRef]

34. Westbrook, J.; Wood, D. "PEST" degradation in beryllides, silicides, aluminides, and related compounds. J. Nucl. Mater. 1964, 12, 208-215. [CrossRef]

35. Shah, D.M.; Anton, D.L.; Musson, C.W. Feasibility Study of Intermetallic Composites. MRS Proc. 1990, 194, 333-340. [CrossRef]

36. Halliop, W.; McAlary, G.M.; George, R.A. Fuel Cell System with Degradation Protected Anode. WO Patent 2004012288A2, 5 February 2004.

37. Menon, E.S.K.; Mendiratta, M.G.; Dimiduk, D.M. Oxidation behaviour of complex niobium based alloys. In Proceedings of the International Symposium Niobium 2001, Orlando, FL, USA, 2-5 December 2001; Niobium 2001 Limited: Bridgeville, PA, USA, 2002; pp. 121-145, ISBN 0971206805.

38. Menon, E.S.K.; Mendiratta, M.G.; Dimiduk, D.M. High temperature oxidation mechanisms in Nb-silicide bearing multicomponent alloys. In Structural Intermetallics; Hemker, K.J., Dimiduk, D.M., Clemens, H., Darolia, R., Inui, H., Larsen, J.M., Sikka, V.K., Thomas, M.J., Whittenberger, D., Eds.; TMS: Warrendale, PA, USA, 2001; pp. 591-600.

39. Jackson, M.R.; Bewlay, B.P.; Zhao, J.-C. Niobium Silicide Based Composites Resistant to Low Temperature Pesting. U.S. Patent 6,419,765, 16 July 2002.

40. Balsone, S.J.; Bewlay, B.P.; Jackson, M.R.; Subramanian, P.R.; Zhao, J.-C.; Chatterjee, A.; Heffernan, T.M. Materials beyond superalloy-exploiting high temperature composites. In Structural Intermetallics 2001; Hemker, K.J., Dimiduk, B.M., Clemens, H., Darolia, R., Inui, M., Larsen, J.M., Sikka, V.K., Thomas, M., Whittenberger, J.D., Eds.; T.M.S. The Minerals, Metals \& Materials Society: Pittsburgh, PA, USA, 2001; pp. 99-108. ISBN 0-87339-511-5.

41. Zhen, X.; Utton, C.; Tsakiropoulos, P. A study of the effect of 2 at.\% Sn on the microstructure and isothermal oxidation at 800 and $1200{ }^{\circ} \mathrm{C}$ of Nb-24Ti-18Si based alloys with $\mathrm{Al}$ and/or Cr additions. Materials 2018, 11, 1826. [CrossRef]

42. Zhen, X.; Utton, C.; Tsakiropoulos, P. A study of the effect of 5 at.\% Sn on the microstructure and isothermal oxidation at 800 and $1200{ }^{\circ} \mathrm{C}$ of $\mathrm{Nb}-24 \mathrm{Ti}-18 \mathrm{Si}$ based alloys with $\mathrm{Al}$ and/or Cr additions. Materials 2020, 13, 245. [CrossRef]

43. Li, Z.; Tsakiropoulos, P. The Effect of Ge Addition on the Oxidation of Nb-24Ti-18Si Silicide Based Alloys. Materials 2019, 12, 3120. [CrossRef] [PubMed]

44. Knittel, S.; Mathieu, S.; Portebois, L.; Vilasi, M. Effect of tin addition on Nb-Si based in situ composites. Part II: Oxidation behaviour. Intermetallics 2014, 47, 43-52. [CrossRef]

45. Hernández-Negrete, O.; Tsakiropoulos, P. On the Microstructure and Isothermal Oxidation at 800 and $1200{ }^{\circ} \mathrm{C}$ of the Nb-24Ti-18Si-5Al-5Cr-5Ge-5Sn (at.\%) Silicide-Based Alloy. Materials 2020, 13, 722. [CrossRef] [PubMed]

46. Zhao, J.; Utton, C.; Tsakiropoulos, P. On the Microstructure and Properties of Nb-12Ti-18Si-6Ta-2.5W-1Hf (at.\%) Silicide-Based Alloys with Ge and Sn Additions. Materials 2020, 13, 1778. [CrossRef] [PubMed]

47. Zhao, J.; Utton, C.; Tsakiropoulos, P. On the Microstructure and Properties of Nb-12Ti-18Si-6Ta-5Al-5Cr2.5W-1Hf (at.\%) Silicide-Based Alloys with Ge and Sn Additions. Materials 2020, 13, 3719. [CrossRef] 
48. Tsakiropoulos, P. Alloys. U.S. Patent 10,227,680, 12 March 2019.

49. Jackson, M.R.; Bewlay, B.P.; Briant, C.L. Creep Resistant Nb-Silicide Based Two Phase Composites. U.S. Patent 6,447,623.B1, 9 October 2002.

50. Tsakiropoulos, P. On Nb silicide based alloys: Part II. J. Alloy. Compd. 2018, 748, 569-576. [CrossRef]

51. MacKay, R.A.; Gabb, T.P.; Smialek, J.L.; Nathal, M.V. Alloy Design Challenge: Development of Low Density Superalloys for Turbine Blade Applications; NASA/TM-2009-215819; NASA: Washington, DC, USA, October 2009.

52. Geng, J.; Tsakiropoulos, P.; Shao, G. The effects of Ti and Mo additions on the microstructure of Nb-silicide based in situ composites. Intermetallics 2006, 14, 227-235. [CrossRef]

53. Grammenos, I.; Tsakiropoulos, P. Study of the role of Hf, Mo and W additions in the microstructure of $\mathrm{Nb}-20 \mathrm{Si}$ silicide based alloys. Intermetallics 2011, 19, 1612-1621. [CrossRef]

54. Papadimitriou, I.; Utton, C.; Tsakiropoulos, P. Ab initio study of ternary W5Si3 type $\mathrm{TM}_{5} \mathrm{Sn}_{2} \mathrm{X}$ compounds ( $\mathrm{TM}=\mathrm{Nb}, \mathrm{Ti}, \mathrm{X}=\mathrm{Al}, \mathrm{Si}$ ). Materials 2019, 12, 3217. [CrossRef]

55. Fujikura, M.; Kasama, A.; Tanaka, R.; Hanada, S. Effect of Alloy Chemistry on the High Temperature Strengths and Room Temperature Fracture Toughness of Advanced Nb-Based Alloys. Mater. Trans. 2004, 45, 493-501. [CrossRef]

56. Geng, J.; Tsakiropoulos, P. A study of the microstructures and oxidation of Nb-Si-Cr-Al-Mo in situ composites alloyed with Ti, Hf and Sn. Intermetallics 2007, 15, 382-395. [CrossRef]

57. Resende, A.; Tsakiropoulos, P.; University of Sheffield, Sheffield, UK. Oxidation of Sn Containing Nb-Silicide Based Alloys. Unpublished research. 2017.

58. Zacharis, E.; Tsakiropoulos, P.; University of Sheffield, Sheffield, UK. Development of Sn Containing $\mathrm{Nb}$-Silicide Based Alloys. Unpublished research. 2011.

59. Li, Z.; Tsakiropoulos, P. On The Microstructures and Hardness of The Nb-24Ti-18Si-5Al-5Cr-5Ge and Nb-24Ti-18Si-5Al-5Cr-5Ge-5Hf (at.\%) Silicide Based Alloys. Materials 2019, 12, 2655. [CrossRef] [PubMed]

60. Tsakiropoulos, P. On the macrosegregation of silicon in niobium silicide based alloys. Intermetallics 2014, 55, 95-101. [CrossRef]

61. Zelenitsas, K.; Tsakiropoulos, P. Study of the role of $\mathrm{Al}$ and $\mathrm{Cr}$ additions in the microstructure of $\mathrm{Nb}-\mathrm{Ti}-\mathrm{Si}$ in situ composites. Intermetallics 2005, 13, 1079-1095. [CrossRef]

62. McCaughey, C.; Tsakiropoulos, P. Type of Primary Nb5Si3 and Precipitation of Nbss in $\alpha \mathrm{Nb} 5 \mathrm{Si} 3$ in a Nb-8.3Ti-21.1Si-5.4Mo-4W-0.7Hf (at.\%) Near Eutectic Nb-Silicide-Based Alloy. Materials 2018, 11, 967. [CrossRef]

63. Tsakiropoulos, P. On the Alloying and Properties of Tetragonal Nb5Si3 in Nb-Silicide Based Alloys. Materials 2018, 11, 69. [CrossRef]

64. Tsakiropoulos, P. Alloying and Hardness of Eutectics with Nbss and Nb5Si3 in Nb-silicide Based Alloys. Materials 2018, 11, 592. [CrossRef]

65. Papadimitriou, I.; Utton, C.; Tsakiropoulos, P. Phase equilibria in the Nb-rich region of Al-Nb-Sn at 900 and $1200{ }^{\circ} \mathrm{C}$. Materials 2019, 12, 2759. [CrossRef]

66. Sun, Z.; Guo, X.; Zhang, C. Thermodynamic modeling of the Nb-rich corner in the Nb-Si-Sn system. Calphad 2012, 36, 82-88. [CrossRef]

67. Bulanova, M.; Tretyachenko, L.; Meleshevich, K.; Saltykov, V.; Vereshchaka, V.; Galadzhyj, O.; Kulak, L.; Firstov, S. Influence of tin on the structure and properties of as-cast Ti-rich Ti-Si alloys. J. Alloy. Compd. 2003, 350, 164-173. [CrossRef]

68. Geng, J.; Tsakiropoulos, P.; Shao, G. Oxidation of Nb-Si-Cr-Al in situ composites with Mo, Ti and Hf additions. Mater. Sci. Eng. A 2006, 441, 26-38. [CrossRef]

69. Sekido, N.; Hildal, K.; Sakidja, R.; Perepezko, J. Stability of the Nb5Si3 phase in the Nb-Mo-Si system. Intermetallics 2013, 41, 104-112. [CrossRef]

70. Ma, C.L.; Li, J.G.; Tan, Y.; Tanaka, R.; Hanada, S. Microstructure and mechanical properties of Nb/Nb5Si3 in situ composites in Nb-Mo-Si and Nb-W.-Si systems. Mater. Sci. Eng. A 2004, 386, 375-383. [CrossRef]

71. Li, Z.; Tsakiropoulos, P. The microstructure of Nb-18Si-5Ge-5Al and Nb-24Ti-18Si-5Ge-5Al in situ composites. J. Alloys Compd. 2013, 550, 553-560. [CrossRef]

72. Zelenitsas, K.; Tsakiropoulos, P. Study of the role of Ta and $\mathrm{Cr}$ additions in the microstructure of $\mathrm{Nb}-\mathrm{Ti}-\mathrm{Si}-\mathrm{Al}$ in situ composites. Intermetallics 2006, 14, 639-659. [CrossRef] 
73. Sekido, N.; Kimura, Y.; Miura, S.; Wei, F.-G.; Mishima, Y. Fracture toughness and high temperature strength of unidirectionally solidified $\mathrm{Nb}-\mathrm{Si}$ binary and $\mathrm{Nb}-\mathrm{Ti}-\mathrm{Si}$ ternary alloys. J. Alloy. Compd. 2006, 425, 223-229. [CrossRef]

74. Miura, S.; Aoki, M.; Saeki, Y.; Ohkubo, K.; Mishima, Y.; Mohri, T. Effects of Zr on the eutectoid decomposition behaviour of Nb3Si into (Nb)/Nb5Si3. Metall. Mater. Trans. 2005, 36, 489-496. [CrossRef]

75. Zelenitsas, K.; Tsakiropoulos, $\mathrm{P}$. Effect of $\mathrm{Al}, \mathrm{Cr}$ and $\mathrm{Ta}$ additions on the oxidation behaviour of $\mathrm{Nb}-\mathrm{Ti}-\mathrm{Si}$ in situ composites at $800^{\circ} \mathrm{C}$. Mater. Sci. Eng. A 2006, 416, 269-280. [CrossRef]

76. Vellios, N. Design of Nb-Silicide Based Alloys for Aero-Engines. Ph.D. Thesis, University of Surrey, Guilford, UK, 2007.

77. Tsakiropoulos, P.; Zelenitsas, K.; Vellios, N. Study of the effect of Al, Cr and Sn additions on the microstructure and properties of $\mathrm{Nb}$ silicide based alloys. MRS Proc. 2011, 1295. [CrossRef]

78. Tankov, N.; Utton, C.; Tsakiropoulos, P.; University of Sheffield, Sheffield, UK. Unpublished research. In Progress. 2019.

79. Zhao, J.-C.; Jackson, M.R.; Bewlay, B.P. Oxidation Resistant Coatings for Nb-Based Silicide Composites. European Patent Application EP1229146 A2, 24 January 2002.

80. Ghadyani, M.; Utton, C.; Tsakiropoulos, P. Microstructure and isothermal oxidation of the alumina forming Nb1.7Si2.4Ti2.4Al3Hf0.5 and Nb1.3Si2.4Ti2.4Al3.5Hf0.4 alloys. Materials 2019, 12, 222. [CrossRef]

81. Ghadyani, M.; Utton, C.; Tsakiropoulos, P. Microstructure and isothermal oxidation of the alumina scale forming Nb1.45Si2.7Ti2.25Al3.25Hf0.35 and Nb1.35Si2.3Ti2.3Al3.7Hf0.35 alloys. Materials 2019, 12, 759. [CrossRef] [PubMed]

82. Hernández-Negrete, O.; Tsakiropoulos, P.; Negrete, H. On the Microstructure and Isothermal Oxidation at 800,1200 , and $1300^{\circ} \mathrm{C}$ of the Al-25.5Nb-6Cr-0.5Hf (at \%) Alloy. Materials 2019, 12, 2531. [CrossRef] [PubMed]

(C) 2020 by the authors. Licensee MDPI, Basel, Switzerland. This article is an open access article distributed under the terms and conditions of the Creative Commons Attribution (CC BY) license (http://creativecommons.org/licenses/by/4.0/). 